\title{
Westinghouse Radiological OSTI Containment Guide
}

Prepared for the U.S. Department of Energy Office of Environmental Restoration and Waste Management

\section{(2) Westinghouse \\ Wanford Company Richland, Washington}

Hanford Operations and Engineering Contractor for the

U.S. Department of Energy under Contract DE-AC06-87RL10930 


\section{LEGAL DISCLAIMER}

This report was prepared as an account of work sponsored by an agency of the United States Government. Neither the United States Government nor any agency thereof, nor any of their employees, nor any of their contractors, subcontractors or their employees, makes any warranty, express or implied, or assumes any legal liability or responsibility for the accuracy, comfleteness, or any third party's use or the results of such use of any information, apparatus, product, or process disclosed, or represents that its use would not infringe privately owned rights. Reference herein to any specific commercial product, process, or service by trade name, trademark, manufacturer, or otherwise, does not necessarily constitute or imply its endorsement, recommendation, or favoring by the United States Government or any agency thereof or its contractors or subcontractors. The views and opinions of authors expressed herein do not necessarily state or reflect those of the United States Government or any agency thereot.

This report has been reproduced from the best available copy. Available in paper copy and microtiche.

Available to the U.S. Department of Energy and its contractors from

Office of Scientific and Technical Information

P.O. Box 62

Oak Ridge, TN 37831

(615) $576-8401$

Available to the public from the U.S. Department of Commerce National Technical Information Service

5285 Port Royal Road

Springtield, VA 22161

(703) $487-4650$

Printed in the United States of America 


\section{Westinghouse Radiological Containment Guide}

S. B. Aitken

Idaho National Engineering Laboratory

R. L. Brown

Westinghouse Hanford Company

J. R. Cantrell

Westinghouse Savannah River Company

D. P. Wilcox

West Valley Nuclear Services

Date Published

March 1994

Prepared for the U.S. Department of Energy

Office of Environmental Restoration and

Waste Management

(2) Westinghouse P.O. Box 1970

Hanford Company Richland, Washington 99352

Hanford Operations and Engineering Contractor for the

U.S. Department of Energy under Contract DE-AC06-87RL10930 


\section{RELEASE AUTHORIZATION}

Document Number: WHC-EP-0749

Document Title:

Westinghouse Rídiological Containment Guide

Release Date:

February 25, 1994

$* * * * * * * * * * * * *$

This document was reviewed following the procedures described in WHC-CM-3-4 and is: APPROVED FOR PUBLIC RELEASE

$* * * * * * * * * * * * *$

WHC Information Release Administration Specialist: MN Boston

M. Boston

February 25, 1995 


\section{CONTENTS}

1.0 PURPOSE AND SCOPE $\ldots \ldots \ldots \ldots \ldots \ldots \ldots \ldots \ldots \ldots \ldots \ldots \ldots$

2.0 DISCUSSION AND PROGRAM ELEMENTS $\ldots \ldots \ldots \ldots \ldots \ldots \ldots \ldots$

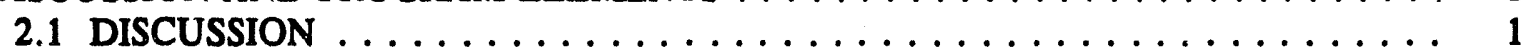

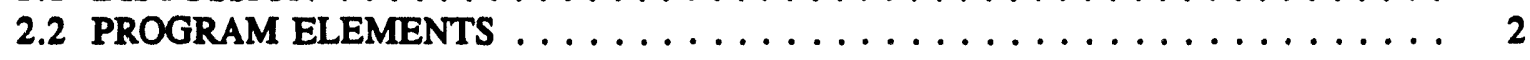

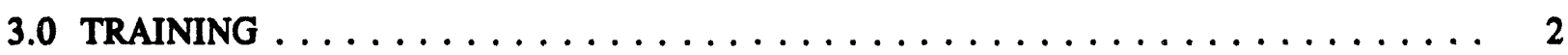

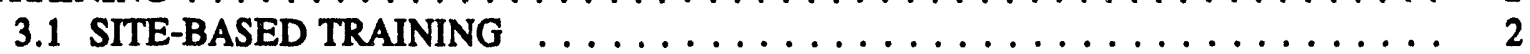

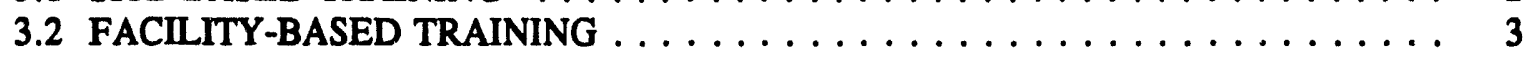

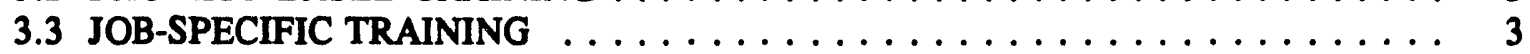

4.0 SELECTION, DESIGN, AND SPECIFICATION $\ldots \ldots \ldots \ldots \ldots \ldots \ldots$

4.1 METHODS OF CONTAINMENT $\ldots \ldots \ldots \ldots \ldots \ldots \ldots \ldots \ldots$

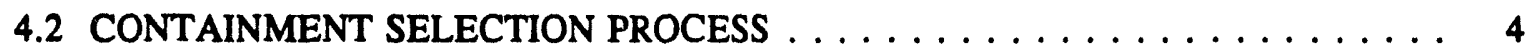

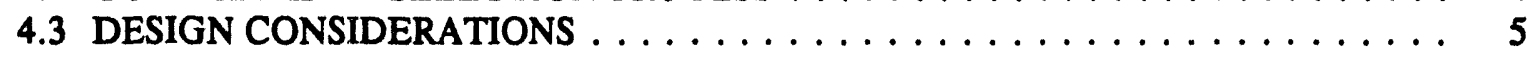

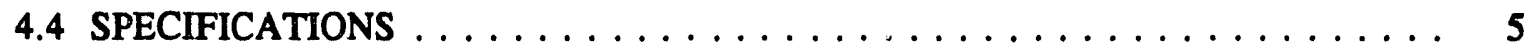

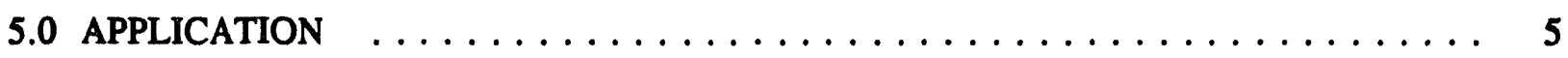

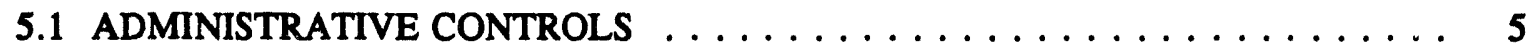

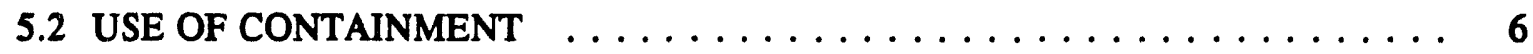

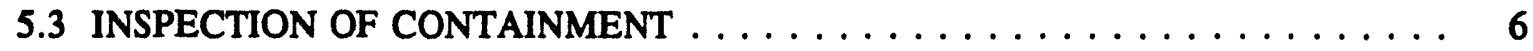

5.4 TESTING OF CONTAINMENTS $\ldots \ldots \ldots \ldots \ldots \ldots \ldots$

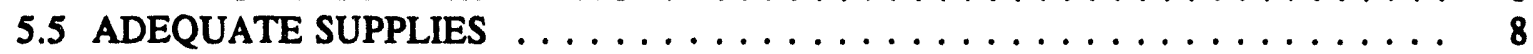

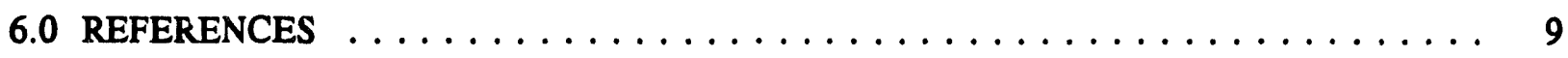
APPENDIXES

A CONTAINMENT SELECTION PROCESS $\ldots \ldots \ldots \ldots \ldots \ldots \ldots \ldots \ldots$. . . . $\ldots \ldots$

B GUIDANCE ON USE OF CONTAINMENTS $\ldots \ldots \ldots \ldots \ldots \ldots \ldots \ldots \ldots \ldots$

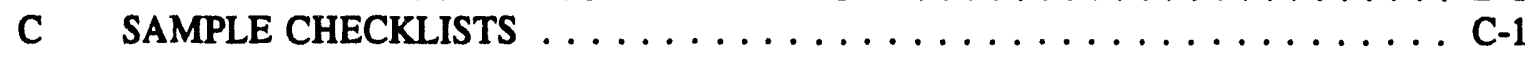

D CONTAINMENT DESIGN AND SPECIFICATION $\ldots \ldots \ldots \ldots \ldots \ldots \ldots \ldots$ D-1

E SAMPLE TRAINING GUIDES $\ldots \ldots \ldots \ldots \ldots \ldots \ldots \ldots \ldots \ldots \ldots$

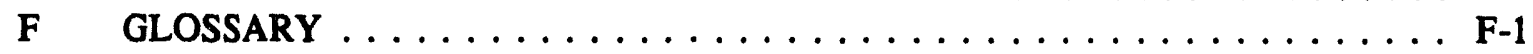




\section{WHC-EP-0749}

This page intentionally left blank. 
WHC-EP-0749

\section{WESTINGHOUSE RADIOLOGICAL CONTAINMENT GUIDE}

\subsection{PURPOSE AND SCOPE}

This document provides uniform guidance for Westinghouse contractors on the implementation of radiological containments. This document reflects standard industry practices and is provided as a guide. The guidance presented herein is consistent with the requirements of the DOE Radiological Control Manual (DOE N 5480.6).

This guidance should further serve to enable and encouruge the use of containments for contamination control and to accomplish the following:

- Minimize personnel contamination

- Prevent the spread of contamination

- Minimize the required use of protective clothing and personal protective equipment

- Minimize the generation of waste.

\subsection{DISCUSSION AND PROGRAM ELEMENTS}

\subsection{DISCUSSION}

As used in this document, "containment" is not limited to the concept of total enclosure, but also encompasses the application of engineered barriers applied in varying degrees to prevent the spread of radioactive contamination.

Two key principles influence the application of containments:

- Establishing the contamination barrier (the containment) as near to the source as possible

- Whenever possible, using containments around the work area instead of requiring workers to use additional protective clothing or other personal protective equipment.

The challenges experienced at many individual facilities, for example, tritium, ${ }^{20} \mathrm{Pu}$ oxide, criticality issues, chemically active materials or processes, or other facility-specific issues, will affect the application of containment. This document is not intended to override established and safe work practices for these or other special applications. 


\subsection{PROGRAM ELEMENTS}

A successful containment program should contain the following elements:

- Training

- Selection and design

- Specifications

- Installation/inspection criteria

- Operating guidelines.

The program elements are described in detail in the following sections.

\subsection{TRAINING}

Containment training should be accomplished on three levels: site-based training, facility-based training, and job-specific training. Each level of training should be performed in conjunction with training described in the DOE Radiological Control Manual, Section 6.0.

\subsection{SITE-BASED TRAINING}

Appendix E contains sample lesson plans to support site-based training requirements.

\subsubsection{Radiological Worker Training}

Site-based training should be integrated into Radiological Worker II (DOE N 5480.6) training and should include the following program elements:

- Basic types and application of containments

- Standard features of containment devices

- Standard work practices

- Inspection criteria.

\subsubsection{Radiological Control Technician Training}

Radiological Control Technicians should receive training that includes the following elements:

- Basic types and application of containments

- Inspection criteria

- Standard work practices

- Standard features of containment devices. 


\subsubsection{Training for Planners and Engineers}

Persons responsible for planning tasks that involve the use of containment should receive training that includes the following elements:

- Selection

- Design

- Ventilation.

\subsection{FACILITY-BASED TRAINING} training):

Facility-based training should include the following elements (unless covered in site-based

- Facility-specific actions for abnormal conditions

- Installation/removal process for containments

- Facility-specific applications and rules.

\subsection{JOB-SPECIFIC TRAINING}

Job-specific training on containments is encouraged as part of facility work control or ALARA $^{1}$ programs. An example of job-specific training would be mock-up training for highexposure or complex tasks, or when the application of a given containment would be unique to the job.

\subsection{SELECTION, DESIGN, AND SPECIFICATION}

\subsection{METHODS OF CONTAINMENT}

The various containment methods are summarized in the following discussion. Appendix B contains application guidance and drawings that identify the components discussed.

- Containment Tents - Containment tents are a class of large enclosures, generally constructed of flexible sheeting, which allow personnel to physically enter a contaminated environment to perform work. Containment tents can also be used as anterooms for access to cells, tank risers, and other highly contaminated environments.

- Glove Bags - A glove bag is a flexible containment used to establish an enclosure around a contaminated item, allowing personnel to accomplish repairs or manipulations via gloved sleeves without contacting the contaminated environment.

\footnotetext{
${ }^{1}$ ALARA = "As low as reasonably achievable."
} 
- Polyethylene Bottles - Poly bottles are 5- or 15-gal polyethylene containers used to collect small quantities of contaminated liquids. Bottle assemblies generally include a filtered vent assembly.

- Miscellaneous - Other types of containment devices include sleeving, mechanical joint containments, plastic sheeting, and drop cloths. The following containments are discussed in more detail.

- Catch Containments (Drapes) - Catch containments are partial enclosures usually used to collect falling debris or small amounts of liquid.

- Wind Break or Bull Pen - A bull pen is a walled, or partially walled, enclosure that allows personnel to enter and work in a contaminated environment. They are generally roofless and are used on low risk activities to protect immediate area from contaminants, as well as protect the work area from external factors which could result in contaminated material being spread.

- Air curtains - Air curtains use moving air to draw contaminants into a filtered exhaust plenum. Applications of air curtains include open faced hoods, strategically placed exhaust ducts, or any other means of capturing the contaminants at or near the source with filtered ventilation.

\subsection{CONTAINMENT SELECTION PROCESS}

Establishing an effective containment involves the following general steps: defining that a containment is needed, determining what type of containment is appropriate, designing the containment, and obtaining and using the containment. The process should consider the following elements:

- A standardized method of determining containment needs

- Design considerations for developing specific applications

- Integration of containment design process with the work planning process

- Standard specifications for commonly used containments.

The document that controls the work should indicate the need for and the type of containment to be used.

The task should be reviewed and the containment selected based on component size, arrangement, work requirements, and surrounding interferences. be used.

When more than one craft will use a single containment, all should be consulted on the type to

The work package should state if liquid is expected in the containment, and if so, the probable composition and quantity of the liquid, and whether criticality concerns exist.

NOTE: If it is determined that the same temporary containment device is being used over and over, consideration should be given to establishing a permanent containment. 


\subsection{DESIGN CONSIDERATIONS}

Contamination control and personnel safety are the key considerations when designing containments. Contamination levels, temperature, area configuration, isotope(s), and the radiological characteristics of the immediate vicinity should also be considered.

Designs of certifiable containm'snts should be approved by the Radiological Control Organization and the Line Organization.

Detailed design considerations are described in Appendix D.

\subsection{SPECIFICATIONS}

Specifications should be written and approved using site-specific procedures. Specifications should address the following:

- Reference Standards

- Material

- Fabrication

- Framing

- Components

- Quality Assurance Requirements.

A detailed discussion of the specification process and sample specifications are contained in Appendix D.

\subsection{APPLICATION}

\subsection{ADMINISTRATIVE CONTROLS}

Administrative controls are necessary to ensure the standardized application of containments. As a minimum, the following items are recommended:

- Acceptance checklists - standard checklists to document initial installation and inspection of certifiable containments.

- Identification - a method of identifying a containment that includes the job being performed and a record of the date and time of inspection.

Where multiple containments are in use in a given site/facility, a containment tracking system should be considered. Such a system should allow the site/facility to document the number and types of certifiable containments used and manage their application. This will allow the facility to gauge the need for designing and installing permanent containments for specific jobs/systems. 


\subsection{USE OF CONTAINMENT}

General guidelines and good work practices for the use of containments are included in Appendix B. These guidelines are not intended to serve as procedures, but do, in some cases, contain specific guidance on the operation of containment devices. The appendix includes separate discussions for

- General use criteria

- Tents

- Glove bags

- Poly bottles

- Other containments (i.e., catch containments, mechanical joint containments).

\subsection{INSPECTION OF CONTAINMENT}

Inspection of radiological containments is necessary to ensure the end product of the containment design and installation process meets established standards.

Containments generally fall into two categories: certified and noncertified. Certified containments are usually limited to tents and glovebags. All other methods of containment fall into the uncertified category.

Inspections for certified containments should be performed after repair, daily while in use, and at least monthly when not in use to determine need for repairs, replacement, or decontamination and removal. routinely.

Inspections for noncertified containments are not formally documented but should be performed

\subsubsection{Inspection Criteria for Certified Containments}

The following are recommended inspection items that should be considered. This is not an inclusive list and may be modified to fit particular sites, facilities, or work procedures.

Tents

- The tent should be free of tears, loose seams, cuts or other loss of integrity.

- The tent should be properly oriented and supported.

- Sharp objects should be properly covered to prevent inadvertent penetration of the tent.

- Installed service leads should be sleeved and secured. Unused sleeves should be sealed or taped closed.

- Radiological postings and protective clothing removal procedures should be prominently posted at the entrance/exit. 
- Sufficient lighting should be provided.

- All zippered and/or Velcro entrances should work properly.

- The tent seal to the component should be properly made.

- If HEPA-filtered ventilation is used, the system should be properly installed, including the connections, proper labeling, and current efficiency test.

- Step-off pad(s) and receptacles for used clothing should be in place.

- If welding, grinding, or burning is to be done inside or nearby the outside of a containment tent, the affected area should be covered with flame retardant materials.

- The inspection certification should be posted on or near the containment.

NOTE: Containments to be used outdoors should be attached to the frame by a flexible cord.

\section{Glove Bags}

- The glove bag should be free of holes, tears, or defects in materials.

- Components and surfaces inside the glove bag should be covered (where possible).

- The containment should be protected from sharp objects, internal and external.

- The glove bag and installed service sleeves should be supported properly.

- The gloves should be properly attached and free of cracks, splits, or holes.

- The glove bag seal to the component should be adequate and inside seals should be used (if possible) whenever liquids are expected in the containment.

- The glove bag should be properly aligned to allow access to the work.

- If a drain is used, it should be located in a low point of the glove bag and should be unobstructed. The drain line should be securely fastened to an appropriate collection system.

- If a vacuum is used with the glove bag, it should be HEPA filtered and efficiency tested.

\subsubsection{Inspection Criteria for Noncertified Containments}

Noncertified containments, such as drapes, poly bottles, and sleeving should be inspected routinely. Routine walk through of the work area should ensure the devices are maintained properly; in some cases, formal inspection criteria may be included in the work controlling documents that required the devices. An example of a situation requiring formal inspection criteria is a poly bottle 
where liquid levels or dose rates may need to be monitored at some given frequency. A site wide program isn't needed to support this, but the specific installation process should include steps to ensure any inspections beyond routine, are performed.

\subsection{TESTING OF CONTAINMENTS}

\subsubsection{Containment Tents}

Containment tents do not routinely undergo preinstallation tests; hov'ever, a smoke test is sometimes used to verify negative ventilation. The smoke test consists of releasing a small amount of nontoxic smoke near an opening and observing to see if it is drawn inside the tent.

\subsubsection{Glove Bags}

Because of their unique application as the sole barrier to contamination spreads, glove bags often require specific tests to verify their ability to contain contamination. Two specific types of tests are routinely performed: air testing and water testing

5.4.2.1 Air Testing. (Air testing is described in greater detail in Appendix B, Section B.3.3.1.) Because air testing is generally used to determine glove bag integrity before installation, air testing is usually performed by the manufacturer or the installation craft. The test consists of pressurizing the glove bag to approximately $3 \mathrm{oz} / \mathrm{in}^{2}(0.2 \mathrm{psi})$ and then applying leak detector (soap solution) to the seams. Variations to this specific method may be performed; however, the key function of the test is to detect faulty seams or find holes in the containment device.

5.4.2.2 Water Testing. (Water testing is described in greater detail in Appendix B, Section B.3.3.2.) Water testing is generally used on installed glove bags to ensure the containment will not leak liquid. The test consists of putting a small amount of liquid (as a minimum, the amount expected to be accumulated) in the containment and verifying none leaks past the component seal or any other low points in the glove bag. The test is always used to test drain assembly installations and for any glove bag where liquid will be present.

\subsection{ADEQUATE SUPPLIES}

Adequate stocks of containment supplies are fundamental to any containment program. To accomplish this, standard containments and equipment should be identified and maintained accesible to the operations and maintenance organizations. An effective containment program should also include the collection and storage of containment materials that meet site-specific standards for reuse. Contamination control considerations should be included in any site policy concerning the reuse of containments or containment supplies. 


\subsection{REFERENCES}

DOE, 1992, U. S. Department of Energy Radiological Control Manual, DOE/EH-0256T,

U.S. Department of Energy, Washington, D.C.

NRC, 1982, Radiological Containment Handbook, NUREG-0914, U.S. Nuclear Regulatory Commission, Washington D.C.

WHC, 1993, Generic Tank Farm Specifications for Walk-in Containment Tent, WHC-S-172, Westinghouse Hanford Company, Richland, Washington.

WHC, 1993, Westinghouse Hanford Containment Program, WHC-SD-GN-RD-20002, Westinghouse Hanford Company, Richland, Washington.

WHC, 1993, WHC Radiological Control Manual, WHC-CM-1-6, Westinghouse Hanford Company, Richland, Washington.

WINCO, 1988, Radiological Work Practices Information Manual, Westinghouse Idaho Nuclear Company, Idaho Falls, Idaho. 
WHC-EP-0749

This page intentionally left blank. 
WHC-EP-0749

APPENDIX A

\section{CONTAINMENT SELECTION PROCESS}

$$
\text { A-1 }
$$


WHC-EP-0749

This page intentionally left blank. 


\section{CONTAINMENT SELECTION PROCESS}

The appropriate containment for a given task should be selected based on the fundamental concepts of contamination control and personnel safety. In this document, containment has been broken down into four categories. The categories above are subjective in nature. Table A-1 provides a guideline for determining containment category. This table is a guide from which to begin the planning and evaluation process and is not intended to be the sole means of determining what level of containment should be used. Other considerations should include impact of containment failure, area dose rates, waste minimization, ventilation, etc. When all factors are considered, the final determination may vary from the matrix.

\section{REMOVABLE CONTAMINATION LEVELS}

Removable contamination is defir- ${ }^{-}$as radioactive material that can be removed from surfaces by nondestructive means such as cas itact, wiping, brushing, or washing. The table breaks the criteria down into three distinct categories, those being less than 10 times Table $2-2(<10,000 \mathrm{dpm}$

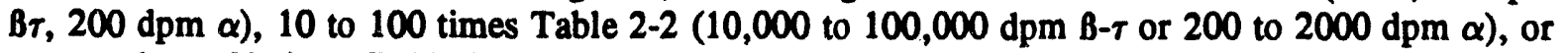

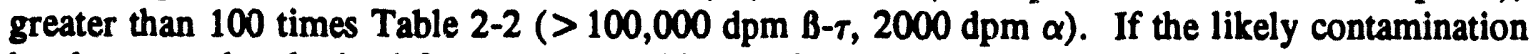
levels cannot be obtained from survey or historical data, the most limiting category should be used.

\section{CONTAMINATION STABILITY}

As noted above, removable contamination is defined as radioactive material that can be removed from surfaces by casual contact. Stability is a qualitative assessment of how easily this transfer occurs and how easily the contamination may be transported from surface to surface or surface to air. For determining containment stability is broken into three categories, high, medium, and low. For example, contamination that, if disturbed, readily resuspends into the air would be categorized as low stability, while contamination suspended in liquid, or on a moist or oily surface would generally be considered high stability, other contaminated surfaces would generally fall between these criteria based on surface texture, weathering and a variety of other factors to be considered.

\section{WORK ACTIVITY}

Work activities are considered to be those actions which will be performed in the contaminated portion of the work area. The containment selection process breaks work activities into five categories:

1. Simple material movement such as walking, lifting, carrying.

2. Vigorous material movement such as repackaging waste, HEPA filter manipulation, packing replacement, etc.

3. Using power tools in the area or manually cutting, abrading, or shaping the material. 
4. Using low-velocity power tools (portable band saws, electric drills operated at low speeds, etc.) on the contaminated components.

5. Using high-velocity power tools (grinders, high-speed drills, etc.) on the contaminated components.

\section{CONTAINMENT CATEGORIES}

\section{Very Low Risk}

For tasks involving a very small risk of contamination spread, no specific containment beyond the administrative controls of good work practices would apply. This does not preclude using containment, it instead leaves the selection to the workers. Experience and training of the work force would be the basis for containment selection. In this category, containment might be a damp rag, sleeving, an air curtain, or even a plastic bag.

\section{Low Risk}

Tasks where the risk of contamination spread is low, but the containment device is specified. Examples of devices in this category are catch containments, drip pans, bull pens, sleeving, air curtains, etc.

\section{Moderate Risk}

Tasks where the risk of contamination spread is moderate and containment becomes total enclosure such as is obtained by heavy sleeving, glove bags, or containment tents.

\section{High Risk}

Tasks where the risk of contamination spread is high and containment should be accomplished by ventilated tents or glove bags, used independently or in conjunction with each other. 
WHC-EP-0749

Table A-1. Recommended Containments for Specific Work Activities.

\begin{tabular}{|c|c|c|c|}
\hline $\begin{array}{c}\text { Removable } \\
\text { Contamination Level }\end{array}$ & $\begin{array}{l}\text { Contamination } \\
\text { Stability }\end{array}$ & Operation & $\begin{array}{l}\text { Containment } \\
\text { Category }\end{array}$ \\
\hline $\begin{array}{c}<10 \text { times Table } 2-2 \\
6\end{array}$ & $\begin{array}{c}\text { Very Stable } \\
4\end{array}$ & $\begin{array}{c}\text { Simple material movement } \\
5\end{array}$ & $\begin{array}{l}\text { Very Low Risk } \\
\text { Total }=15-20\end{array}$ \\
\hline $\begin{array}{c}<100 \text { times Table } 2-2 \\
12\end{array}$ & $\begin{array}{c}\text { Moderately Stable } \\
8\end{array}$ & $\begin{array}{l}\text { Vigorous material movement } \\
10\end{array}$ & $\begin{array}{c}\text { Low Risk } \\
\text { Total }=21-31\end{array}$ \\
\hline \multirow[t]{3}{*}{$\begin{array}{c}>100 \text { times Table } 2-2 \\
18\end{array}$} & \multirow[t]{3}{*}{$\begin{array}{l}\text { Low Stability } \\
\qquad 12\end{array}$} & $\begin{array}{l}\text { Use of power tools in area or } \\
\text { manual cutting, shaping or } \\
\text { abrading of material } \\
15\end{array}$ & $\begin{array}{l}\text { Moderate Risk } \\
\text { Total }=32-45\end{array}$ \\
\hline & & $\begin{array}{l}\text { Use of low velocity power tools } \\
\text { to cut, shape or abrade material } \\
\qquad 20\end{array}$ & \multirow{2}{*}{$\begin{array}{l}\text { High Risk } \\
\text { Total }>45\end{array}$} \\
\hline & & $\begin{array}{l}\text { Use of high velocity power tools } \\
\text { to cut, shape or abrade material } \\
\qquad 25\end{array}$ & \\
\hline- & + & + & $=$ \\
\hline
\end{tabular}

Intructions: Solect the appropriate block from each of the firt three columns. Add the numbers from the appropriate block in cach column and select the appropriate containment class.

NOTES:

1. Removable contamination level refers to the DOE Radiological Control Manual Table 2-2.

2. Containment requirements may be revised up or down based on general area contamination levels, or dose rates, and personnel protection afforded (for example, respirator, ventilation, engineering controla).

3. When contamination levels cannot be verified, either by murvey or hirtorical data, the moat limiting level for contamination ahould be used.

4. The valuee on the chart call for aubjective analyais. The Radiological Control Organization in reaponaible for making the final determination of the level of containment. This should be done in consultation with the line organization. 
WHC-EP-0749

This page intentionally left blank. 
WHC-EP-0749

APPENDIX B

GUIDANCE ON USIE OF C.ONTAINMENTS

B-1 
WHC-EP-0749

This page intentionally left blank.

B-2 


\section{GUIDANCE ON USE OF CONTAINMENTS}

This appendix provides industry-accepted good practices and methods of using containments. Section B.1 provides general guidance; subsequent sections provide specific guidance for tents, glove bags, poly bottles, and other containments such as catch containments and drop cloths.

\section{B.1 GENERAL GUIDANCE}

\section{B.1.1 CONTAINMENT USE}

- Inform the Radiological Controls Department of intentions to work in a specific containment, and ensure the containment is in working condition and has been certified for use.

- Notify Radiological Control personnel if the containment is damaged or if you question the appropriateness of the device for the planned activity.

- Establish contamination limits for containment.

- Do not step on containments or use them to support other equipment unless the containment or support device is specifically designed for this purpose.

- Do not step on temporary drain or drain collection systems.

- If a containment support must be moved, ensure that it will provide the same support as the original location.

- Use only facility ventilation, high-efficiency particulate air (HEPA)-filtered vacuum cleaners, or portable HEPA ventilation units to exhaust from a containment.

- Use trained personnel to supervise or install and remove containments.

- Prefabricate/pretest containments as much as practical outside of the radiologically posted areas. This will

- Reduce personnel exposure

- Reduce radioactive waste volume in case containments fail pretest.

- Eliminate the need for wearing protective clothing or respirators during fabrication.

- When more than one craft is involved in the use of a containment, all should be consulted on the containment to be used. 
- Each job should have assigned contamination limits for both inside and outside the containment. Surveys should be performed during the job to ensure the contamination levels remain within the prejob guidelines. It may be necessary to stop work and decontaminate the containment in order to keep the contamination levels as low as reasonably achievable (ALARA).

\section{B.1.2 HOT WORK}

Hot work such as welding, burning, or grinding may be performed in a containment only if flame retardant material, such as fire retardant blankets, has been provided to protect the containment from damage.

\section{B.1.3 LIGHTING}

\section{B.1.3.1 Incandescent Lighting}

When used, incandescent lights shall be enclosed and less than 50 watts. Unenclosed incandescent droplights are prohibited for use in containments.

\section{B.1.3.2 Fluorescent Lighting}

Enclosed fluorescent lighting is the preferred method of providing lighting for containments when natural light is insufficient. 


\section{B.2 GUIDANCE ON USE OF CONTAINMENT TENTS}

Containment tents use the basic approach of donning and removing protective clothing, step off pad arrangement, and waste handling associated with activities that may encounter radioactive contamination, more so than glove bags, catch containments, or poly bottles. Because the DOE Radiological Control Manual (DOE N 5480.6) addresses many of these issues, much of that information is not covered in this appendix. Only those aspects of radiological controls unique to containment tent operations are discussed.

\section{B.2.1 GOOD PRACTICES ASSOCIATED WITH TENT OPERATION}

- Tents and enclosures use the "bagging the worker" concept; therefore, consideration must be made for the removal of protective clothing and respiratory protection. Standard application of step-off pads, unsuiting methodology, and waste handling generally apply.

- Where ventilation systems are used, the system should be verified operational. This will be evident by tent sides bowing in and air rushing in through any penetrations. This can also be verified routinely by smoke testing.

- All doors should be closed, service sleeves secured, dump sleeves closed, etc. before the start of work.

- All tools should be staged in the tent before start of work.

- Protective clothing should be worn in accordance with the requirements of the radiation work permit (RWP).

- If hot work is to be done inside or nearby the outside of a containment tent, cover the affected areas with flame retardant cloths.

- Firmly anchor and support all tents and enclosures. Tape over any sharp or rough edges that could puncture or abrade the containment.

- Do not allow incandescent lights to come in contact with containment tent material. Fluorescent lights are the preferred method of lighting in tents. Where used, incandescent lights should always be less than $\mathbf{5 0}$ watts.

- All penetrations (i.e., ventilation duct, air lines, electrical cords, etc.) should gain access through service sleeve(s) securely attached to the tent and taped to the sleeve.

- Containments should have the floors covered with an easily removable material for ease of decontamination.

- Airlocks should be used for personnel entry and exit with areas maintained at lowering contamination levels towards the exit point.

- Multiple layers of flooring should be considered for jobs where high contamination levels are expected. 


\section{B.2.2 GOOD PRACTICES ASSOCIATED WITH USE OF SUPPLIED AIR}

The use of supplied air in containment tents causes unique problems. Air lines should not be laid in door ways during tent operations. When using supplied air in conjunction with a containment tent, observe the following good practices:

- Keep breathing air lines on hooks off the floor near the entrance to the tent to preclude contaminating the air supply and to allow quick access upon entry. The female quick disconnect inside the tent should be surveyed for removable contamination before and after each use.

- Airline hose hangers should be securely attached to the containment and used for hanging and separating airlines inside the containment.

- Airline check box, if used, should be securely attached to the containment and used for hanging and separating the airline hose ends. The airline check box should be mounted to allow the Radiological Control Technician to check the airline connection for contamination from outside the containment.

- Numbers should be placed on the utility ports, airline hose hangers, and airline check boxes. Airlines are marked or tagged with the corresponding number on the utility ports, hangers, and check boxes. When the airline connections are found to be contaminated, the line is easier to trace and replace.

\section{B.2.3 GOOD PRACTICES ASSOCIATED WITH USE OF VENTILATION}

Most issues regarding ventilation will be dealt with in the design section of this document (Appendix D). However, once the tent is designed, ventilation is installed, tent is certified, and work is begun, the ventilation configuration is a major concern to tent operation. Most tents will have flexible ventilation trunk(s) extended into the work area. A major consideration for ventilation design and installation is to ensure the ventilation system draws contaminates away from the workers. Figure B-1 shows an example of good ventilation configuration.

\section{B.2.4 REMOVAL OF CONTAINMENT TENTS}

- Tents should be decontaminated to acceptáble levels before removal.

- Service leads should be removed or disconnected before removal.

- HEPA-filtered vacuum cleaners or exhausters are an effective way of collapsing a tent. The supports can be removed gradually allowing sections of the tent to collapse preferentially, this makes the packaging of a tent, either for waste or reuse much easier. 

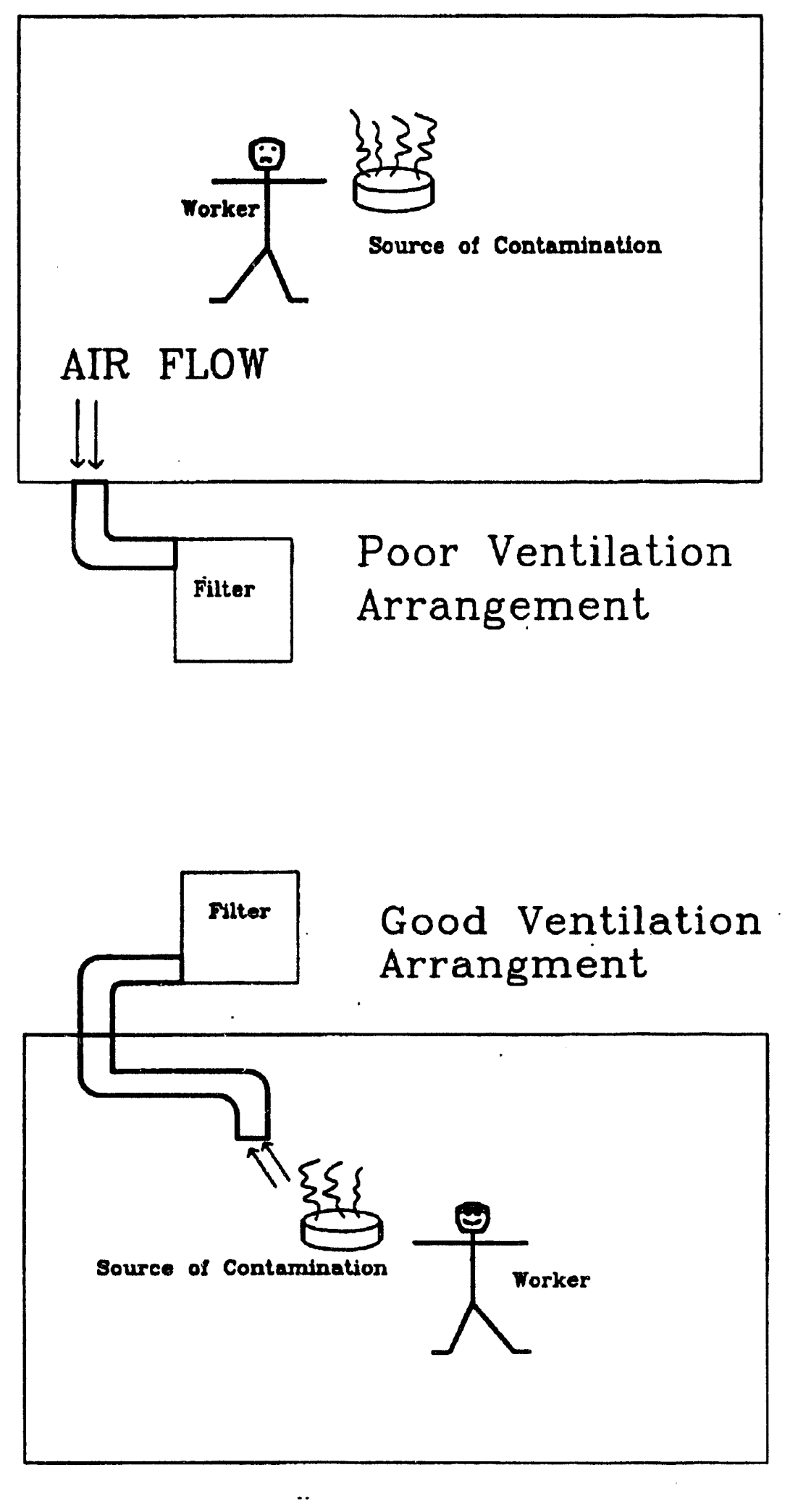

Figure B-1. Ventilation Configuration. 
WHC-EP-0749

\section{B.3 GUIDANCE ON USE OF GLOVE BAGS}

Glove bags are an effective proven method of radioactive contamination control. The following instructions are provided as guides and are not inclusive of all methods of glove bag preparation, installation, use, or removal.

\section{B.3.1 PREREQUISITES, PRECAUTIONS, AND LIMITATIONS}

- Use trained personnel for fabrication, installation, and removal of glove bags.

- Fabricate/pretest glove bags as much as practical outside of the radiologically posted areas. This will

- Reduce personnel exposure

- $\quad$ Reduce radioactive waste volume in case glove bags fail pretest

- Eliminate the need for wearing protective clothing or respirators during fabrication.

- Do not use absorbent material in glove bags equipped with a drain.

CAUTION: If the containment assembly is used to control/collect liquids or materials that could create a criticality concern, contact Criticality Safety for geometry, design criteria, and acceptance of the glove bag and collection bottle.

- The work package should state if liquid is expected, and if so, the probable composition and quantity of liquid. When poly bottles are used in conjunction with glove bags, the organization responsible for changing and/or emptying full bottles should be identified and should stage a spare bottle in the area if deemed necessary.

- Clear and verify that the area intended for glove bag installation is free of any obstructions before the glove bag is installed.

\section{B.3.2 PREINSTALLATION, FABRICATION}

- Accumulate the glove bag(s) and accessories (i.e., gloves, glove rings, filters, drain assemblies).

- Visually check the glove bag body, gloves, and sleeving for holes, tears, or defects.

NOTE: Allow sufficient time for containments that have been stored in a cold/cool area to warmup. Flexing of cold polyvinyl chloride (PVC) may cause premature failure of the containment. 


\section{WHC-EP-0749}

- Install rubber gloves (size 10 or 11 gloves are suggested), at locations indicated in the installation sheet (see Figure B-2). Ensure proper orientation for working position.

NOTE: Canister filters are generally used if the glove bag has negative ventilation; 2-cfm filters are used on nonventilated glove bags.

- Install Canister (30-40 cfm) filter(s) (if required) (see Figure B-3, Canister Filter Installation).

- Tape over possible sharp edges on the filter to protect sleeving.

- Trim excess sleeving (concentric taper) and install filter as close to containment as practical to prevent the sleeving from twisting or folding over and pinching off the air flow path.

- Install 2-cfm filter(s) (if required) (Figure B-4, 2-cfm Filter Installation).

- Install filter(s) in the highest practical position on the containment.

- Ensure the filter(s) does not obstruct visibility of the work area.

- Check the following:

- Filter housing is intact

- Elements are intact

- Threads on the filter are in good condition.

- Install transfer sleeve - prepare the ring and sleeving (Figure B-5A, Transfer Sleeve and Figure B-5B, Transfer Sleeve - Alternative Method).

- Install gravity drain in the lowest portion of the containment at least $1 / 2$ in. from seams (Figure B-6, Drain Fitting). 


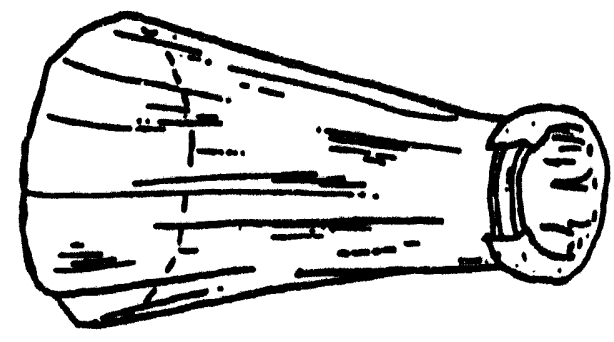

1) Insert the end of the sleeve through the ring. Then fold the end of the sleeve out to cover the glove ring.

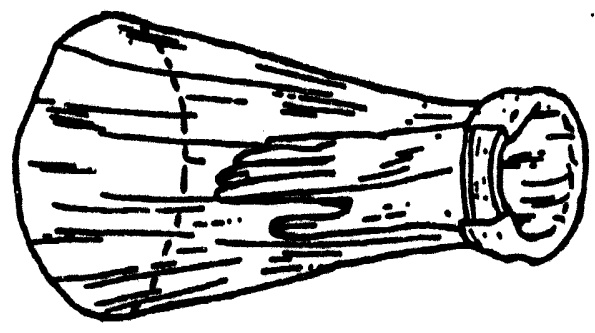

2) Insert the glove into the sleeve in the appropriate working position and fold the cuff of the glove over the glove ring.

3) Place the rubber ring over glove and sleeve

4) Apply tape over rubber ring. and into the groove in the glove ring.

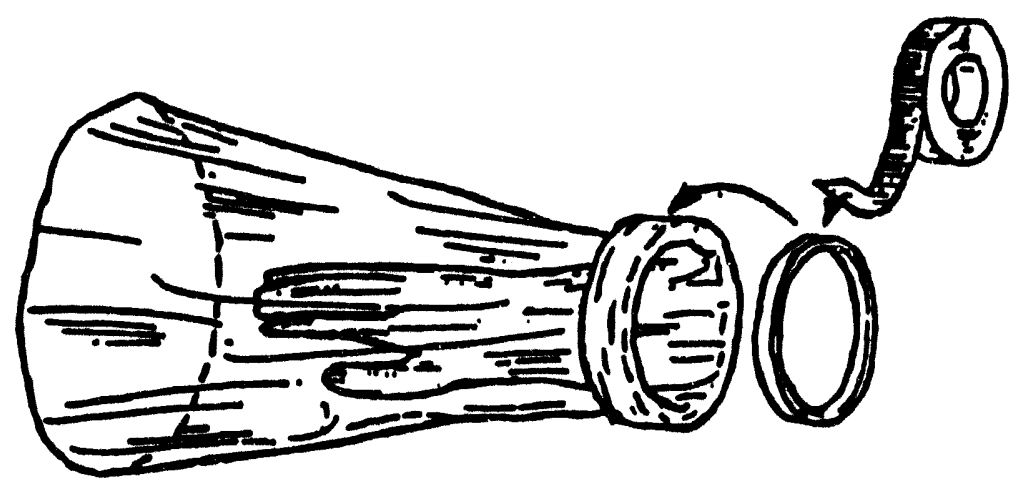

5) Push gloves and sleeves inside the containment.

Figure B-2. Glove Installation. 


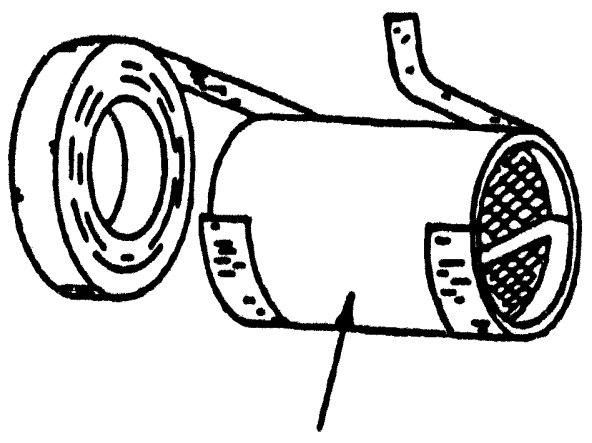

30-40 CFM Filter

1. Check the following:

- Efficiency test stickers attached

- Metal housing intact and not deformed

- Filter elements intact.

2. Install filter in the highest practical portion of the containment.

3. Ensure filter does not obstruct visibility of the work area.

4. Attach tie-off rubber band and cord to metal strap on filter.

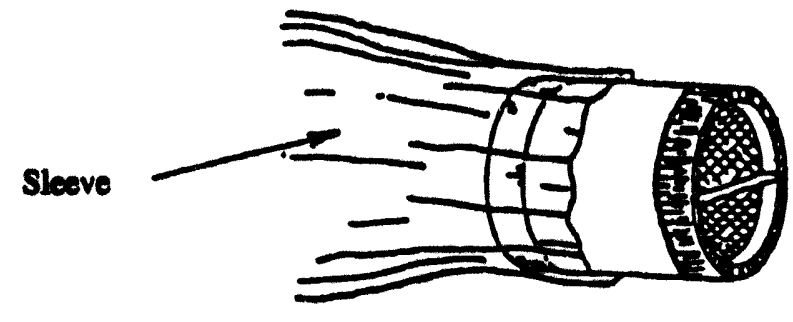

Seal Sleeve To Filter

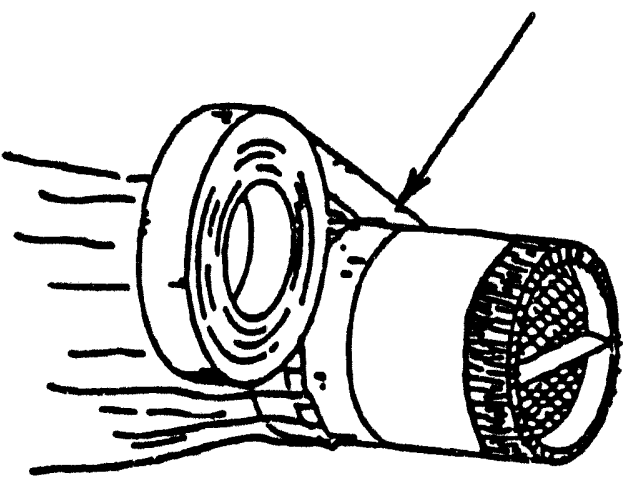

Figure B-3. Canister Filter (30-40 cfm) Installation. 
WHC-EP-0749

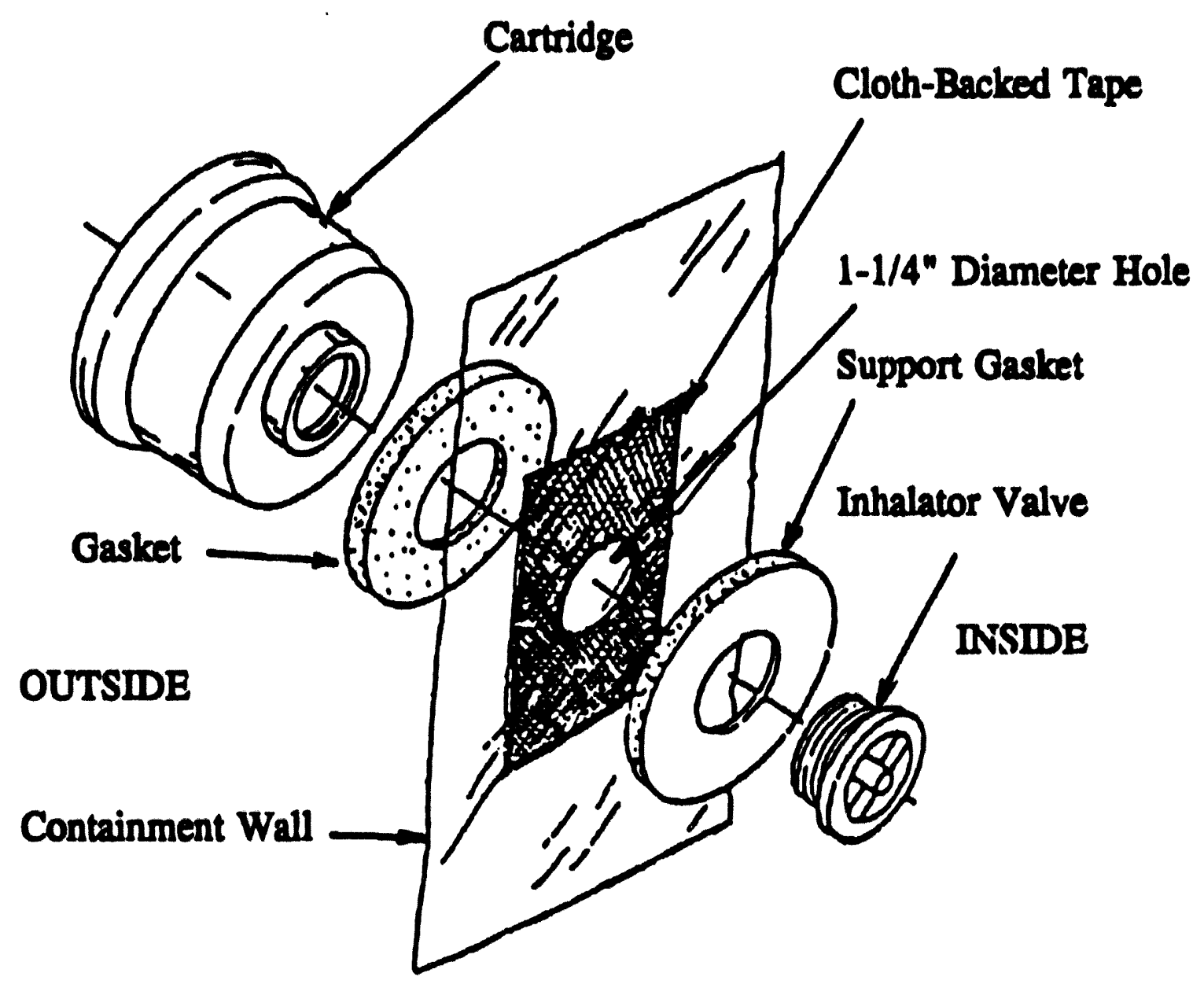

Figure B-4. 2-cfm Filter Installation. 
1) Cover sharp edges of transfer ring with tape.

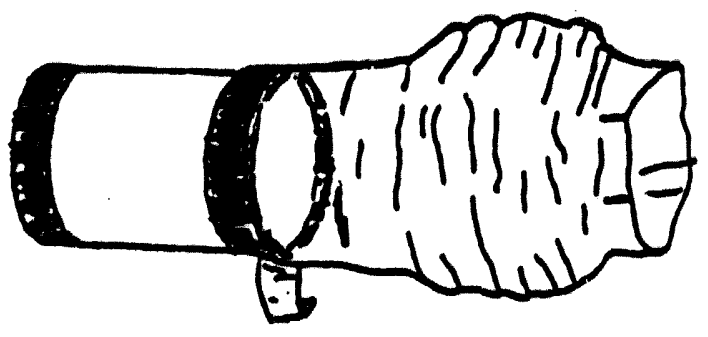

2) Slide FVC/Poly sleeving over ring, tape onto ring end as shown. Install hose clamp or double cable ties (if required).

3) Push slceving over ring, accordion as shown. Apply tape strips to hold sleeving in place.

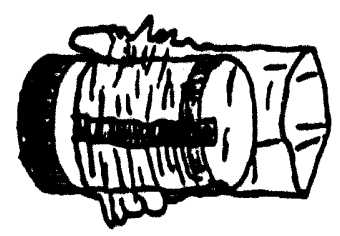

4) Install plastic ring in glove bag sleeve. Secure with tape, clamp over tape, then tape over clamp.

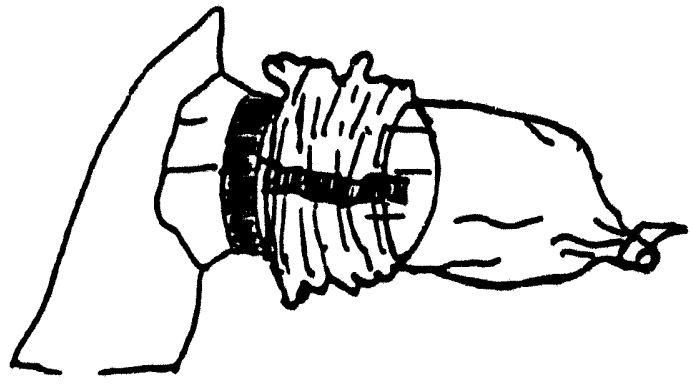

5) Tape open end of sleeve closed.

Figure B-5A. Transfer Sleeve. 


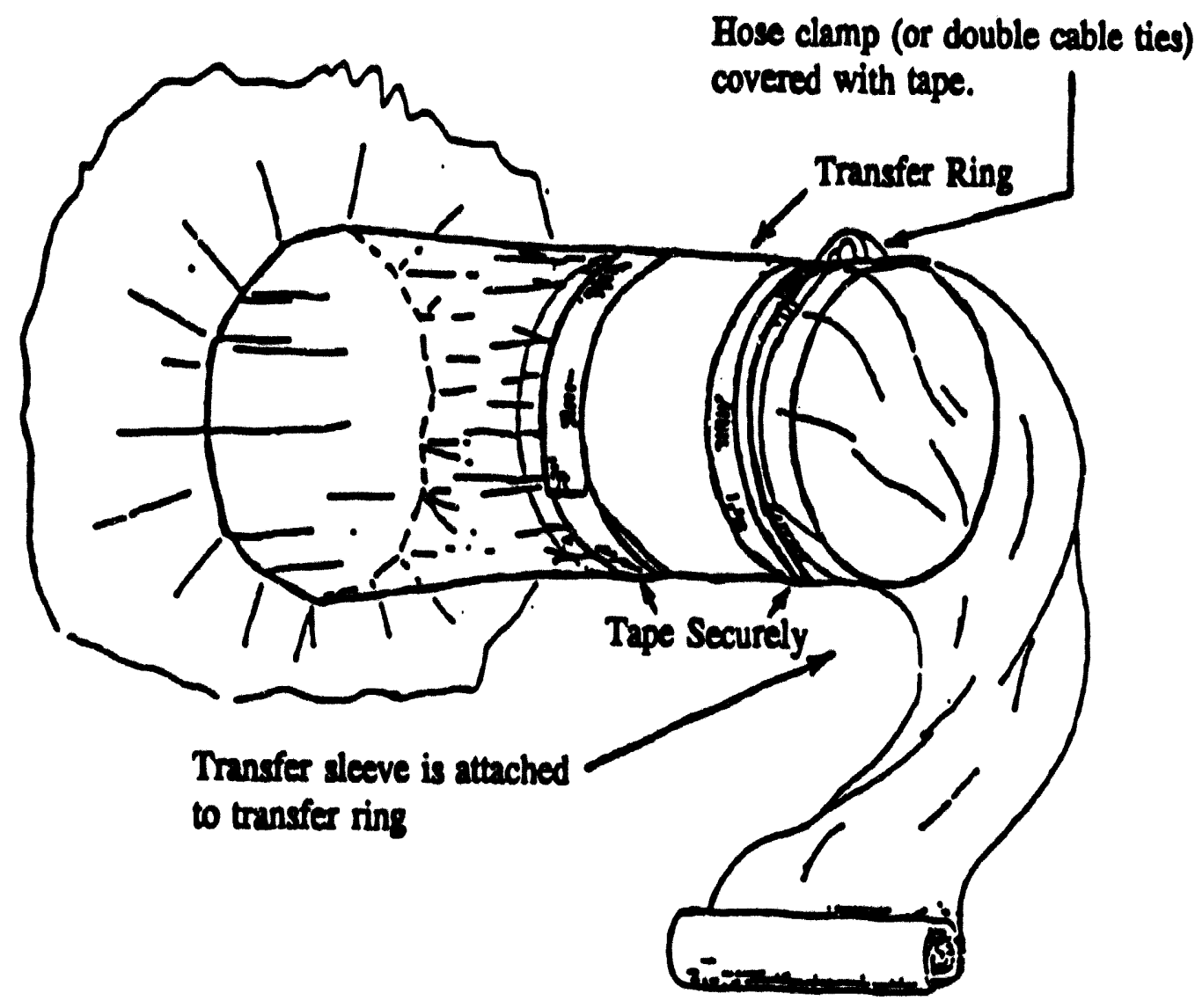

Seal end of transfer sleeve

Figure B-5B. Transfer Sleeve (Alternative Method). 


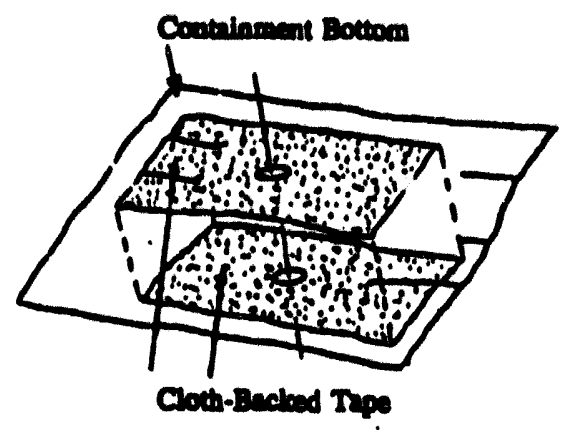

1. Apply cloth-backed tape to an area (approx. 2" $\times 2^{\prime \prime}$ ) inside and outside containment in the area selected for the drain.

2. Cut or punch an appropriate size diameter hole through the tape.

3. Install drain fitting as illustrated.

4. Protect sharp edges with cloth-backed tape (i.e., hose clamps)

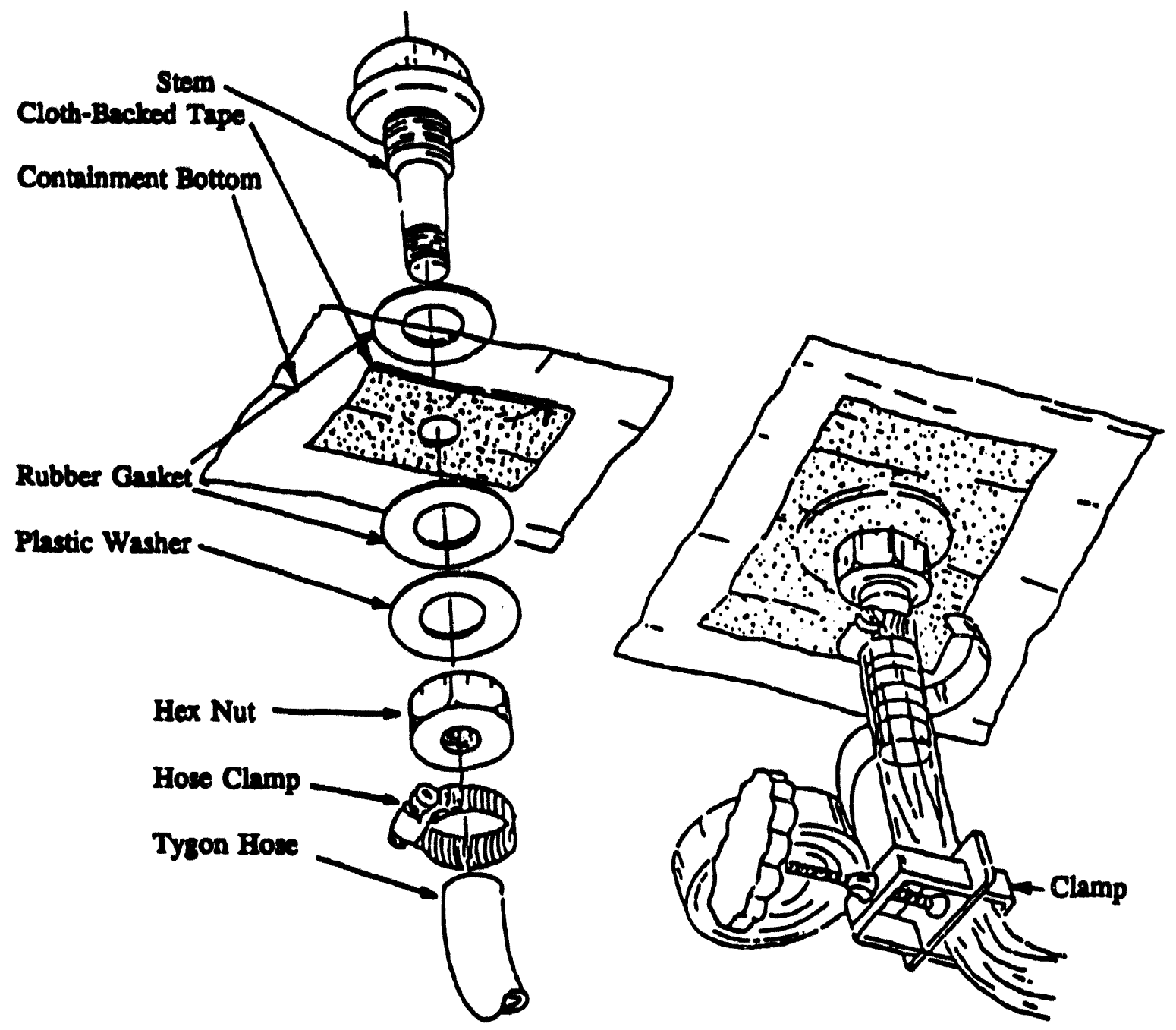

Figure B-6. Drain Fitting. 


\section{B.3.3 TESTING}

Testing is often required to confirm the integrity of the glove bag before installation and after installation is complete.

\section{B.3.3.1 Nir Testing}

NOTE: Air tests are often used to verify the integrity of construction of a glove bag in the shop, before installation in the work place. An air test may be used to verify the installation integrity if pressurization of the glove bag is anticipated.

If an air test is required, use an inflation test rig as shown in Figure B-7 Inflation Test Assembly) or other suitable arrangement that will verify containment integrity at 3-5 oz/in $(0.2-0.3 \mathrm{psi})$.

1. Attach air supply to inflation test rig.

2. Insert the supply tube through an available sleeve or other opening. Obtain an air-tight seal by taping the sleeve around the supply tube. An option is to connect the air line to the drain fitting (if installed).

3. Secure any remaining openings, including filters and drain fittings.

4. Pressurize the glove bag and allow the pressure to stabilize for approximately two minutes.

5. Apply a leak detector solution to the outside of all seams (e.8., snoop, 50/50 mix Ivory soap and water) or likely leak points. Any leakage (indicated by bubbles) constitutes rejection of the unit, unless repairable.

NOTE: Leakage from temporarily taped openings (applied for the leak test) does not constitute a failure.

6. Inspect any sleeve(s) which is isolated from the main body (membrane is not removed, but sleeve may be used later).

7. If the glove bag is free of defects, remove air test rig.

\section{B.3.3.2 Water Testing}

NOTE: Water tests are often used to test glove bag integrity following installation and before use. A water test may also be used to test plant fabricated (non-heat-sealed) glove bags with glued or sewn joints. 


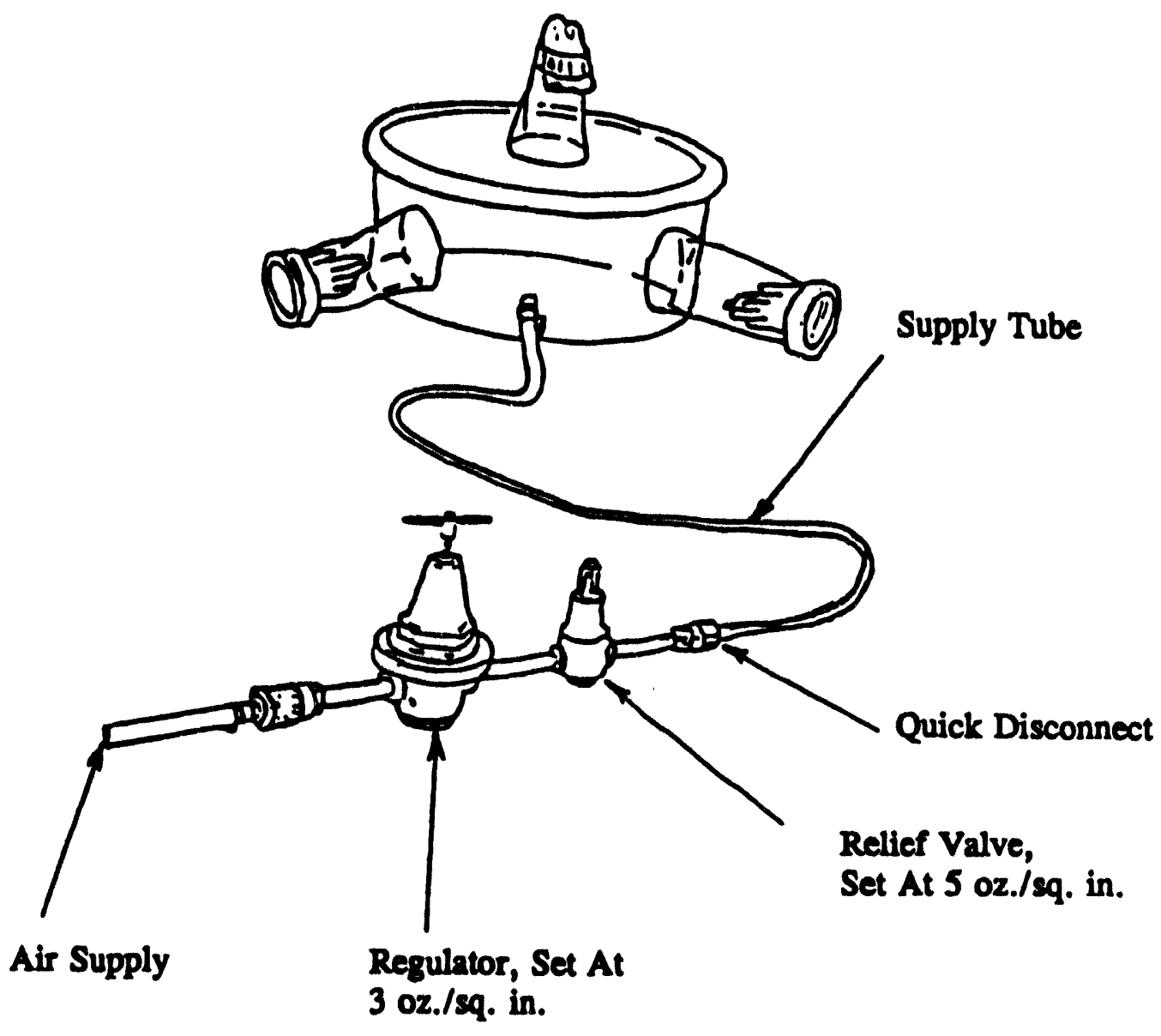

Figure B-7. Inflation Test Assembly.

If a water test is required, sufficient liquid should be used to adequately test the glove bag under expected or likely use conditions.

1. Secure drain line with pinch clamp or crimp and tape.

2. Pour a suitable amount of water through an available opening being careful not to wet the outside of the containment; use enough water to "puddle" around any lower penetrations or seals (e.g., drain fitting).

3. After approximately 2 minutes, check for leaks.

4. Correct deficiencies if practical, or reject the containment.

5. Remove water from the containment after completion of the water test and before start of work. 


\section{B.3.4 INSTALLATION}

1. Prepare the area in the vicinity of the proposed glove bag installation. Cover any sharp or rough edges that could puncture or abrade the glove bag.

2. Cover with fiberglass cloth or equivalent adjacent piping and/or components that are hot (have surface temperatures in excess of $150^{\circ} \mathrm{F}$ ) and may come in contact with the containment.

3. Exposed piping and/or components that will be inside the glove bag should be covered to minimize contamination. Figure B-8 (Tape Application for Component Surface

Protection) illustrates this by using tape to cover the exposed surfaces, note that this also provides a better sealing surface.

4. Make up bottom or component seal as shown in Figure B-9 (Sealing Containment to a Component). Inside seals are normally required for the lower portion of the containment when liquids are expected, unless otherwise authorized by Radiological Control personnel.

5. Tape any openings if membranes have been removed. Ensure presslock zipper tracks and glider zipper tracks are properly aligned (See Figure B-10, Access Zipper Operation and Taping).

6. Connect and adjust tie offs to obtain the best working position for the containment (Figure B-11, Tie Off Assembly).

7. If required, install drain assembly per Figure B-6, Drain Fitting. Connect drain line to pump (if used) and to the appropriate collection container (Figure B-12, Hand Pump Assembly). If the drain assembly will be subjected to stress, consider using a sealant when installing.

NOTE: Ensure drain is in the lowest portion of the glove bag and that undue strain is not put on the lower seal.

8. Connect required services (e.g., air, vacuum cleaner, etc.) through service or glove sleeves not equipped with a glove assembly (Figure B-13, Service Lead Installation).

9. Independently support items, such as hoses, cords, etc. that are connected to the containment to avoid unnecessary strain on the containment.

CAUTION: Ensure CAUTION/DANGER tags or other labeling devices are not obscured by the glove bag.

10. Install Containment Identification tag, if used.

11. Contact Radiological Control Personnel and have the glove bag inspected, tested (if required), and certified. 


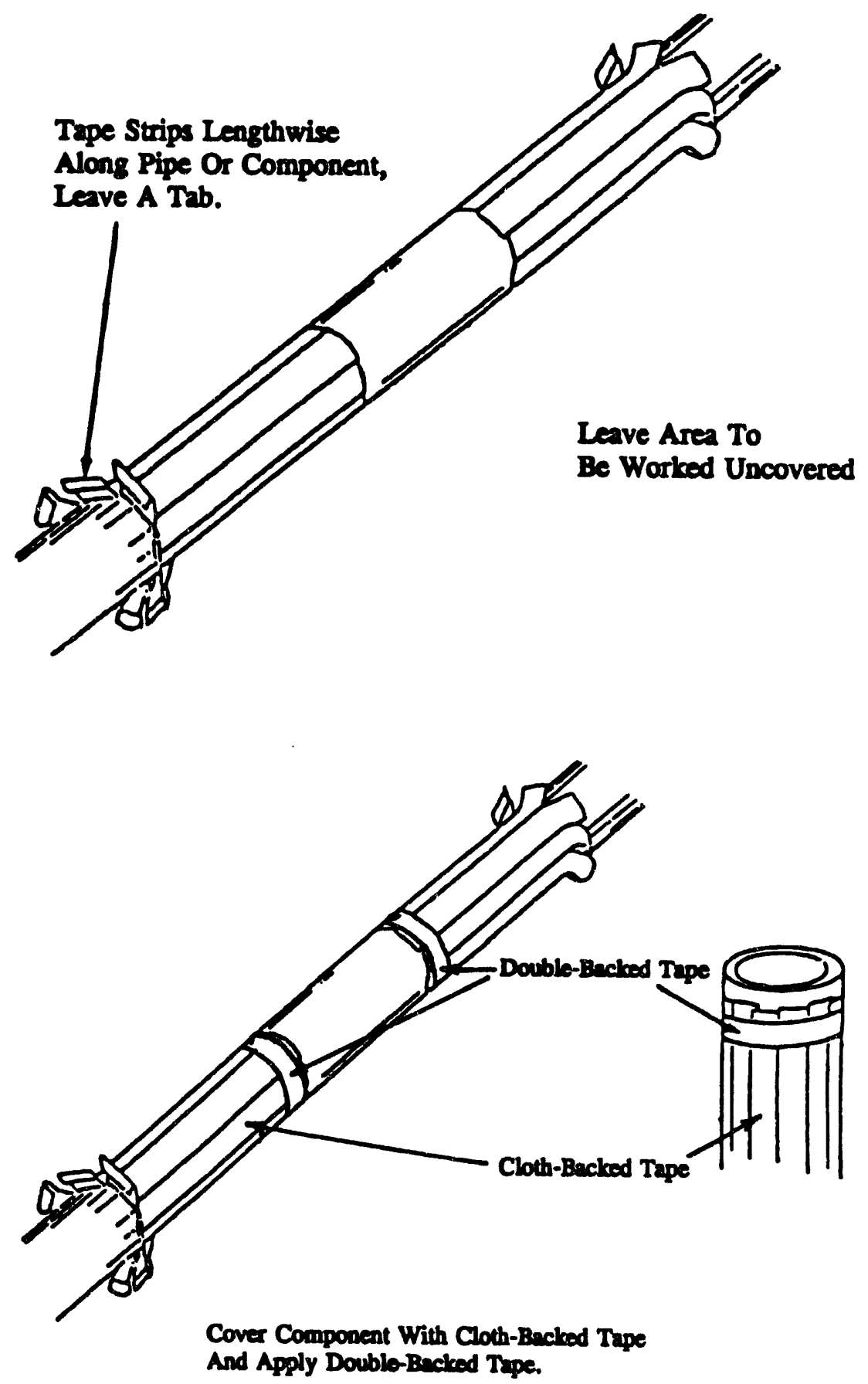

Figure B-8. Tape Application for Component Surface Protection. 

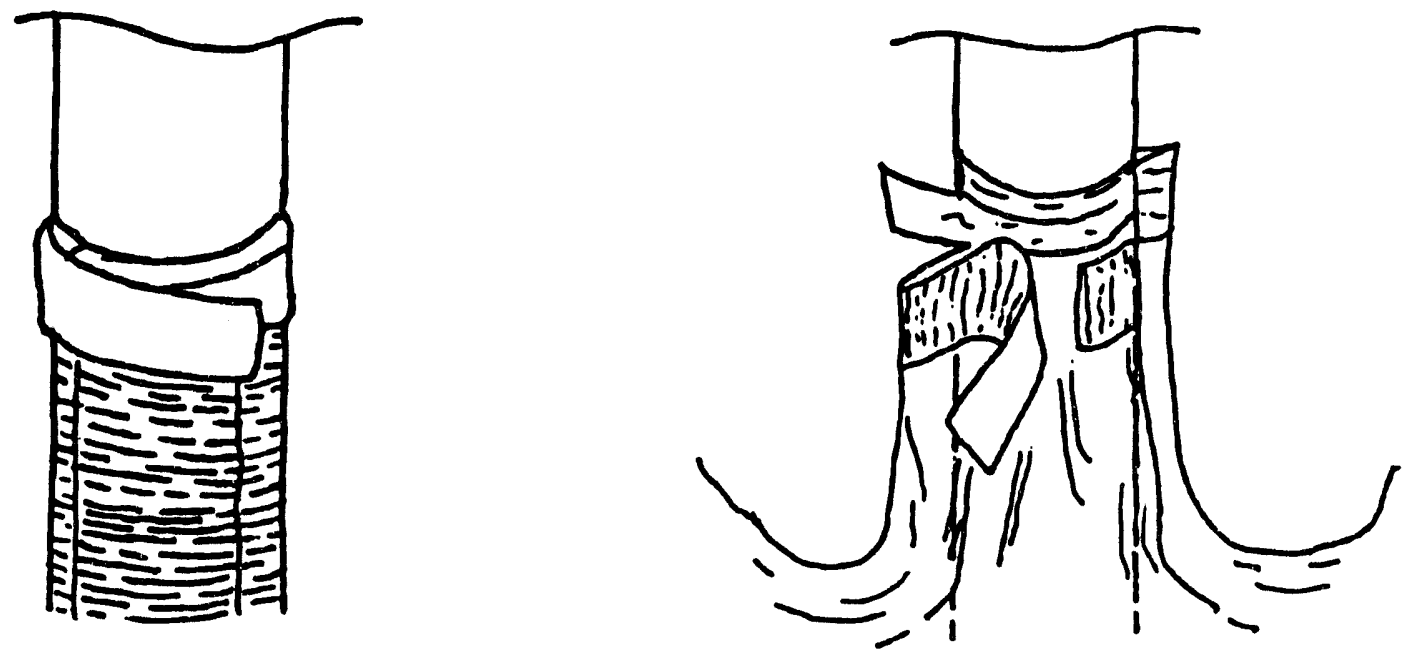

1. Cover piping with cloth backed tape.

2. Apply doublesided tape to cloth backed tape.

3. Attach cloth backed tape to sleeving and double backed tape to make a tight seal.
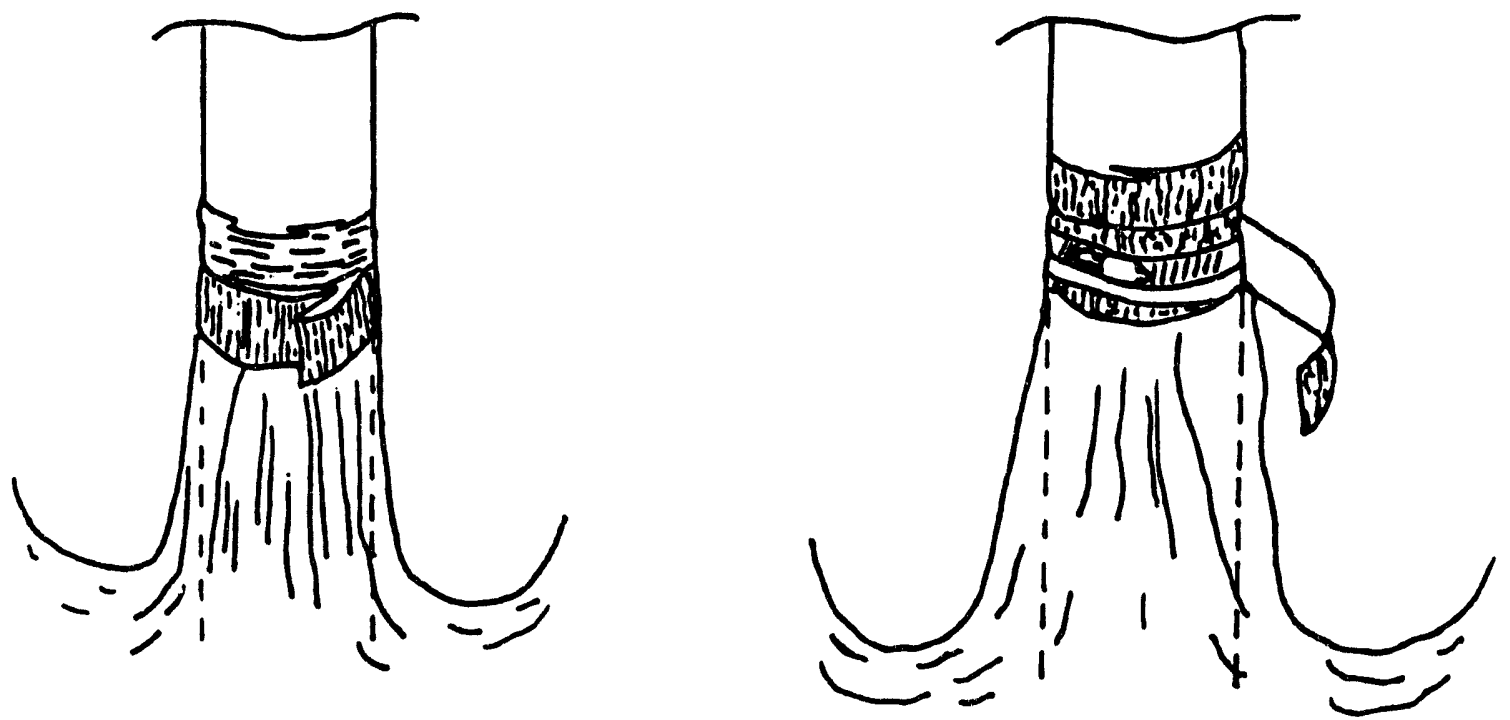

4. Wrap again with cloth backed tape.

5. Install hose clamp and tape over clamp.

Figure B-9. Sealing Containment to a Component. 


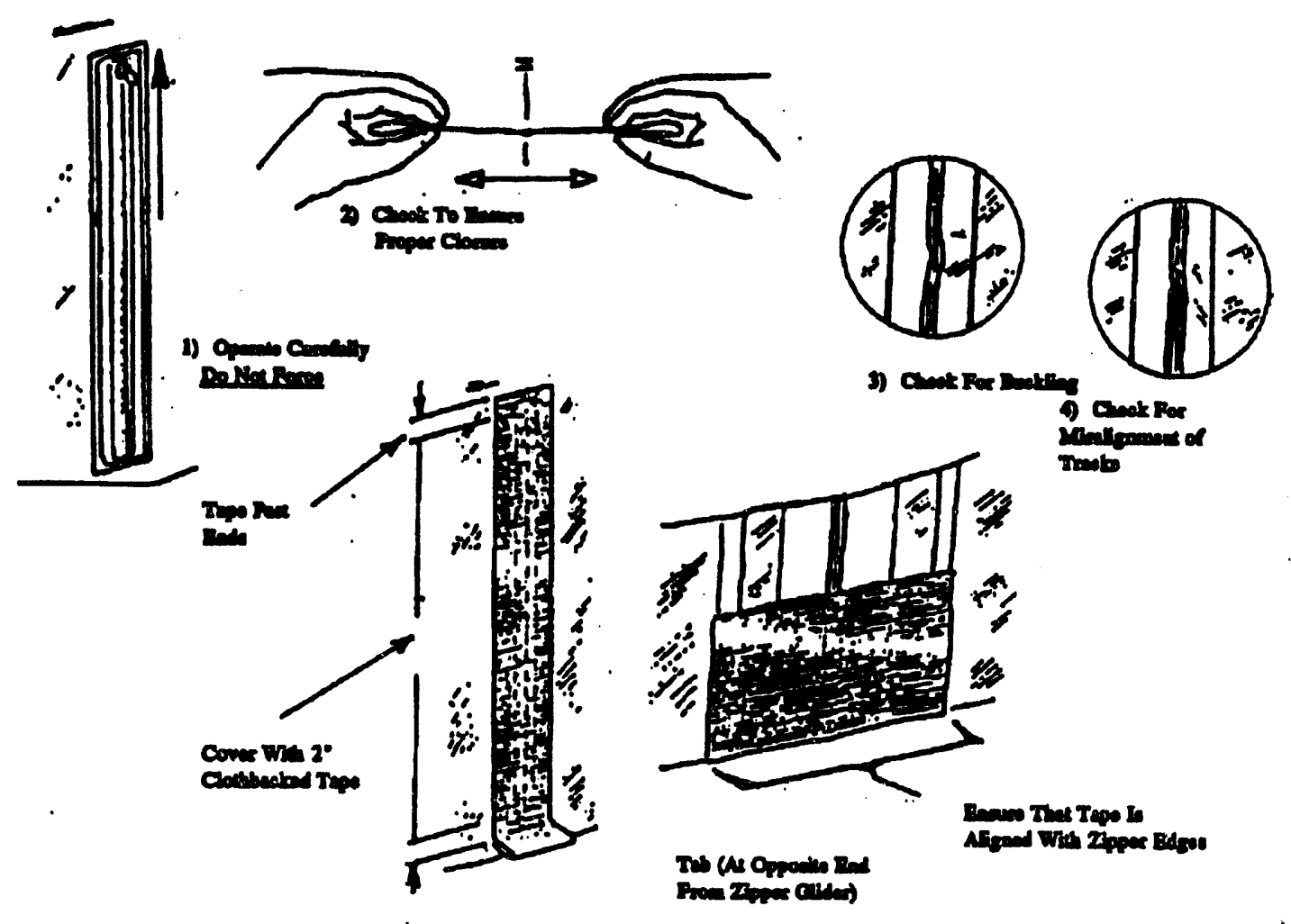

Figure B-10. Access Zipper Operation and Taping.

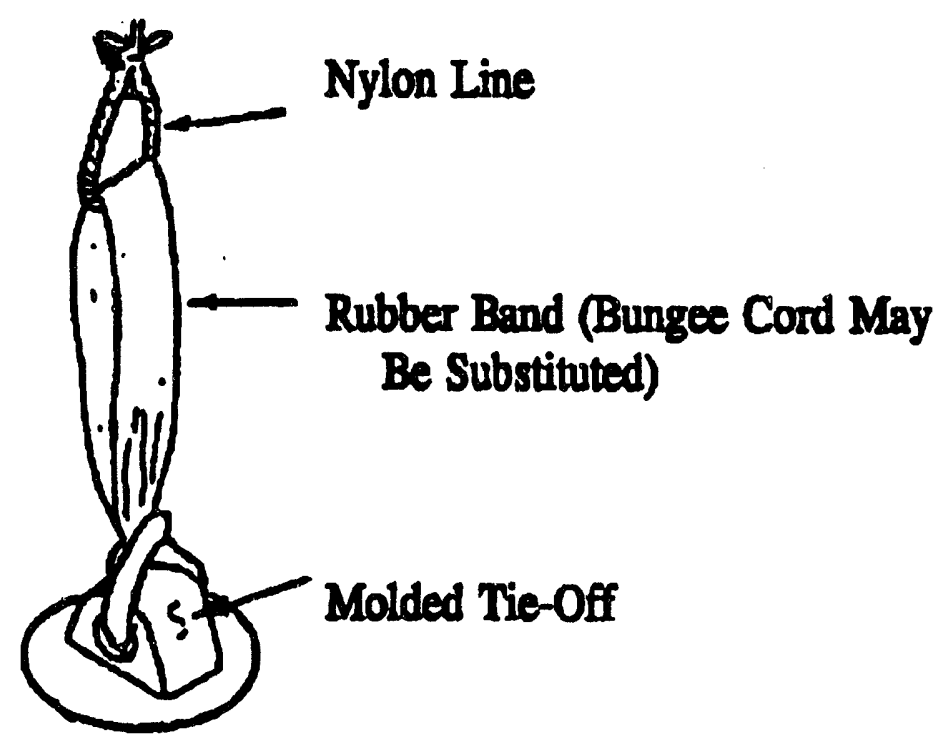

Figure B-11. Tie-Off Assembly. 


\section{WHC-EP-0749}

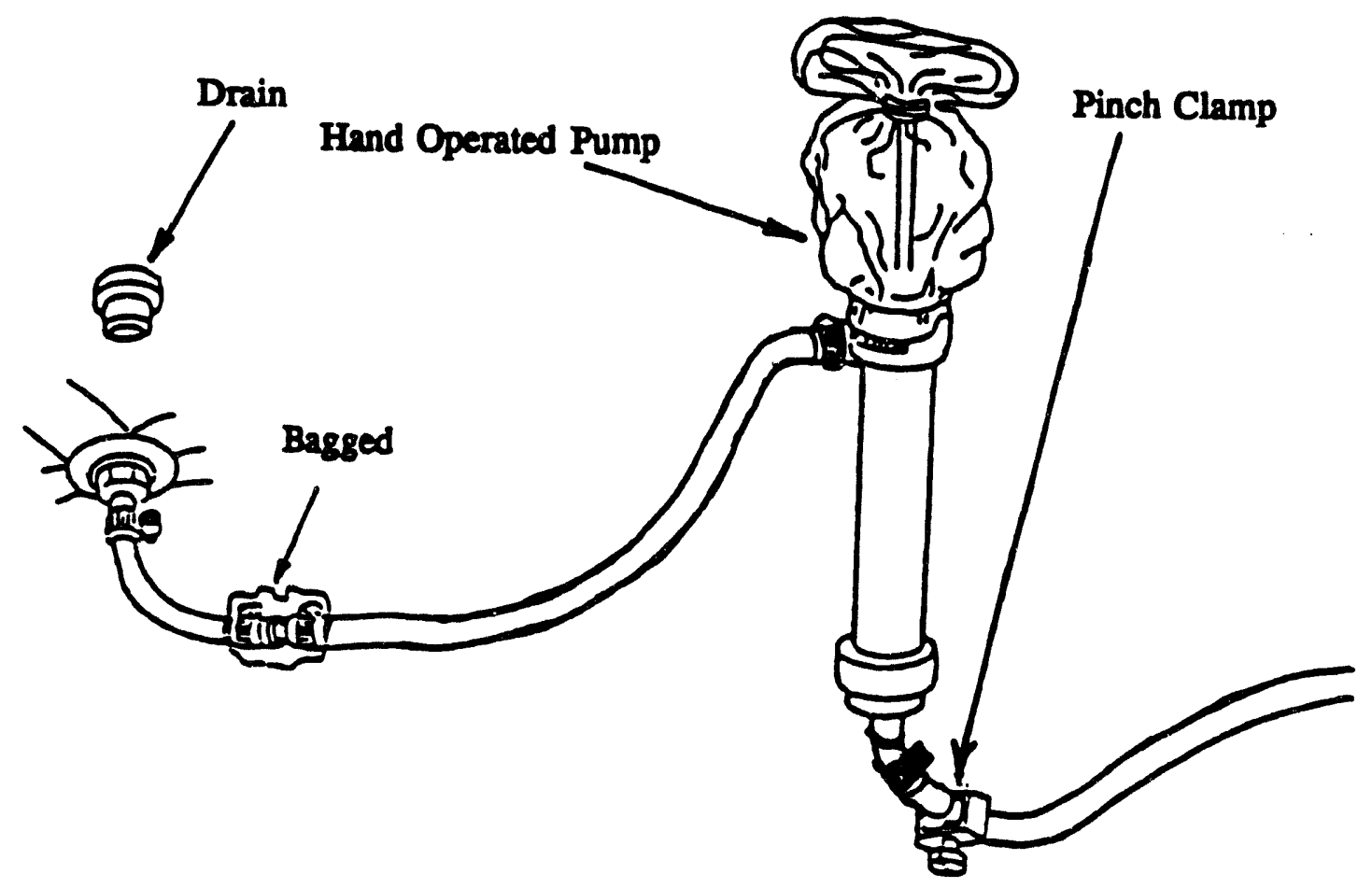

Figure B-12. Hand Pump Assembly.

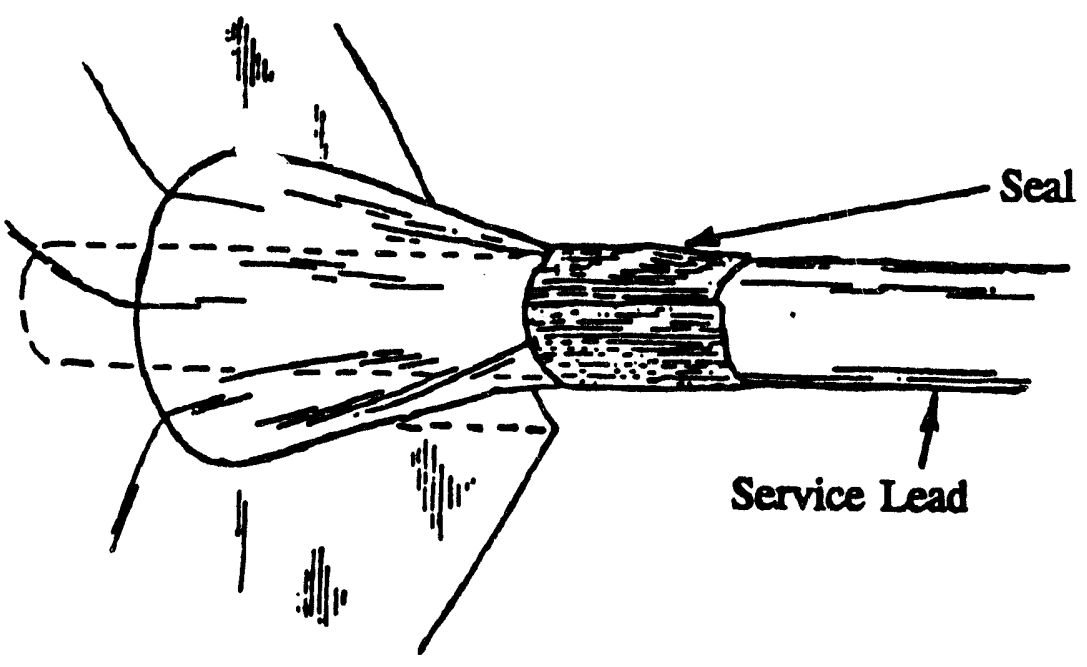

Figure B-13. Service Lead Installation. 


\section{B.3.5 WORK IN A GLOVE BAG}

\section{B.3.5.1 Precautions}

1. The glove bag must be inspected and certified by radiological control personnel before use.

2. Do not overload containments. Install hooks, staging, or other support devices to suspend or support heavy tools, materials, or components.

3. Use only HEPA-filtered ventilation units to exhaust from a glove bag.

4. Additional protective gloves should be worn to protect hands from contamination if the containment gloves are at risk of being punctured or cut.

5. Durable work gloves may be worn inside, over the containment gloves when needed to prevent puncturing of containment gloves.

6. Sharp edges of unused tools and equipment should be covered to prevent puncturing the glove bag.

7. Gloves and glove sleeves should remain inside the glove bag after removing hands from the containment gloves.

\section{B.3.5.2 Inserting or Removing Items From a Glove Bag}

1. The transfer sleeve should be used to insert or remove items from glove bags whenever practical, especially when high levels of contamination are expected.

NOTE: Pass out boxes may be used in lieu of transfer sleeves for transferring small items into glove bags where low levels of contamination exist.

2. Insertion and removal of contaminated items from a glove bag is illustrated in Figure B-14 (Tool/Item Insertion Into a Containment), Figure B-15 (Tool/Item Removal From a Containment) and Figure B-16 (Removing Items Through Zipper/Velcro' Opening).

NOTE: A contamination survey should be performed to ensure contamination is below acceptable levels prior to opening zipper or Velcro openings.

3. When inserting/removing items through zippers or Velcro openings, ensure negative ventilation is operating (if installed).

\footnotetext{
'Velcro is a trademark of Velcro USA, Inc.
} 

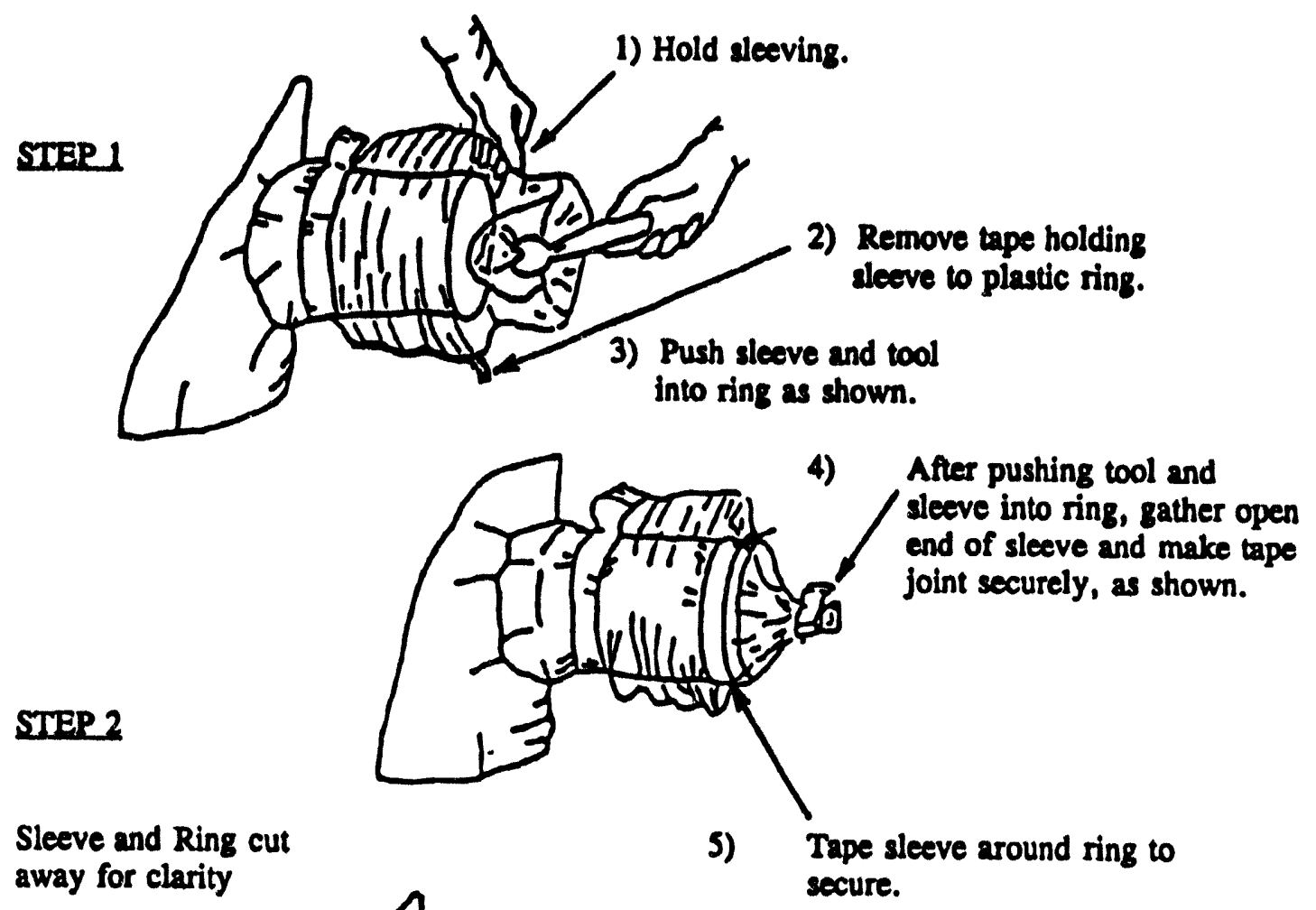

STEP 3

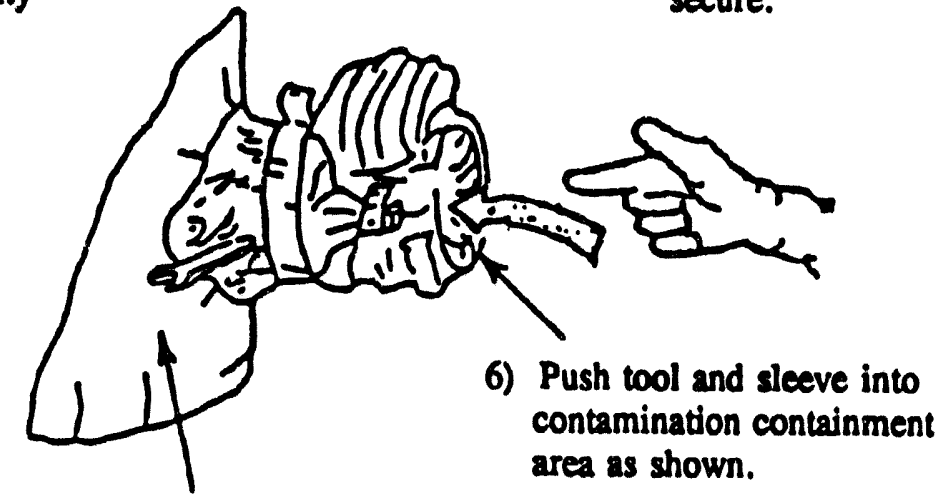

7) From inside contamination containment

area, make opening in sleeving and remove tool.

\section{NOTE: After completing item of step 3, disregard cut portion of sleeving, continue \\ as required with next removal or insertion.}

Figure B-14. Tool/ltem Insertion into a Containment. 


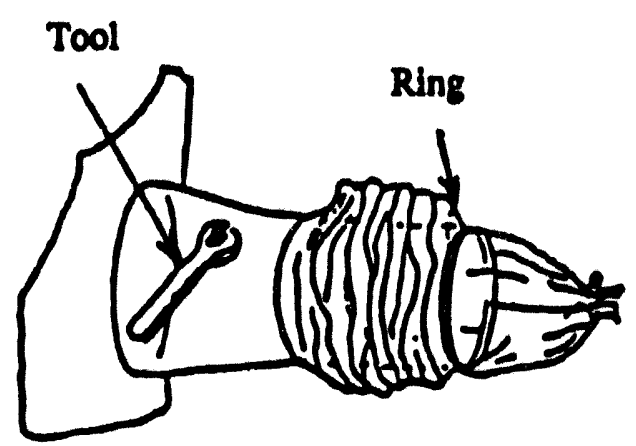

STEP 1

1) Pass tool thru ring into PVC/Poly sleeving.

STER ?

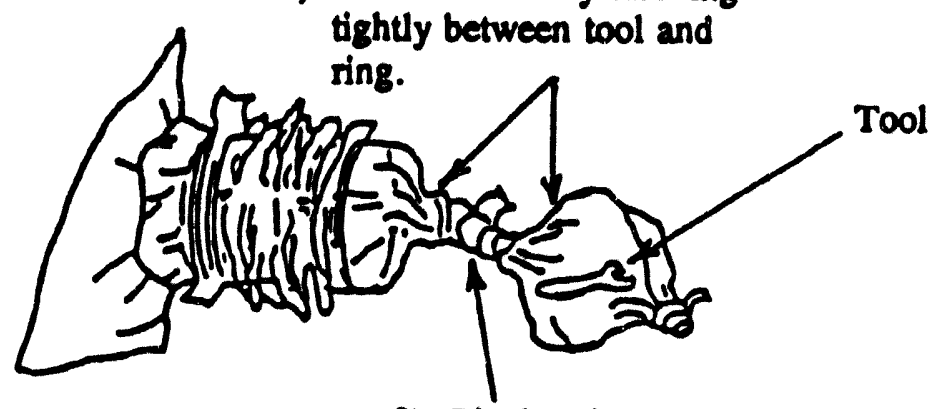

3) Pinch twisted PVC/Poly sleeving and tightly tape.

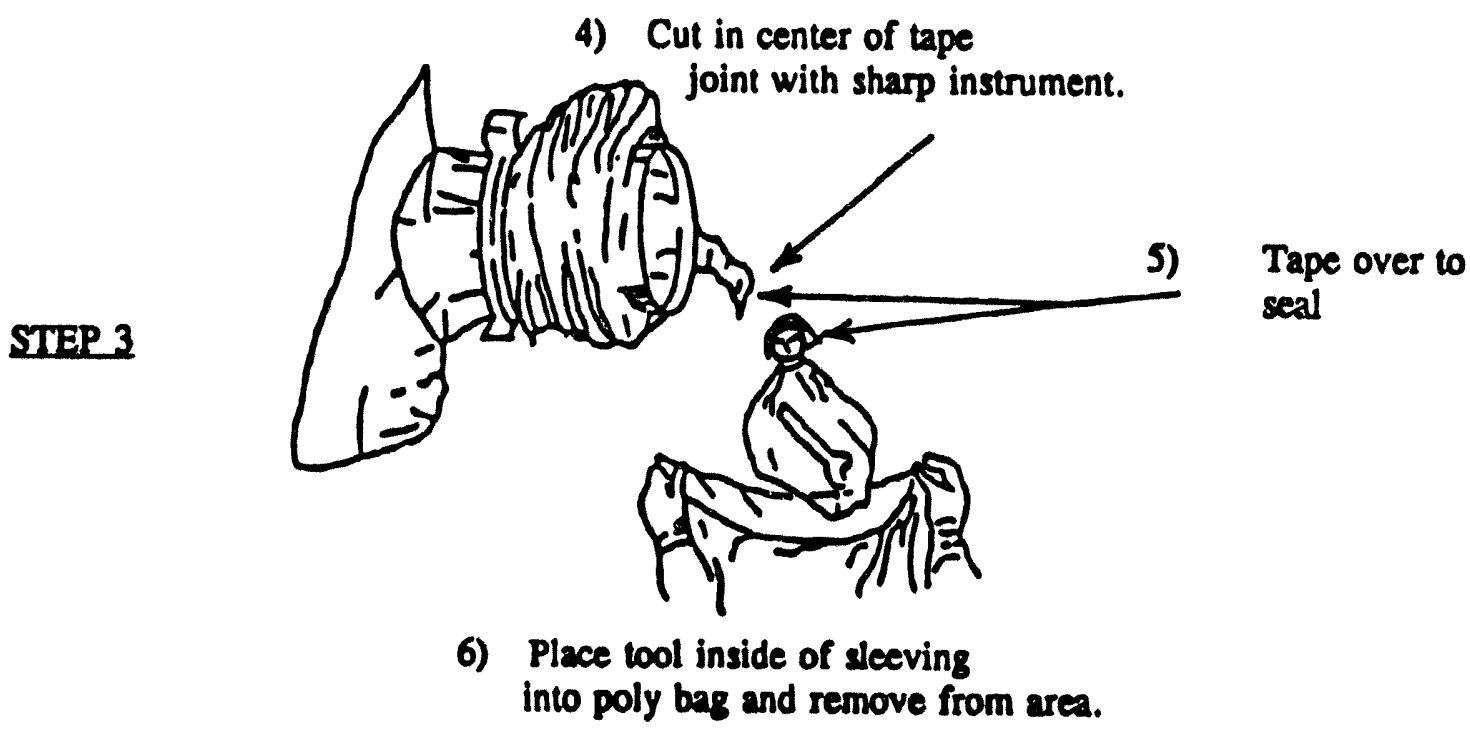

Figure B-15. Tool/Item Removal from a Containment. 
STRP 1 Carefully untape the sipper and open it to the minimum required width.

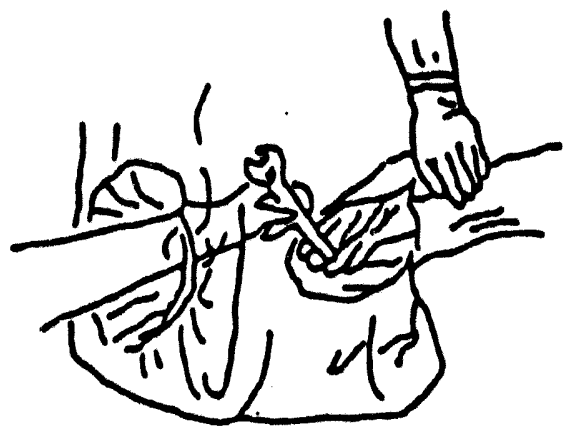

STEP 3 Slowly pull the hand, item, and the bas out and down until it is right side out.

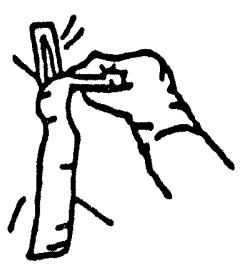

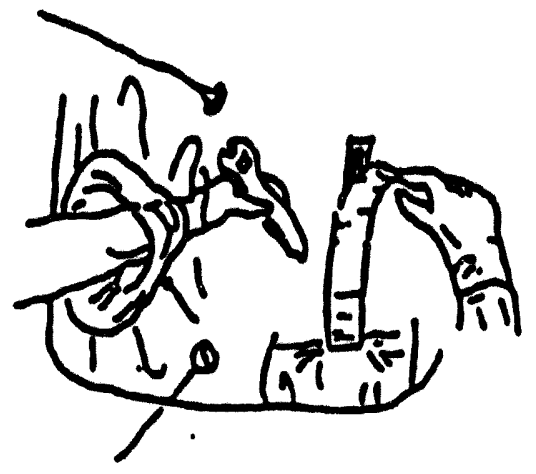

STER 2 Invert a poly bas about halfway and place it over the zipper opening to prevent any contamination apread. Slip a hand through the inverted poly bas while the other hand holds the bas. Grasp the item with the hand in the poly bag.

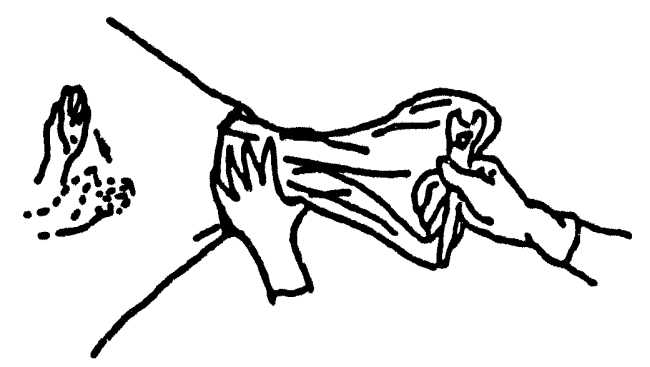

STRP4 Re-seal the zipper with a new piece of cloth-becked tape. Seal the poly bag and remove it from the area.

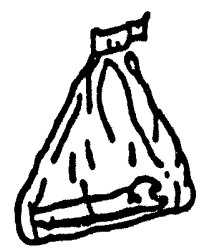

Figure B-16. Removing Items Through Zipper/Velcro Oper ing. 


\section{B.3.5.3 Glove Bas Maintenance}

B.3.5.3.1 Adding Additional Tranfer Sleeving Onto A Glove Bag. Frequently, transfers into and out of a glove bag will deplete the supply of transfer sleeving initially instalied on a glove bag. The following are some suggested methods to replace sleeving on a glove bag.

- Method 1 (Refer to Figure B-17A: Replace Transfer Sleeve (pages 1 and 2).

1. Invert the sleeve remnant into the transfer ring. Cut through the approximate center of the tape securing the transfer sleeve in place around the transfer ring (Step 1). Leave the sleeve remnant intact at this time, remaining inside the transfer ring.

2. Install the new sleeving, taping it onto the transfer ring approximately 1.5 in. past the securing point of the previous sleeve (Step 2).

3. Accordion the new sleeving onto the transfer ring and tape the sleeving end closed (Step 3).

4. Working through the new transfer sleeve, reach into the transfer ring, grasp the depleted transfer sleeve remnant and pull it off the transfer ring (Step 4) and into the end of the new transfer sleeve (Step 5).

5. Isolate the remnant by taping the sleeve closed. Perform an umbilical cut of the transfer sleeve. Properly dispose of the waste material (Step 6).

- Method 2 (No figure)

1. Remove hose clamp or cable ties (if used). Tape holding the sleeving in place should not be removed.

2. Install the new sleeving over the depleted sleeve and tape in place.

3. From inside the glove bag, cut off the depleted transfer sleeve remnant, exercising extreme caution to prevent cutting the new sleeving or any part of the glove bag.

- Method 3 (Refer to Figure B-17B: Replace Transfer Sleeve)

1. Remove hose clamp or cable ties holding the depleted transfer sleeve in place. Do not untape the sleeve.

2. Place a large rubber band over the end of the transfer sleeve to hold the depleted transfer sleeve in place. An appropriate length of $3 / 16$ or $1 / 4$ inch surgical tubing may be substituted for a rubber band.

3. Untape the depleted transfer sleeve remnant and roll the edges over the rubber band.

4. Tape the new transfer sleeving to the transfer ring and install the hose clamp or cable ties. Cover the clamp/ties with tape. 

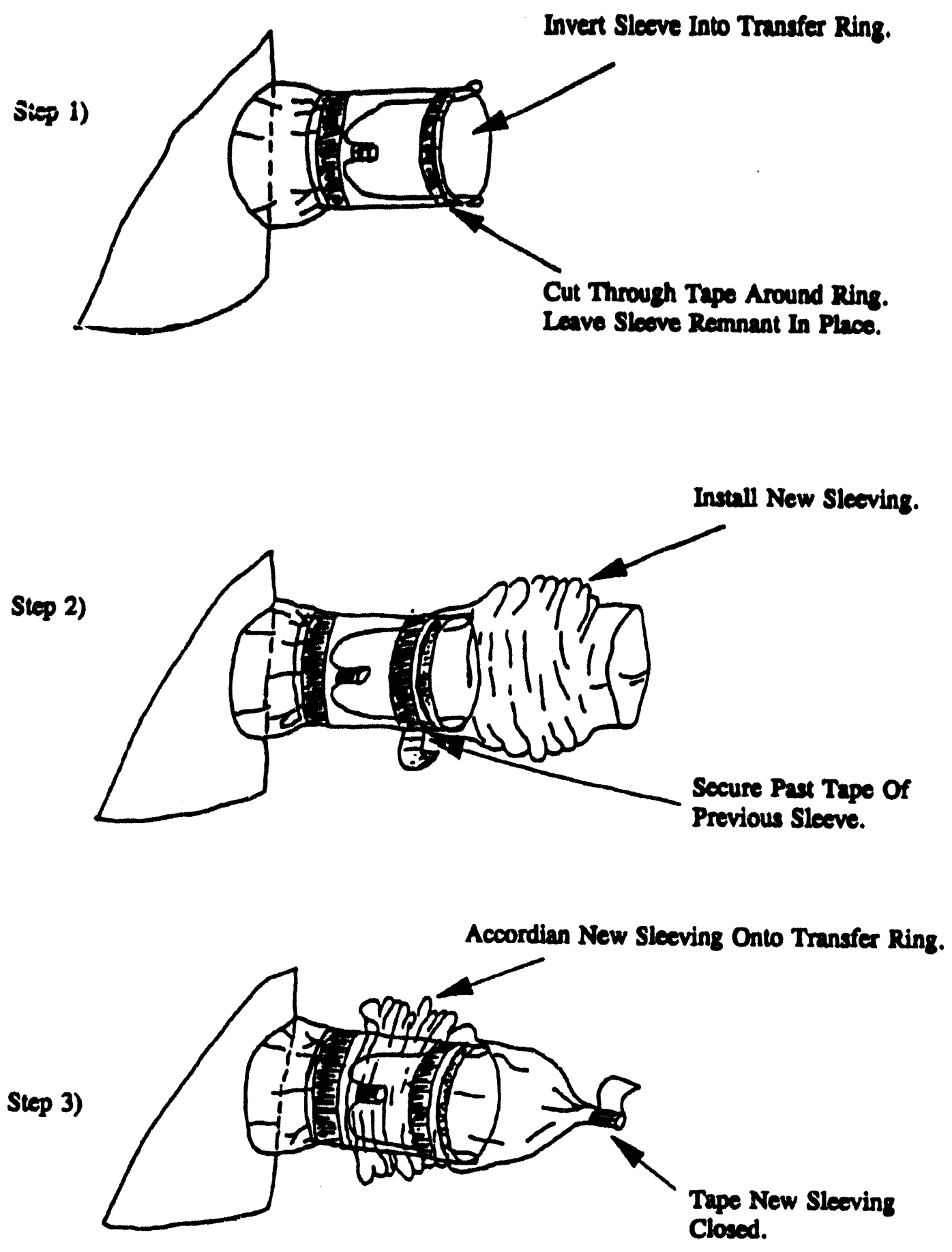

Figure B-17A. Replace Transfer Sleeve. (sheet 1 of 2) 


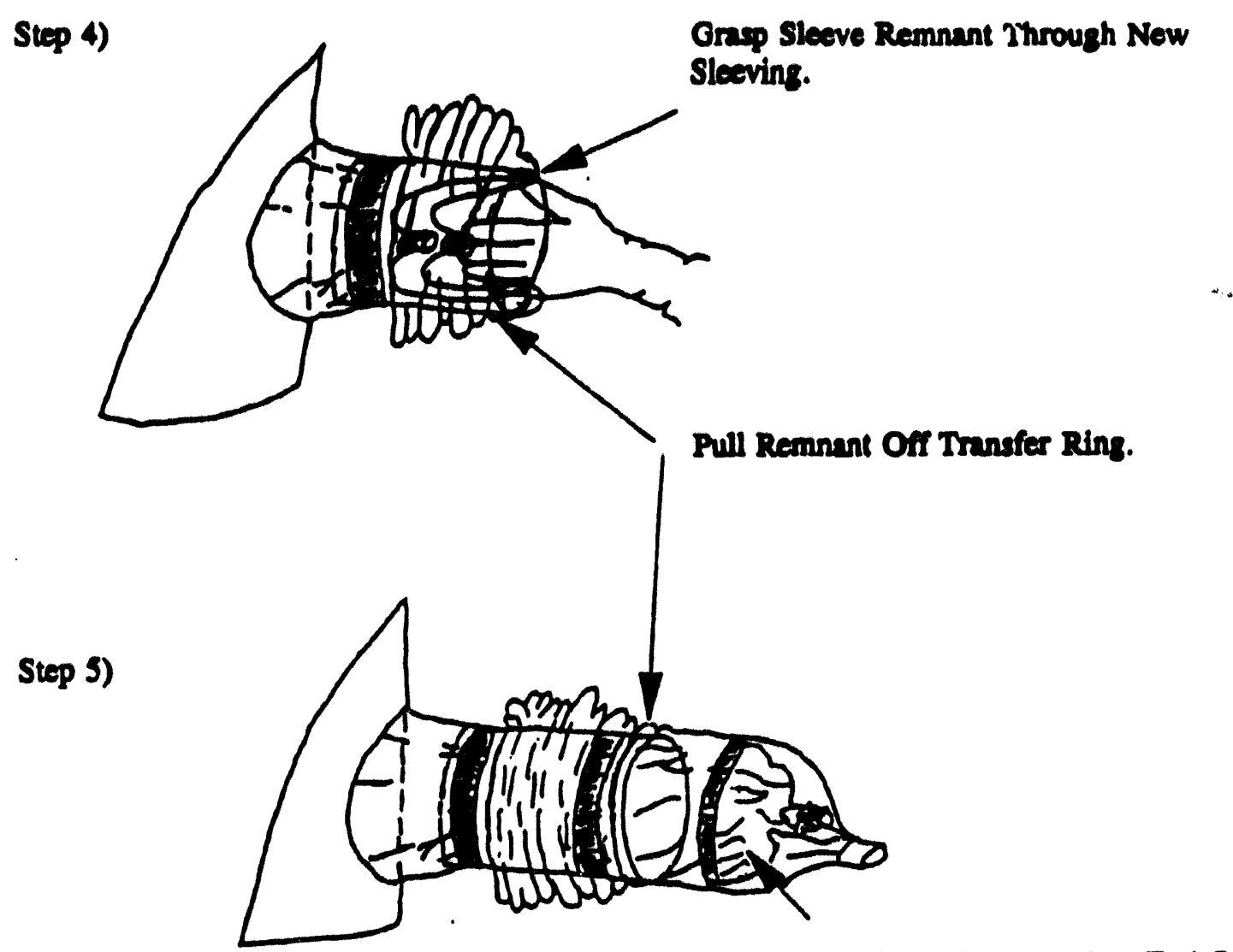

Pull Sleeve Remnant Into End Of Now Sleeving.

Step 6)

Tape Sleeving.

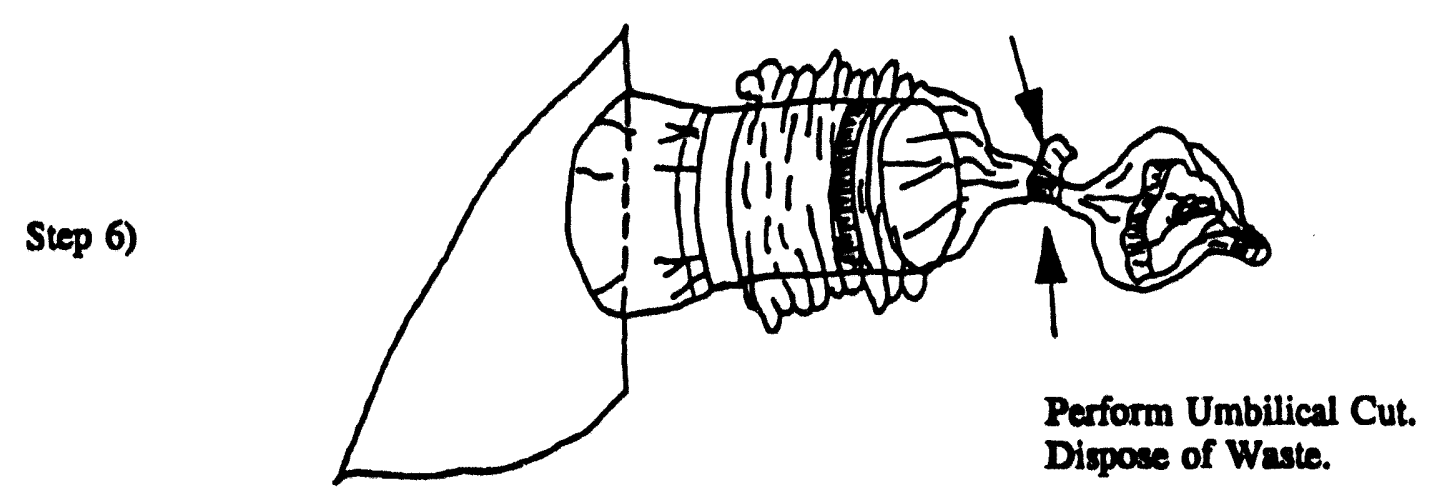

Figure B-17A. Replace Transfer Sleove. (sheet 2 of 2) 


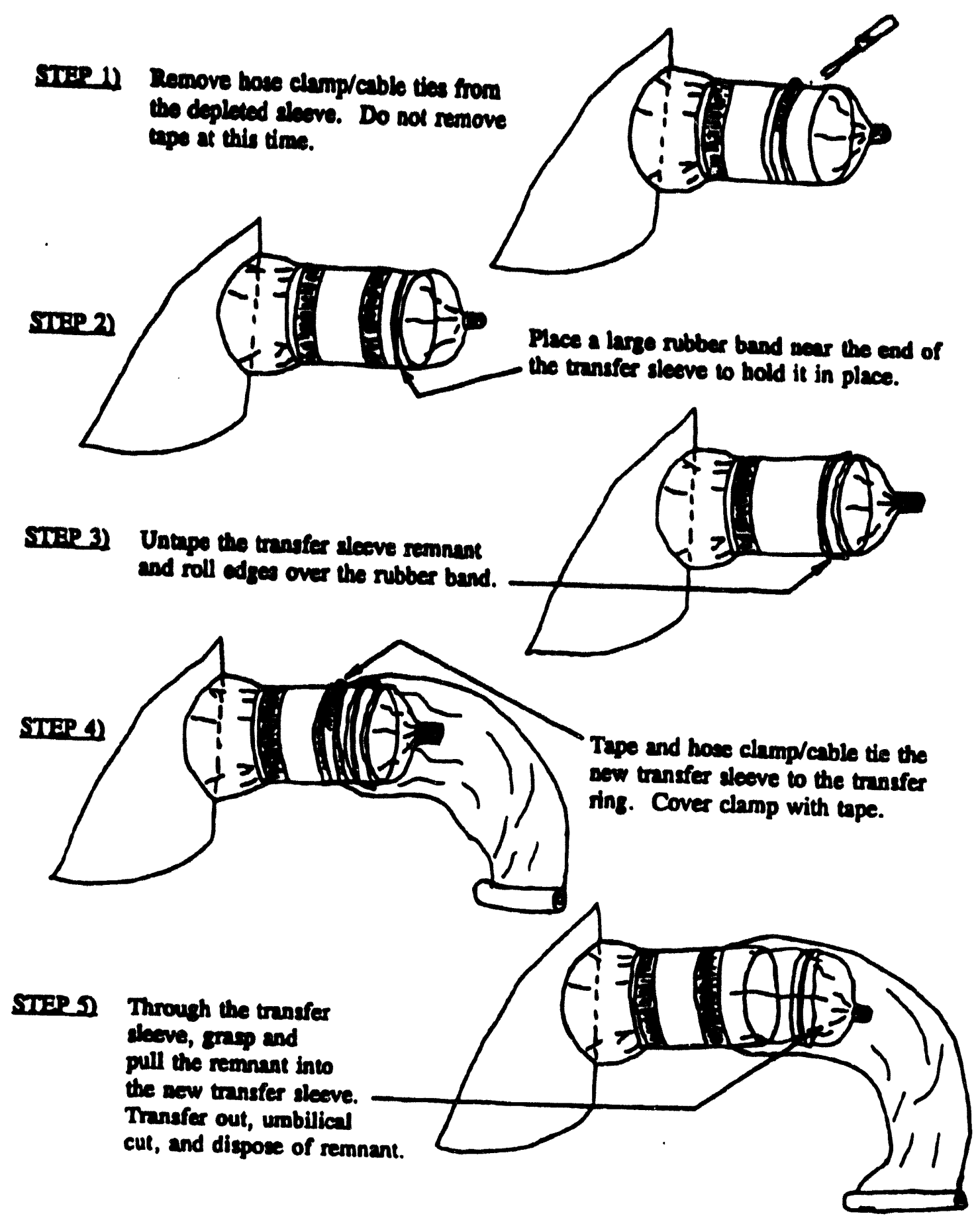

Figure B-17B. Replace Transfer Sleeve (Alternative Method). 
5. Using a length of the new transfer sleeve to cover the hand, grasp the depleted transfer sleeve remnant and pull it free of the transfer ring.

6. The remnant and rubber band should be moved to the end of the new sleeving, isolated by taping the sleeve closed, and performing an umbilical cut. Properly dispose of the sleeve remnant.

\section{B.3.5.4 Damaged Glove Replacement}

Two recommended methods of changing a damaged glove are described below. When damaged gloves are discovered, they should be immediately isolated and assessed to determine the appropriate method for changing the glove.

- Method 1 (Refer to Figure B-18A: Glove Replacement)

1. Pull the damaged glove hand up and out until just the glove is in the sleeve and remove the rubber ring from the sleeve glove ring.

2. Carefully roll the damaged glove cuff lip to the center of the glove ring (Step 1).

3. Place the replacement glove cuff lip over the glove ring (Step 2).

4. With the replacement glove in place, cautiously roll or lift the damaged glove cuff lip over the end of the glove ring. Pull the damaged glove free and draw it into the glove bag for transfer sleeve removal (Step 3).

5. Reinstall the rubber ring and retape (Step 4).

- Method 2 (No figure)

1. Remove hose clamp or cable ties (if used). Tape holding the glove in place should not be removed.

2. Install the new glove over the damaged glove and tape in place.

3. From inside the glove bag, cut off the damaged glove, exercising extreme caution to prevent cutting the new glove or any part of the glove bag.

- Method 3 (Refer to Figure B-18B: Glove Replacement)

1. Pull the damaged glove hand up and out until just the glove is in the sleeve and remove the rubber ring from the sleeve glove ring.

2. Pinch closed and tape around the glove sleeve, isolating the damaged glove (Step 1).

3. Remove tape and rubber ring from the sleeve/glove ring (Step 2). 


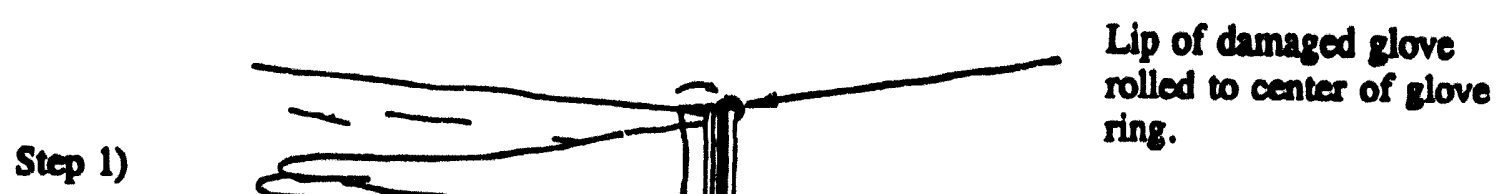

Step 2)

Step 3)

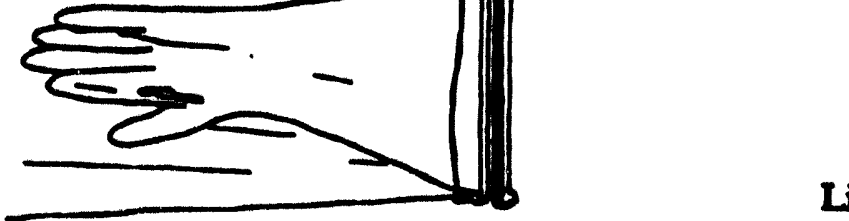

Lip of replacement elove placed over lip of damaged glove and glove ring.

Step 4)

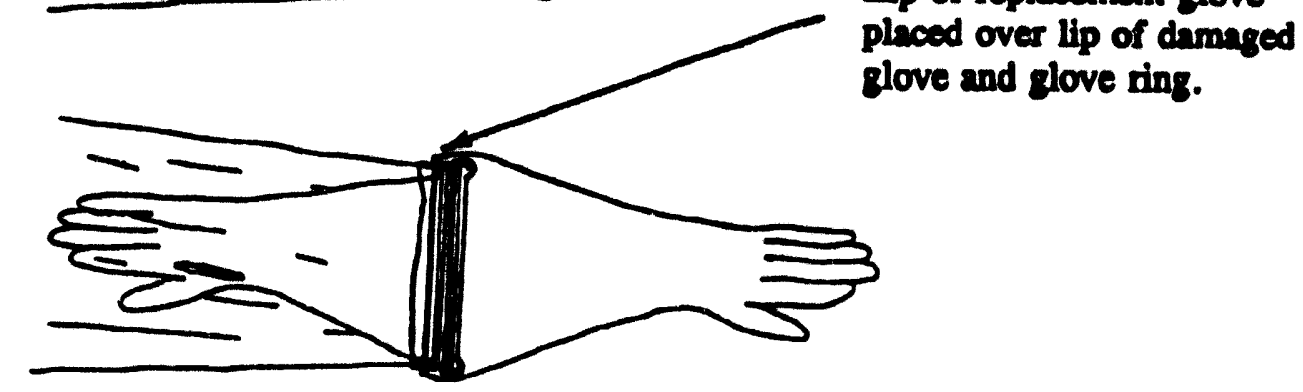

\section{Roll or lift lip of damaged glove}

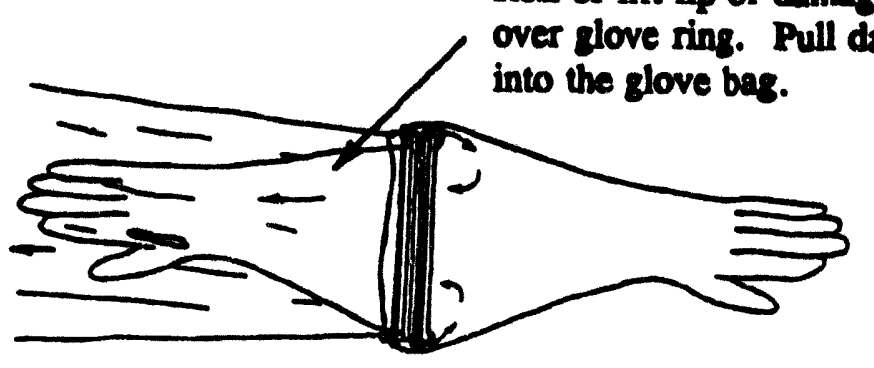

over glove ring. Pull dumaged glove into the glove bas.

Reinstall the rubber ring and retape new glove into place. Replace the glove and sleeve into the glove bag.

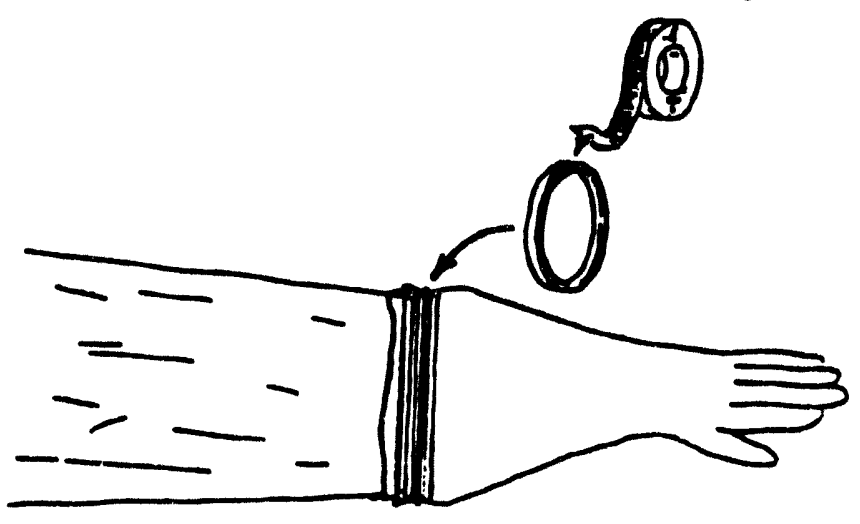

Figure B-18A. Glove Replacement. 
Pinch sleeve closed, tape around, isolating glove.
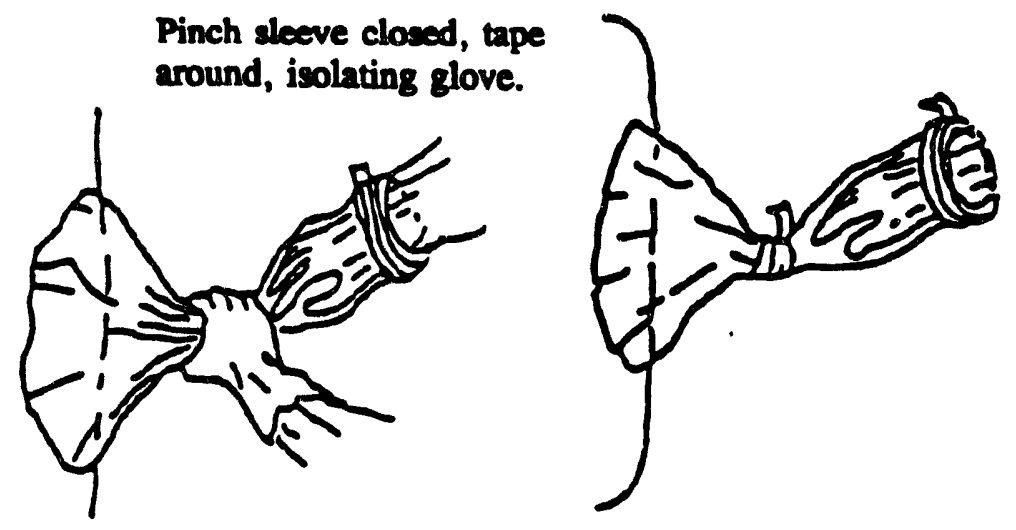

STBP 2) Remove tape and rubber ring from the sleeve/glove ring.

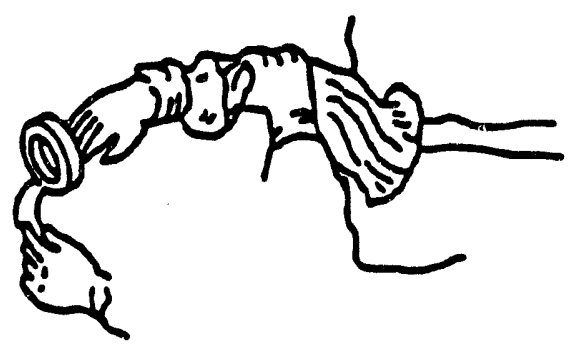

STER 3)

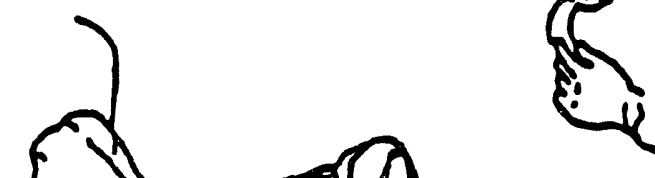

Over open poly bag, remove the damaged glove, allowing it to fall into the bas.

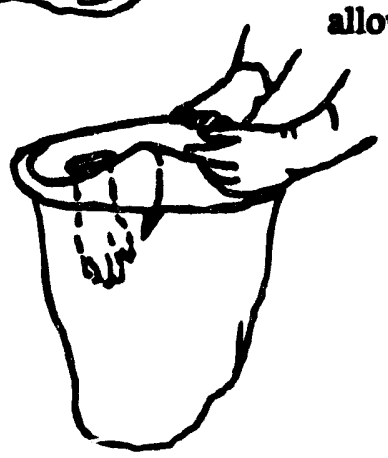

STEP 4) Insert the new glove into the sleeve. Place the glove lip over the glove ring. Reinstall the rubber ring and retape.

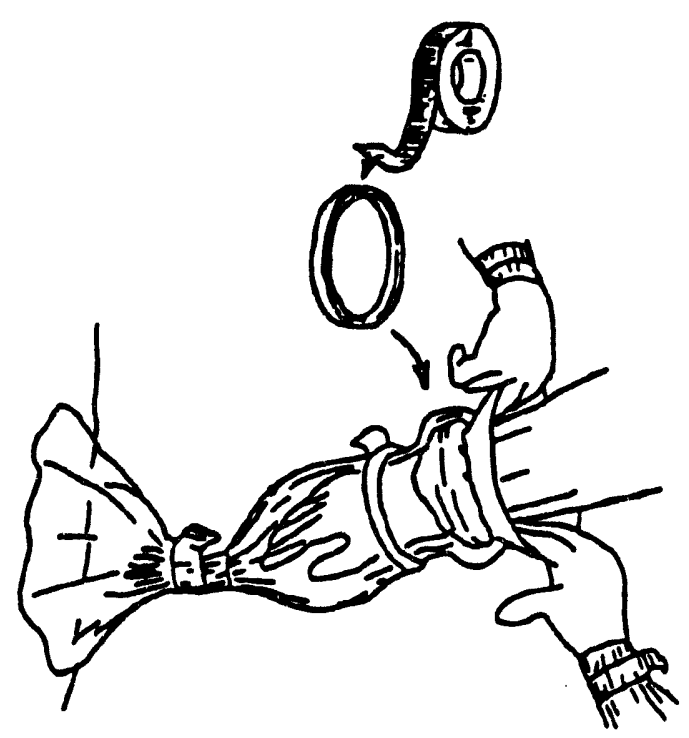

Figure B-18B. Glove Replacement (Alternative Method). 
4. Over an open poly bag, withdraw the glove and allow it to fall into the bag (Step 3).

5. Insert the new glove into the glove bag sleeve. Place the glove lip over the glove ring. Reinstall the rubber ring and retape.

\section{B.3.5.5 Patching Holes/Tears in a Glove Bag}

Holes or tears discovered in a glove bag should be patched immediately with cloth or waterproof tape. Upon evaluation and concurrence of a Radiological Control Technician, work may continue in the glove bag. The hole should be permanently patched as soon as practical.

\section{B.3.5.6 Securing Containments After Work}

1. Glove sleeves should be tucked in the containment body so they cannot form a water collection point or be exposed to damage.

2. Disconnect the air supply (if used) from the air tool lead. Tape over the lead end at the completion of use.

3. Check that the drain hose and poly bottle (if used) remains secured and are unobstructed.

4. At completion of work, make a final check of the containment and nearby work area. Correct any potential hazard, if possible, and report problems to Radiological Control personnel.

\section{B.3.6 GLOVE BAG REMOVAL}

Removing craft should make sure that all liquids, tools and nonwaste itenis have been removed from the containment and required radiological control surveys have verified contamination levels allow containment removal.

1. Using the containment gloves, remove tape covering the component seal clamp and then remove the clamp (Figure B-19, Removing Tape and Clamp). Do not remove tape under clamp at this time.

2. Prepare a poly bag for glove bag disposal.

3. Cut the glove bag support cords and place cord pieces in the poly bag.

NOTE: A vacuum cleaner may be used on large containments (Figure B-20, Collapsing Containment Using HEPA-Filtered Vacuum Cleaner). Allow the vacuum cleaner to collapse the containment and make an umbilical cut below the vacuum cleaner hose.

4. Cut the containment free from the component over a poly bag or over a drop cloth (Figure B-21, Cutting and Removing Containment). 
5. Place the containment and all attached accessories into the previously positioned poly bag (Figure B-22, Lowering Containment into Bag).

6. Carefully remove remaining tape and protective coverings and place in the poly bag. Tape the poly bag closed.

7. Inform radiological controls personnel the glove bag has been removed.
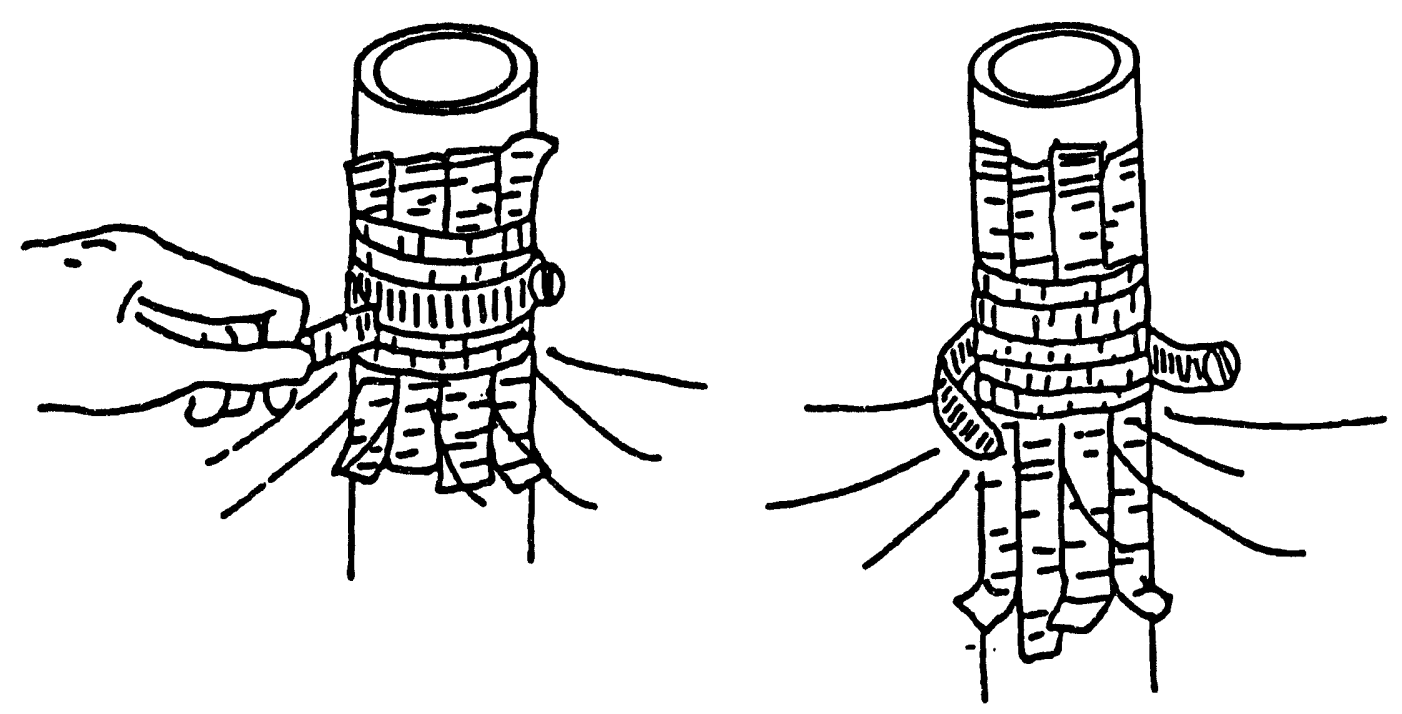

Figure B-19. Removing Tape and Clamp.

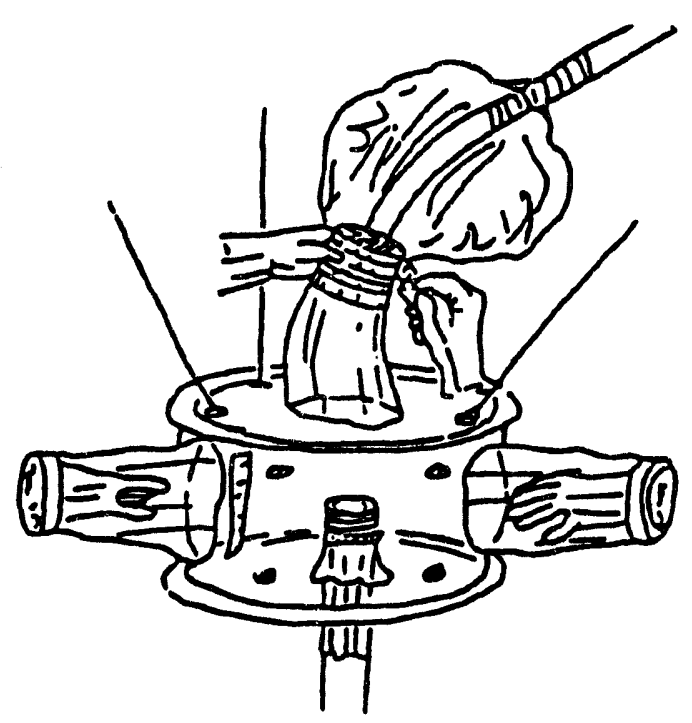

Figure B-20. Collapsing Containment Using HEPA-Filtered Vacuum Cleaner. 


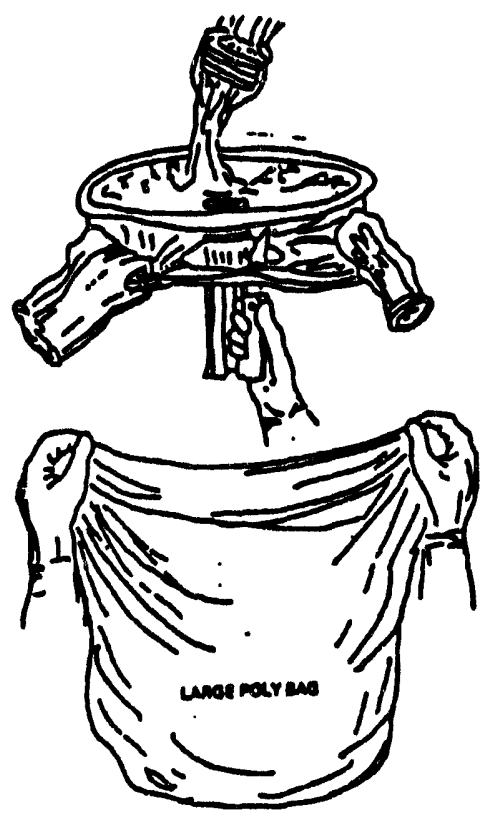

Figure B-21. Cutting and Removing Containment.

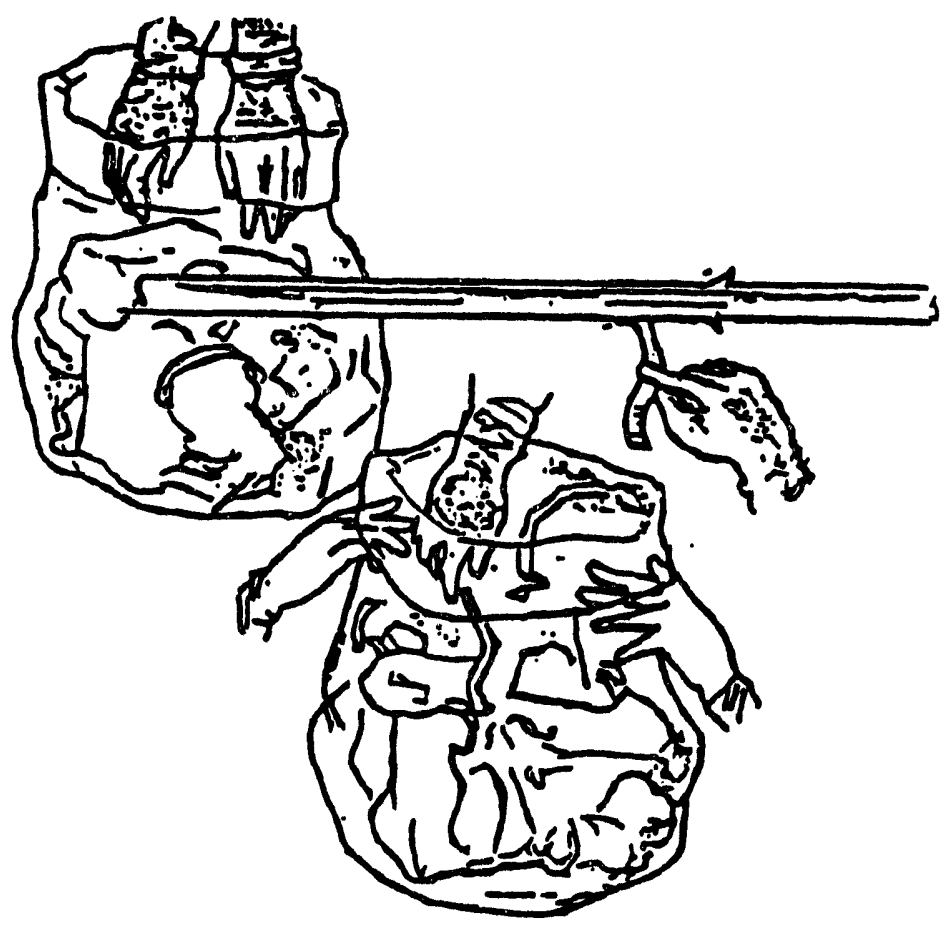

Figure B-22. Lowering Containment into Bag. 
WHC-EP-0749

\section{B.4 GUIDANCE ON USE OF POLY BOTTLE ASSEMBLIES}

This procedure gives instructions for installation and removal of temporary drain systems that use polyethylene containers (poly bottles) to collect contaminated fluid from radiological containments and/or systems.

\section{B.4.1 LIMITS AND PRECAUTIONS}

Radiological Control personnel should be notified before the installation or removal of poly bottles.

The temperatures of liquids collected in poly bottles should not exceed $65^{\circ} \mathrm{C}\left(150{ }^{\circ} \mathrm{F}\right)$ unless provisions are made to disperse the heat.

Ensure that appropriate measures are taken to prevent freezing of the liquid in the temporary collection tubing and/or poly bottle.

Precautions should be taken to prevent spillage of liquids during installation and removal of poly bottles.

Prior to poly bottle use, verify each bottle to be installed has a label identifying the bottle's location and the liquid source to be collected.

Prior to collecting liquid in a poly bottle, verify that dye (red or blue food coloring) has been added to the bottle as a visual aid for determining the liquid level.

Poly bottles should have a maximum fill line which represents $75 \%$ capacity marked on the external surface. Bottles should not be filled above this line.

Poly bottles should be equipped with a HEPA filter and a bottle adaptor. The adaptor provides a hose connection and a means of directing liquid flow to prevent moisture from contacting the HEPA filter media.

The poly bottle size used for a particular installation should be adequate to contain the amount of liquid expected to be collected.

Poly bottles should be located in low traffic areas and placed in a poly bottle containment and securely tied off to prevent tipping over.

All drain collection lines and connections should be leak tested prior to placing the collection system in service.

Drain installation tubing connections should be secured using hose clamps covered with cloth backed tape.

Drain lines between poly bottles and catch containments should be arranged and supported so that low points where liquid can collect are minimized. 
Drain lines should be routed and secured in a manner that will prevent them from being inadvertently pulled out of their connections, pinched off or damaged in any way.

Drain hoses should be identified at frequent intervals with "CAUTION-INTERNALLY CONTAMINATED" tape.

Poly bottles should not be stacked. This applies to installed bottles, filled bottles, and those awaiting removal from the collection area.

Poly bottles containing liquid should be moved using techniques that avoid tipping.

Poly bottles shall not be used with solutions containing or systems which may contain fissile materials unless evaluated by cirticality engineering.

When it becomes necessary to tip a poly bottle in order to remove it from interferences, install the bottle plug prior to moving.

\section{B.4.2 PREREQUISITES}

Requirements for installation and amount of liquid expected should be determined and all necessary sketches, drawings, and plans for the installation have been approved and are available to be used with the work procedure.

Required system isolation, tagging, draining and venting should be completed.

All required tools, equipment and protective equipment should be assembled. The following equipment and supplies should be used to perform this procedure:

- Protective clothing

- Poly bottle(s), bottle adaptor(s) and HEPA filters required by the installation design

- Clear Tygon ${ }^{1}$ tubing of length and size required by the installation design.

- Hose clamps, pinch clamp as required by the installation design.

- Absorbent cloth, duct tape and suitable sized yellow poly bags for removal of contaminated materials, tools and equipment.

- Hand tool required to install drain fittings and drain hose.

- Plug wrench for removing and reinstalling poly bottle plugs.

'Tygon is a registered trademark of U.S. Stoneware Co. 
If the poly bottle collection assembly is to be connected to a system line fitting, the drain hoses should be connected to the poly bottle and the entire drain collection system leak tested prior to line fitting connection.

If the collection assembly is connected to a catch containment, the assembly should be leak tested in place using the steps shown in Appendix B, Section B.3.3.2.

\section{B.4.3 PROCEDURE}

\section{B.4.3.1 Installation of Poly Bottle Adaptor and Filter}

Refer to Figures B-23 through B-25 for aid in performing Steps 1 through 10

1. inspect the poly bottle and poly bottle containment and ensure they are in good condition and free of damage or holes.

2. Remove the poly bottle closure plug and cut out plug diaphragm (see Figure B-23).

3. Remove the shipping plug from the closure plug (if included), place it in a poly bag and tape it to the top of the poly bottle.

4. Reinstall the closure plug gasket.

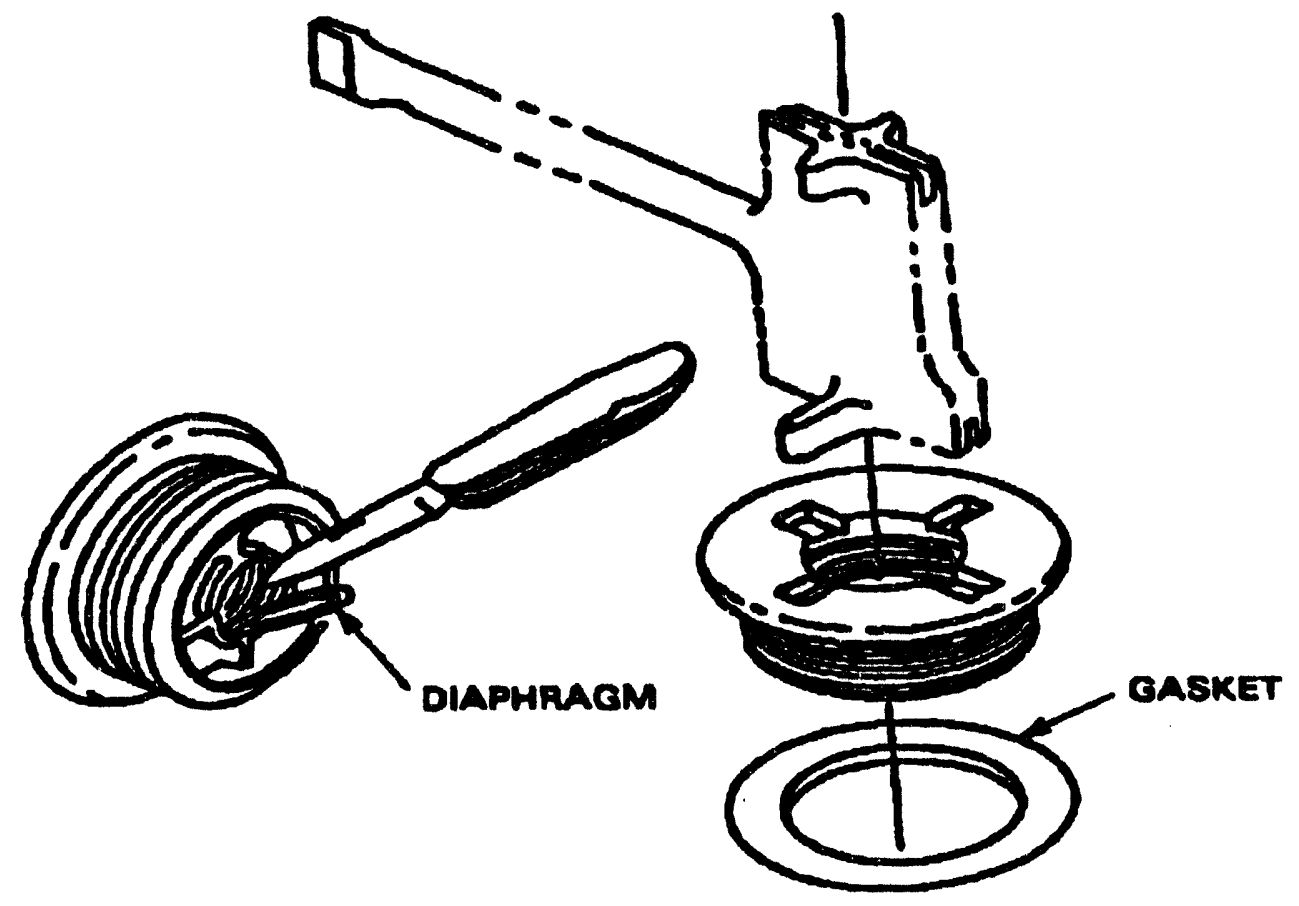

Figure B-23. Closure Plug Removal. 
CAUTION: Over-tightening the closure plug, bottle adaptor or HEPA filter may cause damage to these components.

5. Reinstall the closure plug and tighten it snugly with a plug wrench.

CAUTION: Failure to install the bottle adaptor so the filter connector faces inward could result in damage to the filter and/or the adaptor.

6. Screw the bottle adapter into the closure plug, ensuring that the filter connection faces inward (see Figure B-24).

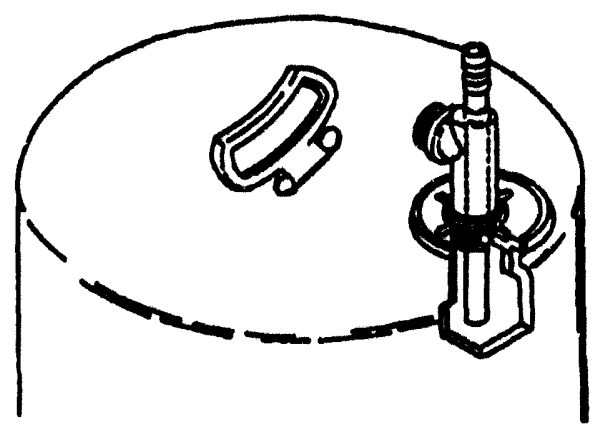

Figure B-24. Bottle Adaptor Installation.

7. Ensure the filter rubber gasket is properly in place.

8. Screw the filter on to the filter connector and tighten snugly by hand.

9. Remove the covering from the face of the filter (if installed, see Figure B-25).

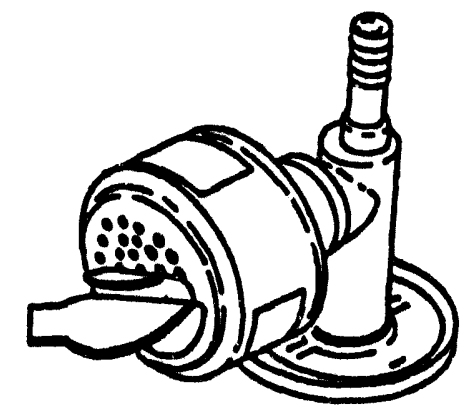

Figure B-25. Removing Filter Face Cover. 


\section{B.4.3.2 Intallation of Poly Bottle at Collection Location}

NOTE: Rigid structures such as hangers, stanchions or systems piping of one inch diameter or greater should be used to secure poly bottles (see Figure B-26 for examples).
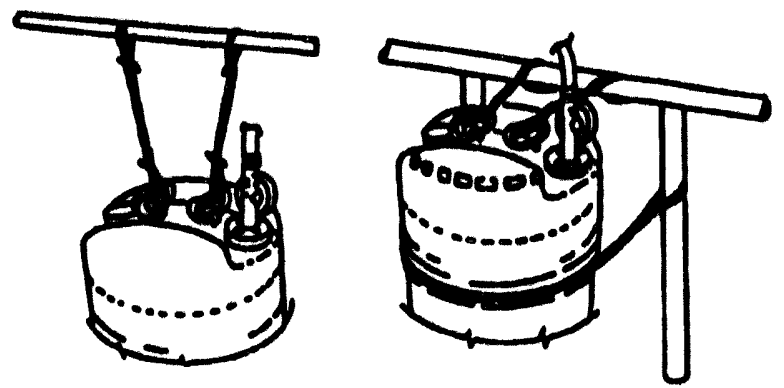

Figure B-26. Securing Poly Bottles to Prevent Tipping.

- Check that the poly bottle(s) to be installed have a properly filled out identification label attached.

- Locate the poly bottles in a low traffic area as near as possible to the point of collection.

Refer to Figures B-26 through B-28 for aid in performing steps 1 through 13.

1. Place the poly bottle in a poly bottle containment (if not already done) at the desired collection location and secure it in place.

2. Install the drain hose (usually Tygon) onto the barbed fitting of the bottle adapter (see Figure B-27)

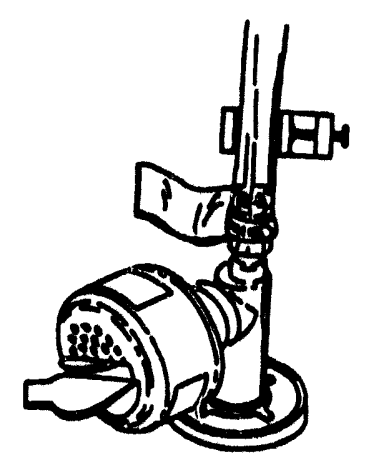

Figure B-27. Drain Hose Inciallation. 
3. Install and tighten a hose clamp to secure the drain hose to the bottle connector.

4. Install cloth back-backed tape over the hose clamp.

5. Route the drain hose between the poly bottle and the collection drain point.

6. If the arrangement of the drain installation will not support gravity draining to the poly bottle, install a hand pump between the collection point and the poly bottle to facilitate pumping the liquid to the poly bottle (see Figure B-28).

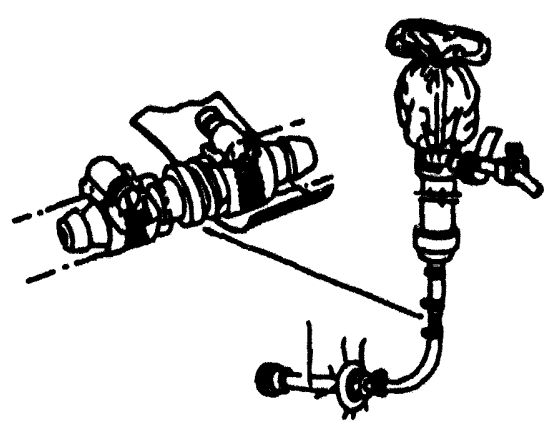

Figure B-28. Hooking Up to Designated Drain (connect handpump if needed).

NOTE: If a handpump is installed, ensure that it is installed in the vertical position with the suction of the pump at the lowest possible point in the collection system.

7. Connect the drain hose to the designated drain connection.

8. Attach an identification tag (indicating the source of the fluid) to the drain line near the poly bottle.

9. Close the top of the poly bottle containment.

10. If the poly bottle is connected to a system, wrap and tape absorbent around the drain hose to system fittings.

11. If the poly bottle is connected to a catch containment, perform a leak test by pouring approximately $500 \mathrm{ml}$ of deionized water into the catch containment and inspect the catch containment and drain hose fittings for leaks. Perform leak repairs as necessary.

12. Loosen the "pinch" clamp to allow flow through the drain line to the poly bottle. If water was added to a catch containment per the above step, ensure that the liquid flows freely from the catch containment to the poly bottle. 


\section{B.4.3.3 Disconnection and Removal of Poly Bottles}

Refer to Figures B-29 through B-36 for aid in performing Steps 1 through 15.

1. Ensure that the drain hose is completely drained. Gently tap the hose and/or rearrange it as necessary to promote draining on gravity systems.

2. Tighten the drain line "pinch clamp" to isolute the drain line.

3. Open the top of the poly bottle containment.

4. Remove the tape from the hose clamp securing the drain hose to the poly bottle connector and remove the hose clamp (see Figure B-29).

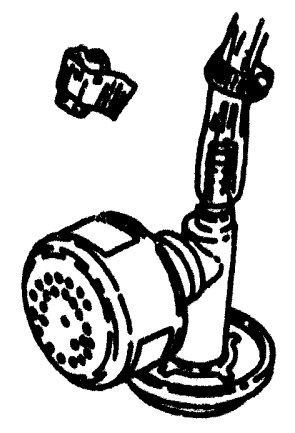

Figure B-29. Removing Tape from Hose Clamp.

5. Wrap a piece of absorbent around the bottle adaptor just below the barbed fitting and gently remove the hose with an up and twisting motion, keeping the absorbent around and under the hose end as it becomes free (see Figure B-30).

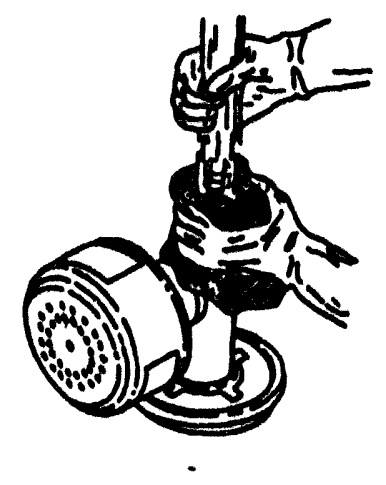

Figure B-30. Removing Drain Hose from the Bottle Adaptor. 
6. Place the loose end of the drain hose and the absorbent into a poly bag and tape it securely (see Figure B-31).

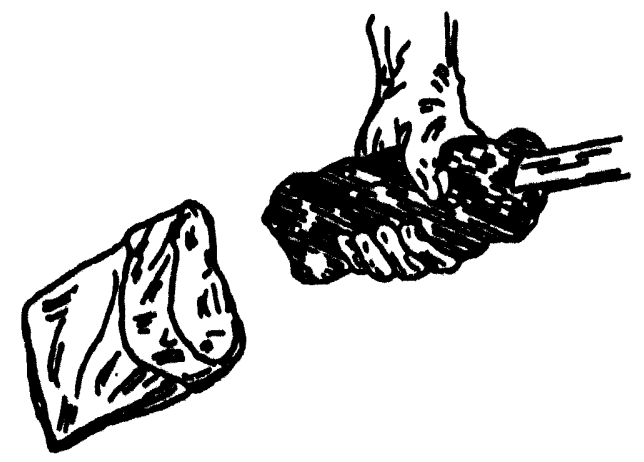

Figure B-31. Placing Drain Hose and Absorbent into a Poly Bag.

7. Install a piece of tape over the end of the bottle adaptor barbed fitting (see Figure B-32).

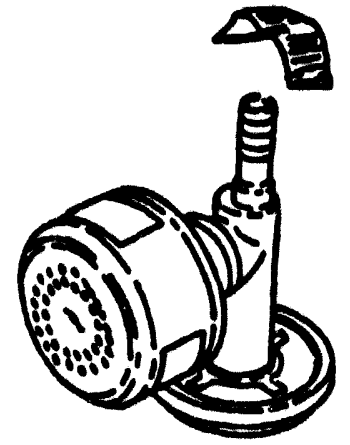

Figure B-32. Taping Over End of Bottle Adaptor Fitting.

8. Wrap a piece of absorbent around the base of the bottle adaptor and gently unscrew the adaptor plug (so that the bottle plug does not also loosen). Keep the absorbent around and under the adaptor as it becomes free of the bottle plug (see Figure B-33)

9. Place the bottle adaptor and the absorbent in a poly bag and tape it securely (see Figure B-34).

10. Remove the shipping plug from the poly bag that should be taped to the bottle and reinstall it into the bottle closure plug (see Figure B-35).

11. Tighten (snug tight only) the shipping plug using the plug wrench. 


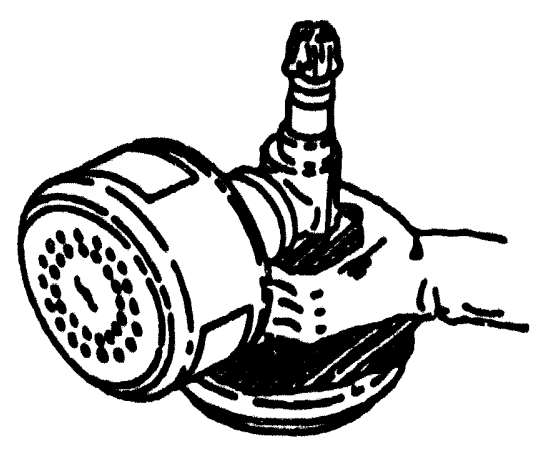

Figure B-33. Removal of Closure Plug.

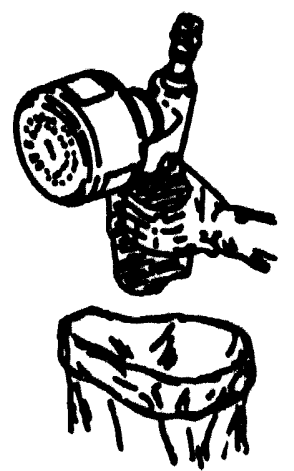

Figure B-34. Placing Bottle Adaptor into Poly Bag.
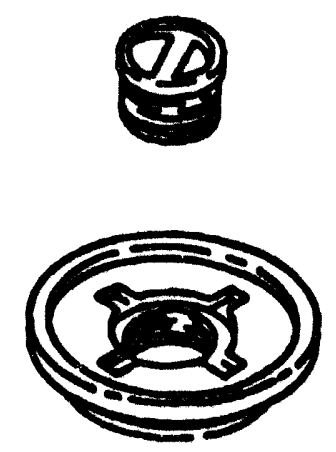

Figure B-35. Reinstalling Shipping Plug Into the Closure Plug.

12. Install and tape absorbent around the closure plug.

13. Move the poly bottle to a temporary storage area at a nearby location or transport it out of the area. 


\section{B.S CATCH CONTAINMENTS, DROP CLOTHS, CURTAIN WALLS, AND BULL PENS}

\section{B.5.1 PREREQUISTTES, PRECAUTIONS, LMITTATIONS}

Proper use of catch containments, drop cloths, curtain walls, and bullpens will reduce the occurrence of cross-contamination to surfaces from contaminated tools or components, serve as a barrier between clean surfaces and radioactive contamination released as a result of work operations, and minimize the effects of an accidental spill and the scope of subsequent cleanup operations.

\section{B.5.2 CatCh CONTAINMENTS}

\section{B.5.2.1 Typical Uses of Catch Containments}

Catch containments may be used:

- To contain debris from minor machine/work operations on small items

- During minor work operations when a minimal amount of low-level contaminated liquid release is expected

- Where it is beneficial to collect or direct a leak of liquids with low levels of contamination to a collection system.

CAUTION: Catch containments are not normally used with solutions that pose a criticality threat or concern. If a catch containment for a solution of this nature is deemed necessary, it must be approved by Criticality Safety on a case-by-case basis.

\section{B.5.2.2 Installation of Catch Containments}

If a catch containment is expected to $l_{\sim}$ permanent or to be used over a long period of time, a metal container with appropriate support (e.g., drip pan) should be considered instead of a catch containment.

Catch containments should be supported using elastic support cords or rubber bands as illustrated in Figure B-36, Support Tie-Offs, and checked routinely for stability and integrity.

Absorbent material should be used if residual liquid is expected. If more than $500 \mathrm{ml}$ of liquid is expected, appropriate drainage capability should be employed. A Tygon or similar hose drain line to a collection facility may be installed as illustrated in Figure B-37, Catch Containment Drain Assembly.

NOTE: Do not use absorbent material in catch containments where drain assemblies are installed.

When a drain is necessary, locate the drain to collect fluids. Support the drain line to avoid low collection points and route it out of the way to avoid damage. 


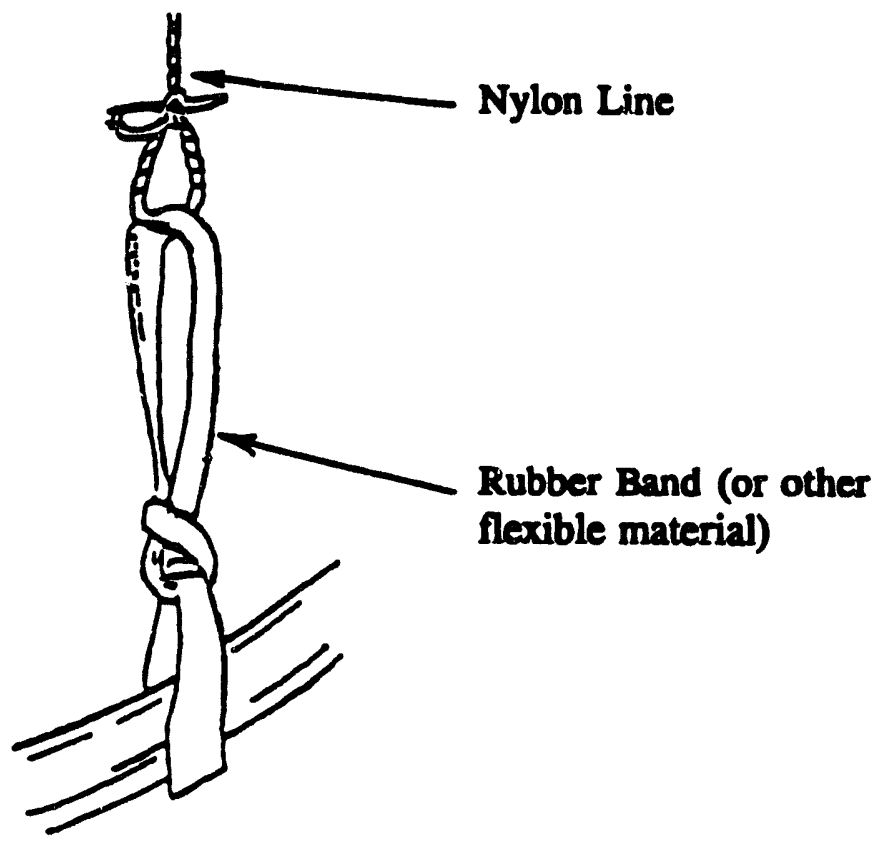

Figure B-36. Support Tie-Offs.

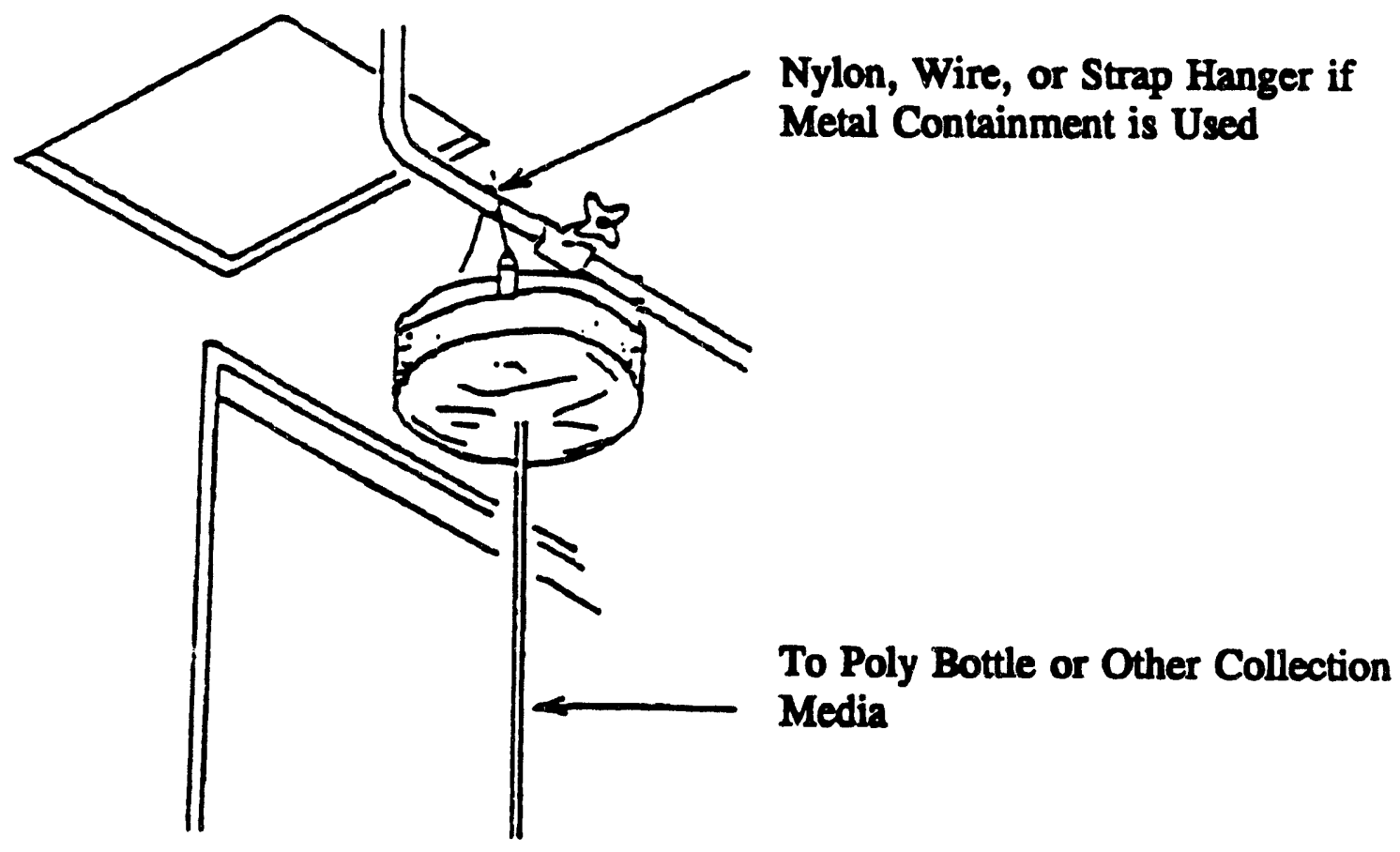

Figure B-37. Catch Containment Drain Assembly. 


\section{WHC-EP-0749}

\section{B.5.2.3 Removal of a Catch Containment}

Figure B-38, Catch Containment Removal, illustrates the removal of a catch containment.

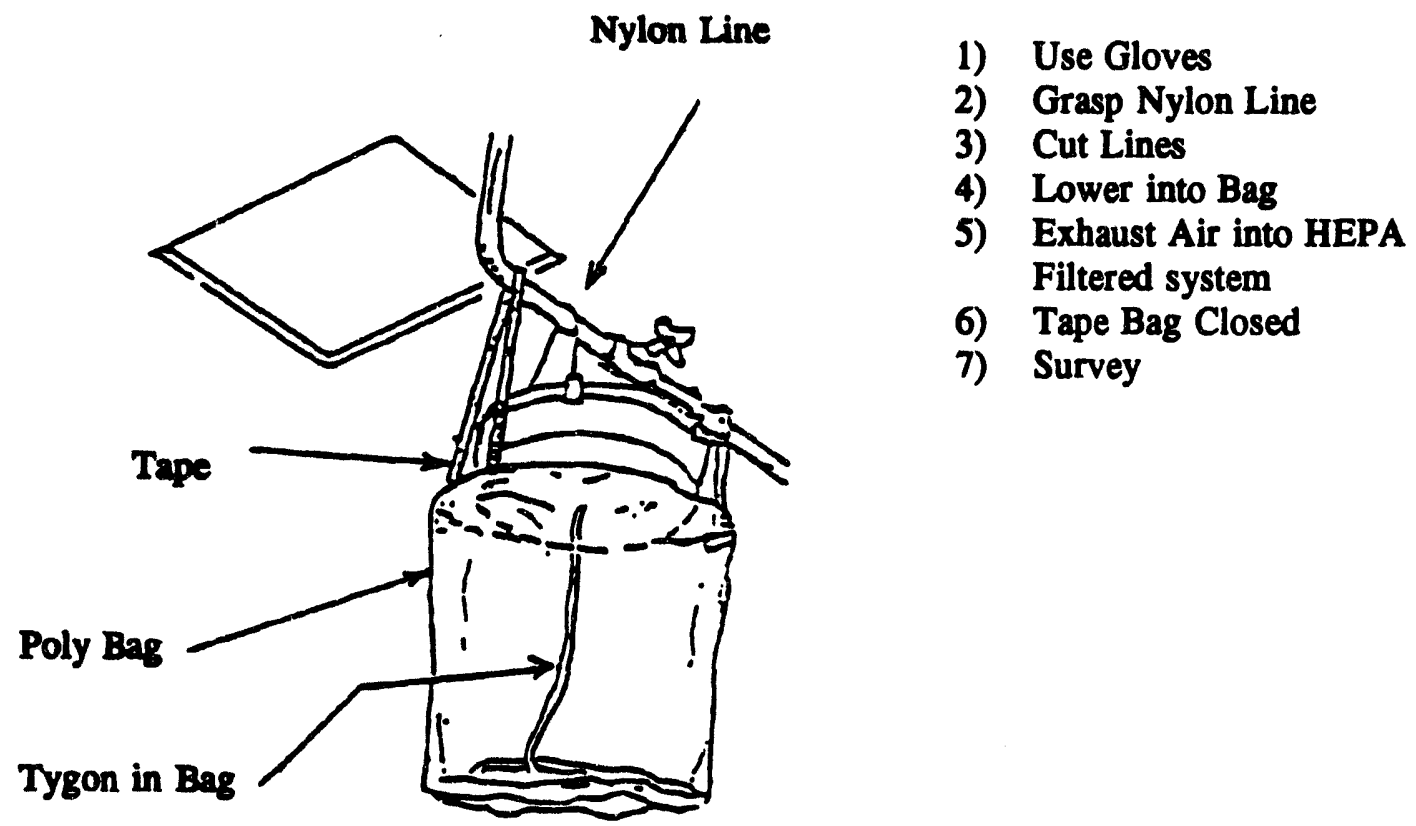

Figure B-38. Catch Containment Removal.

\section{B.5.3 DROP CLOTHS}

\section{B.5.3.1 Typical Uses of Drop Cloths}

NOTE: Drop cloths are interchangeable with catch containments, except that drop cloths are not to be used as the primary receivers of liquids.

Drop cloths may be used:

- Under enclosed containments (as a backup) where the possibility of the leakage of small quantities of potentially contaminated liquid exists

- Where there is a potential for release of small quantities of potentially contaminated liquid during disconnect/dismantling of equipment or components

- To cover uncontaminated areas or areas of low contamination when more highly contaminated tools/items are to be placed on those areas for decon, wrapping, or staging during the work process. 


\section{B.5.3.2 Installation of Drop Cloths}

Size the drop cloth to provide adequate protection for clean or lesser contaminated surfaces.

Locate the drop cloth below the source of leakage or contamination and ensure it is capable of containing that leakage. See Figures B-39, B-40, and B-41, Typical Drop Cloth Installations.

Repair or replace damaged drop cloths. If a drop cloth is wet, cautiously inspect the area above to determine the origin of the moisture.

\section{B.5.3.3 Removal of Drop Cloths}

To remove a drop cloth, fold the outer edges continuously inward tow: ard the center of the drop cloth covering the surface previously exposed to contaminated or potentially contaminated tools or components. The drop cloth should then be bagged and controlled as contaminated waste.

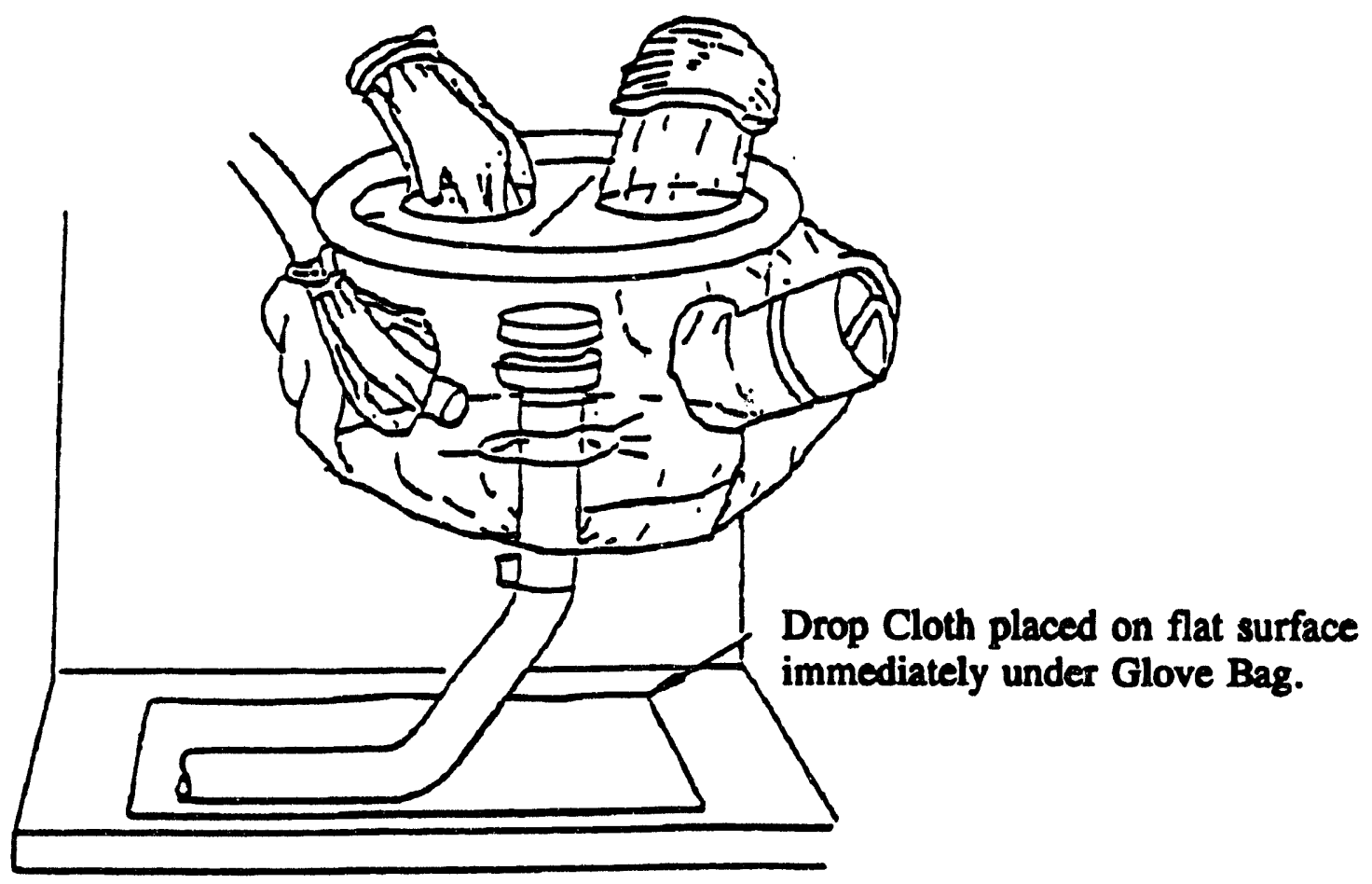

Figure B-39. Typical Drop Cloth Installation. 


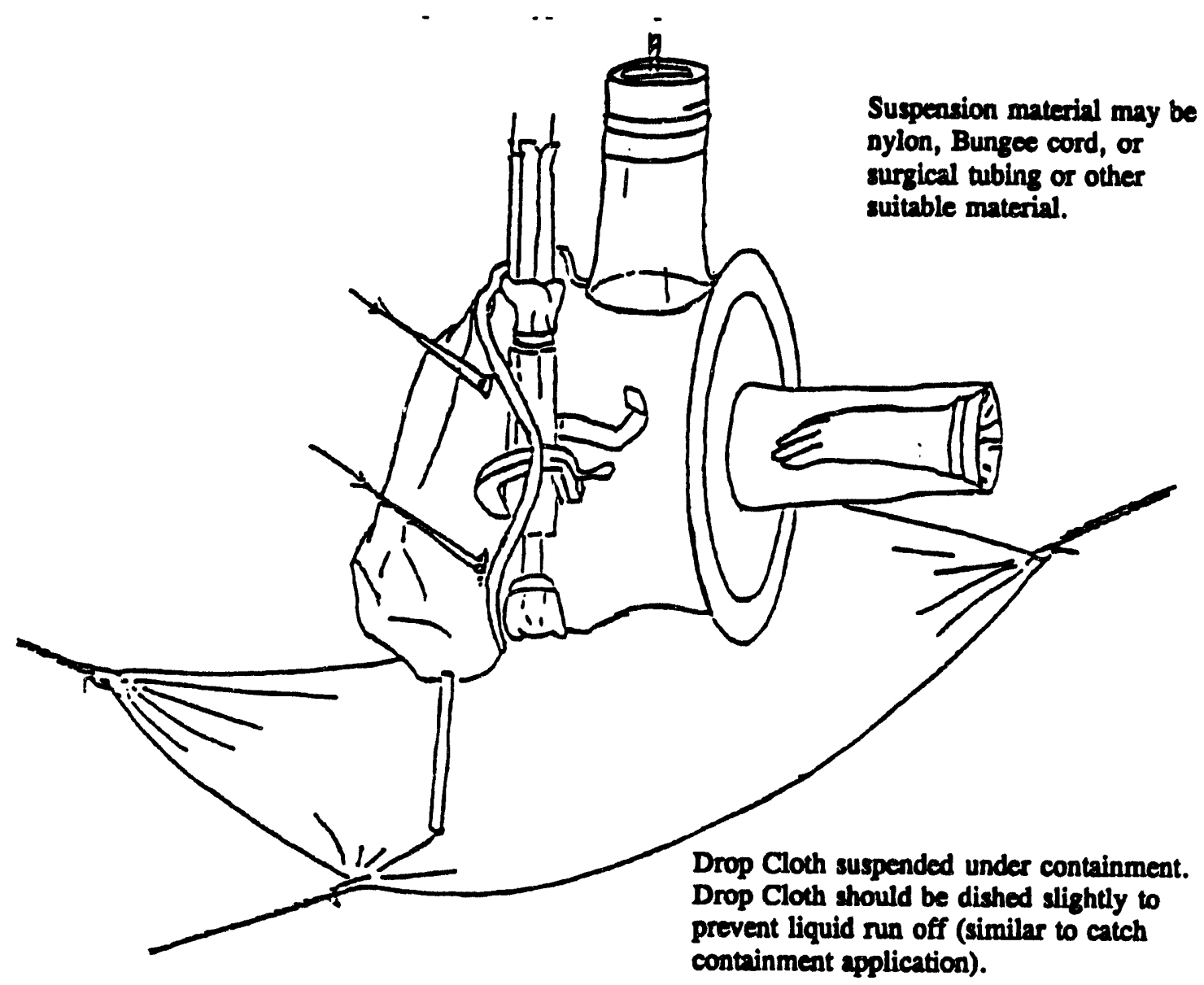

Figure B-40. Typical Drop Cloth Installation.

Drop Cloth place under line being dismantled and prepared for movement.

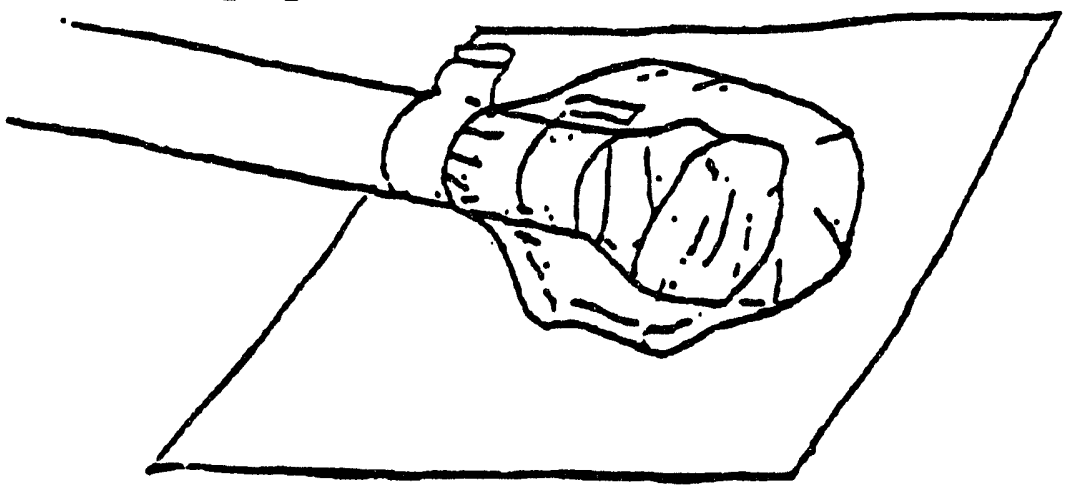

Figure B-41. Typical Drop Cloth Installation. 


\section{B.5.4 BULLPENS AND CURTAIN WALLS}

\section{B.5.4.1 Installation of a Bullpen or a Curtain Wall}

Ensure the area to be enclosed or sectioned off is large enough, allowing personnel and equipment sufficient area to perform the operation.

Include laydown areas for tools and equipment and situate the laydown areas so they are convenient to work operations.

Allow adequate space for access and egress for workers, material, and services.

Use staging to support impermeable fabric walls. Two-by-fours may be used; however consideration should be given to covering the wood before use to reduce waste. Temporary shield walls may also be used as support with Radiological Controls Department concurrence. are adequate.

Consider using grommets in the impermeable fabric for support. Grommets on 18-in. centers

The bullpen should be at least 48 in. high.

Seal all joints, openings, and penetrations as much as practical in the lower part of the bullpen. This may be accomplished by taping, gluing, or other available means.

\section{B.5.4.2 Use of Bullpens and Curtain Walls}

Inspect for integrity before use.

If laying down machinery or heavy tools, protect the containment using cushion material. buildup.

Change drop cloths or laydown areas in bullpens periodically to minimize contamination

\section{B.5.4.3 Removal of Bullpens and Curtain Walls}

Determine specific technique for removal, and provide suitable containers for storage or disposal (e.g., 55-gal drums, 36-in. x 48-in. poly bags). 


\section{WHC-EP-0749}

This page intentionally left blank. 
WHC-EP-0749

APPENDIX C

SAMPLE CHECKLISTS

C-1 
WHC-EP-0749

This page intentionally left blank.

C-2 


\section{SAMPLE CHECKLISTS}

Figure C-1. Containment Cortification Checklist.

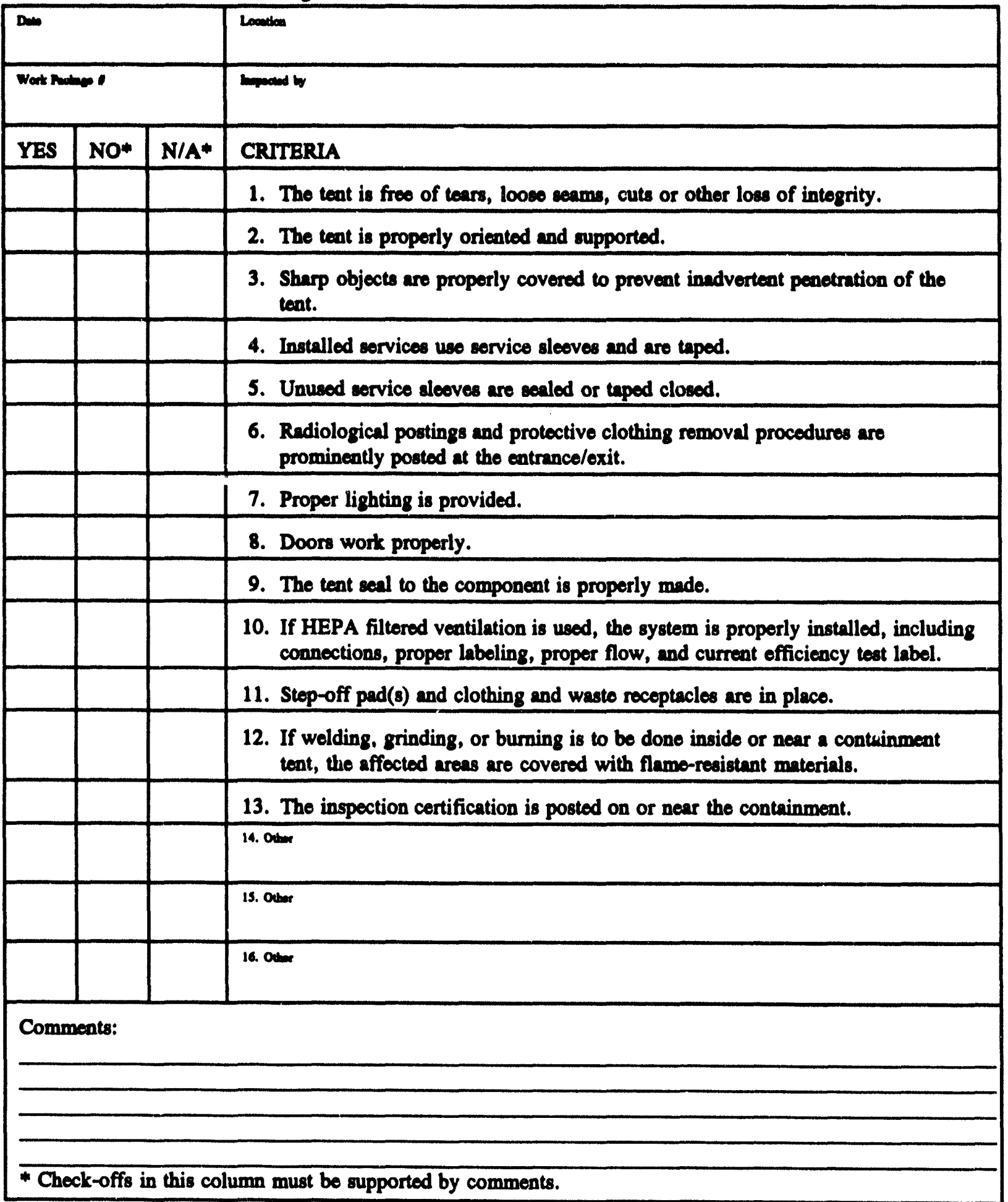


Figure C-2. Glove Bag Certification Checklist.

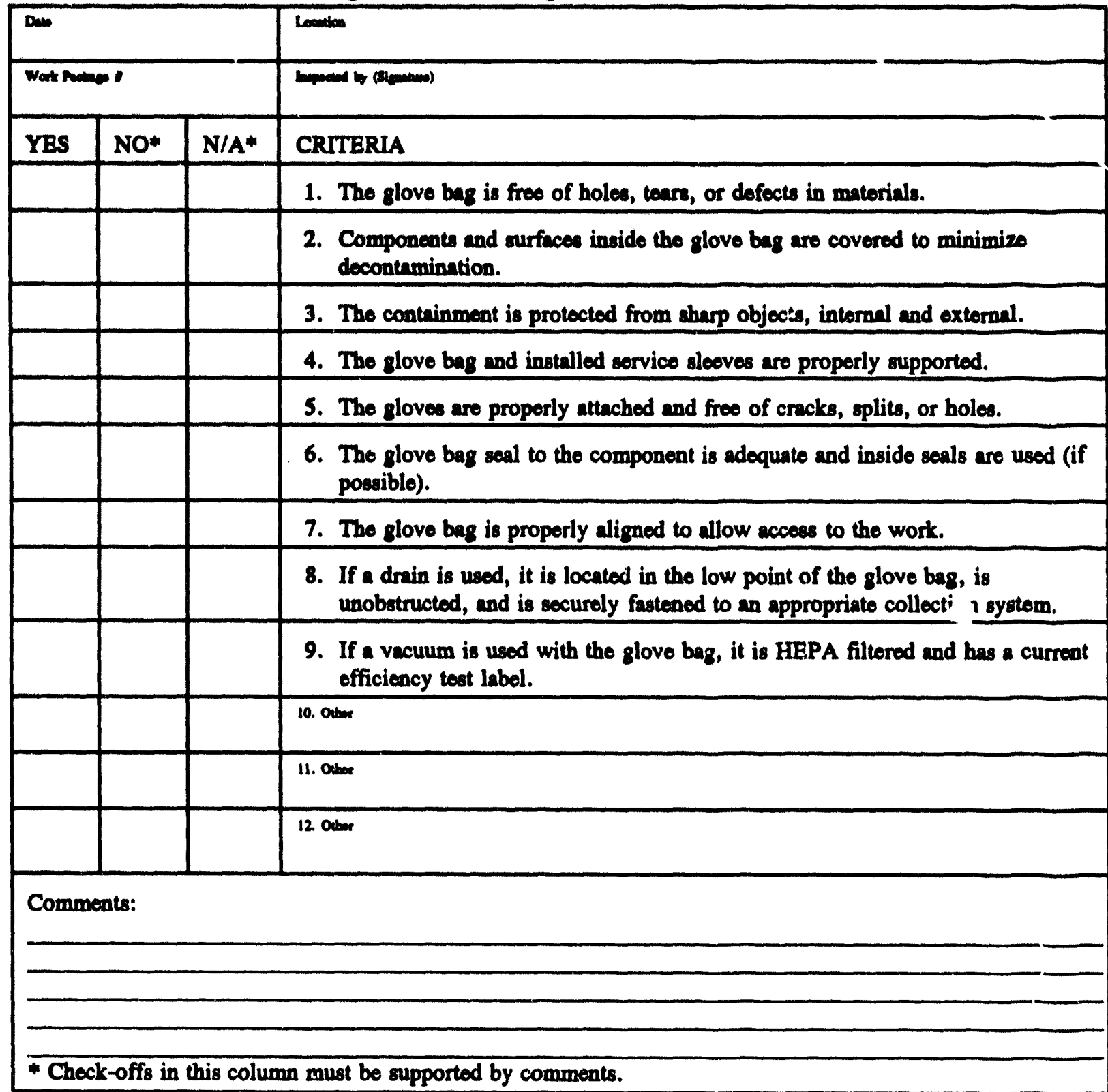


Figure C-3. Contuinment Identification Tag.

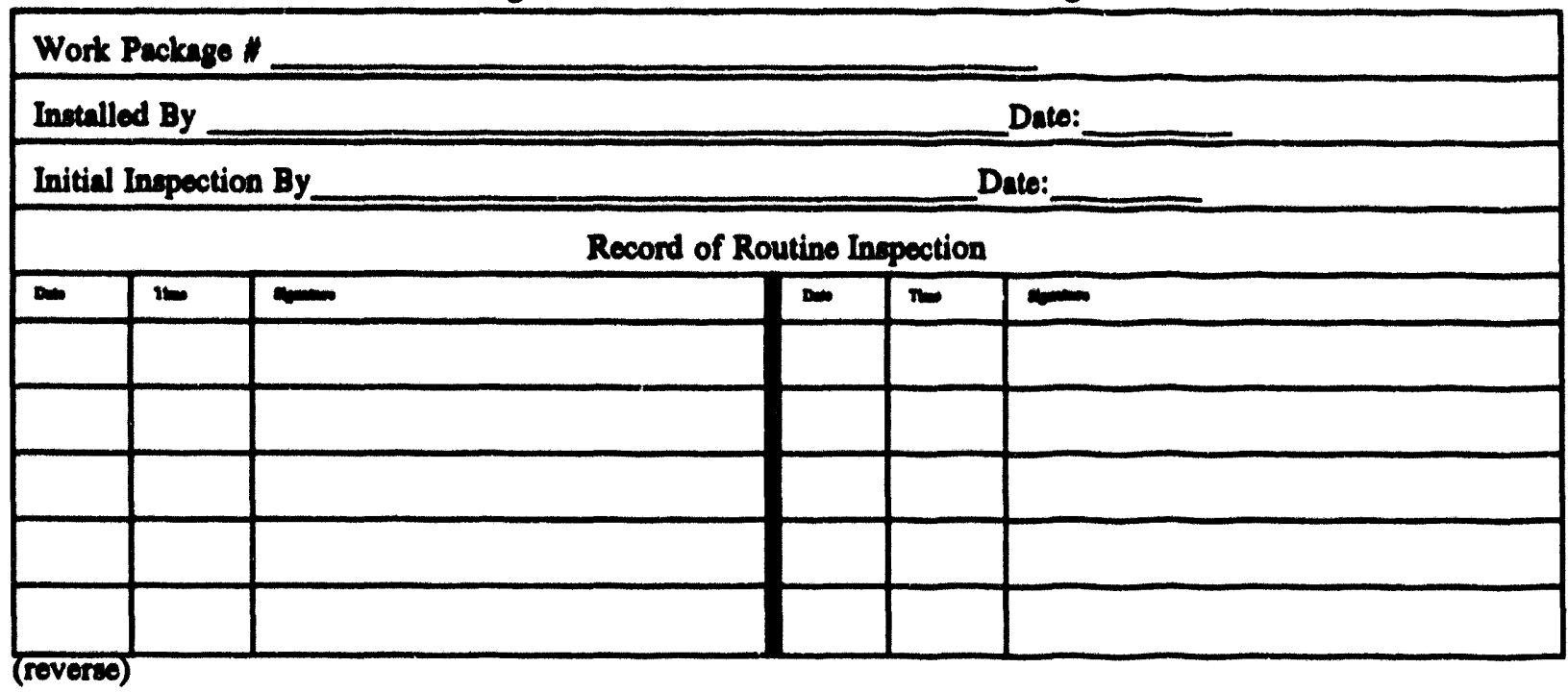

Routine Containment Tent Inspection

1. The tent is free of tears, looes seams, cuts or other loss of integrity.

2. The tent is properly oriented and supported.

3. Sharp objects are be properly covered to prevent inadvertent penetration of the tent.

4. Installed services use service slcoves and are taped.

5. Unused service sleeves are cealed or taped closed.

6. Radiological postings and protective clothing removal procedures are prominently posted at the entrance/exit.

7. Proper lighting is provided.

8. Doors work properly.

9. The tent seal to the component is properly made.

10. If HEPA filtered ventilation is used, the system is properly installed, including connections, proper labeling, proper flow and current officiency test label.

11. Step-off pad(s) and clothing and wasto receptacles are in place.

12. If welding, grinding, or burning is to be done inside or near a containment tent, the affectod area are covered with flame-resistant materials.

13. The inspection certification is posted on or near the contrinment.

\section{Routine Glove Bag Inspection}

1. The glove bag is free of holes, tears, or defocts in materials.

2. Components and surfaces inside the glove bag are covered to minimizo docontamination.

3. The containment is protected from sharp objects, intermal and external.

4. The glove bag and installed service sleeves are properly supported.

5. The gloves ase properly atteched and free of cracks, splits, or holes.

6. The glove bag seal to the component is adequate and inside seals are used (if possible).

7. The glove bag is properisy aligned to allow uccess to the work.

8. If a drain is used, it is located in the low point of the glove bag, is unobstructed, and is securely fastened to an appropriate collection system.

9. If a vacuum is used with the glove bag, it is HEPA filtered and has a current officiency test label. 
WHC-EP-0749

This page intentionally left blank. 
WHC-EP-0749

APPENDIX D

CONTAINMENT DESIGN AND SPECIFICATION

D-1 


\section{WHC-EP-0749}

This page intentionally left blank.

D-2 
WHC-EP-0749

\section{CONTAINMENT DESIGN AND SPECIFICATION}

\section{D.1 PURPOSE}

This appendix provides a uniform methodology for containment design and specification.

\section{D.2 PROCESS}

If the designers understand the facility and the job to be performed, designing a glove bag or tent is generally a simple process that can be easily documented.

A sample design checklist is attached (Attachment 1, Design Checklist). The containment design checklist is a two-page document; page 1 collects needed information, and page 2 includes a sketch that can be used to show the layout of the containment. The attachment includes two versions of page 2: one for glove bags, and one for tents. Some information is repeated, so the two pages may be used independently.

\section{D.3 DESIGN CONSIDERATIONS}

\section{D.3.1 CONTAINMENT TENTS}

The following features should be considered when designing a containment tent:

- External Frame - Where possible, containments should use an external frame. If, for structural or other reasons, an external frame is not practical, every effort should be made to prevent framing materials from becoming contaminated.

- Material - Material should be a flexible, impermeable fabric of sufficient strength to meet the specific environmental conditions.

- Support - For external applications, flexible supports are preferable. All tents should have sufficient tie-offs (e.g., grommet tabs, molded tie-offs, or other such devices) to support the tent.

- Service Sleeves - Service sleeves are used to bring services such as power and air into a tent. As a rule, service sleeves should be a minimum of 3 in. in diameter. 
- Dump Sleeves - Dump sleeves are generally located near exit doors as a receptacle for waste and used protective clothing. Dump sleeves may have collars attached that allow sleeves to be replaced or have long sleeves attached. The advantage uf long sleeves is to allow waste to be collected in the sleeve and removed using a standard bag out method as is used with glove bags. (See Appendix B, Section B.3.)

- Color - Tents should be yellow; however, at times, temperature considerations will necessitate other options such as white or a reflective material. This is acceptable if the material is marked with a radiological symbol.

- Windows - Windows should be clear, and of sufficient number to allow use of external lighting. For outdoor applications, covers should be considered that allow sun side windows to be covered. This will help keep temperatures in the tent ALARA.

- Ventilation - When ventilation is used on a tent, the tent must have a means of taking in make-up air. Acceptable methods of taking in make-up air include, but are not limited to, inlet breather filters or one-way louvers.

- Doors - Doors should be designed to be opened and closed easily. If high radiation area controls are required, consideration should be given to using doors that can be locked. Doors should have a clear viewing panel in the upper half and have posting pouches capable of holding standard size signs on the lower half. For tents to be used for extended periods of time or under harsh conditions, spare or backup doors may be included in the tent.

\section{D.3.2 GLOVE BAGS}

Design consideration for glove bags should consider the following:

- Support - External framing may be needed for support depending on application and ventilation requirements. Molded tie-offs, grommet tabs, or other tie-off devices should be included in the design of the glove bag. Elastic cord is preferable for connecting glove bags to an external frame.

- Service Sleeves - Service sleeves are used to bring needed services into a glove bag and to provide an outlet for air exhaust or liquid drains.

- Color - Glove bags should be clear and/or yellow. Accessories need not be specially colored if they are appropriately labeled.

- Ventilation - All glove bags should contain a 2-cfm or larger HEPA filter located in the upper half of the glove bag. Glove bags having negative ventilation should contain HEPA filters of sufficient flow capacity to prevent the glove bag from collapsing. If air tools are used, the exhaust should be directed out of the glove bag, unless adequate exhaust ventilation is provided.

- Temperature - Glove bags that will be in contact with piping or components where temperatures may exceed $150{ }^{\circ} \mathrm{F}$ should be protected by heat insulating material. 
- Liquid Collection - Where liquid is expected or likely to collect in the glove bag, the glove bag should be verified liquid tight. A drain assembly or pump suction should be included in the design.

\section{D.3.3 POLY BOTTLE INSTALLATIONS}

Design considerations for poly bottle installations should include the following:

- Volume - Estimated volumes of liquid expected should be planned for as part of poly bottle installations; staging of spare poly bottles should be considered.

- Location - Where possible, poly bottles should not be located in walkways or other locations where the bottle, hose, or attachments could easily become damaged, disconnected, or spilled.

- Sizing - Poly bottles generally come in two sizes, 5 and 15 gal. Where movement of a full or partially full bottle is difficult (i.e., stairwells, ladders), the smaller bottle should be used.

- Inspections - Since poly bottles are not routinely certified, consideration must be given to an inspection frequency during the design phase of the process. Considerations should include area traffic, contamination levels, radiation levels, and the expected flow rate into the bottle.

- Spillage - Poly bottles should be supported or tied off to a sturdy point to prevent tip over.

- Ventilation - Poly bottles should be vented in a controlled manner to allow displacement of air due to introduced liquid. Consider nature of hazard when designing ventilation for poly bottles (i.e., do not vent liquids which may contain tritium through HEPA filters).

- Criticality - The use of poly bottles should be evaluated by qualified personnel when used with fissile isotopes.

- Freexing - Where poly bottles are exposed to freezing conditions, freeze protection should be included in the design.

- Liquid Temperature - Liquids greater that $150^{\circ} \mathrm{F}$ should be collected in bottles designed for high-temperature liquids. Poly bottles should not be used unless sufficient liquid is included in the bottle as a heat sink.

- Change out - The organization responsible of changing and/or emptying full poly bottles should be identified.

- Liquid Level - Poly bottles should have dye (red or blue food coloring) added to color the liquid when installed. This allows the liquid level to be observed without tipping the bottle. 


\section{D.3.4 VENTILATION}

If it is determined that a containment should be ventilated, the ventilation should be planned as part of the containment. Ventilation for containment tents usually is operated at $0.01-0.3$ in. of water and 4-20 air changes per hour. Where possible ventilation should be localized using flexible ducting to take it directly to the source of the contamination. This is a far more efficient method of ventilation and may preclude the use of respiratory protection. Vacuum cleaners can also provide an effective source of localized ventilation.

\section{D.4 OUTDOOR CONSIDERATIONS}

When containments are to be used out of doors, key factors must be considered such as wind, rain, snow, lack of support facilities and temperature. Some of the essential features of indoor and outdoor containments are provided for comparison below.

- Indoor containments

- Lower gauge (10 mil) fabric (nylon reinforced plastic)

- UV resistance and plastic stabilizer requirements are not critical

- Structural members will not be required to withstand wind gusts of up to $50 \mathrm{mph}$

- Structural members will not be required to meet load bearing requirements of heavy rains ( 2.0 in./hour)

- More flexible design criteria (dependent upon complex geometry)

- Outdoor containments

- Higher gauge (18 mil) fabric (nylon reinforced plastic)

- UV resistant material should be used

- Structural members will be required to withstand wind gusts of up to $50 \mathrm{mph}$

- Structural members will be required to meet load bearing requirements of heavy rains (2.0 in./hour). 


\section{D.4.1 WIND}

Wind considerations will often mandate that an engineering assessment of outdoor containments be performed. For containment tents, material meeting Mil-C-43006G, Type 1 material requirements, attached with 2.5-in. molded plastic tie offs will generally endure winds $>50 \mathrm{mph}$ if the tie-offs are connected to the frame with flexible cord and the frame is adequately anchored.

Operating considerations for specific sites should include wind speeds at which containment tents are no longer considered stable. When this wind speed is expected, provisions for collapsing tents in place and securing them to frames should be considered.

\section{D.4.2 RAIN}

Rain is only a problem to containments if it is allowed to pool or penetrate unsecured openings. All containment structures used out of doors should include a slope either built into the tent or a secondary cover added externally that allows the containment to shed rain water. Note that the slope should not direct rain water toward a door.

\section{D.4.3 SNOW}

Snow accumulation should be removed as quickly as is reasonable. No reasonably obtainable roof slope will shed all snow. A good method of dealing with snow is to install a secondary cover on the containment that can be put at a much steeper pitch than the roof of the containment and that is external to the frame.

\section{D.4.4 TEMPERATURE}

At colder temperatures many plastics become stiff; this can make many simple operations very difficult. For example it is very difficult change a pass out sleeve or tape up a service lead in cold weather. For tents, little can be done unless the tent can be heated. For glove bags, polyurethane is a viable alternative, it maintains very flexible features in extreme cold.

\section{D.4.5 MiscellaNEOUS CONSIDERATIONS}

Containment tents used outside have a tendency to begin deteriorating at doors and windows. The constant motion caused by wind action can cause door zippers to wear out very quickly. A proven method of resolving this is to have both Velcro and zipper door closures. Another method is to have spare doors actually installed in the containment but not placed in service until needed. 


\section{D.5 SPECIFICATION}

\section{D.5.1 STANDARD SPECIFICATIONS}

Standard specifications are a very useful method of simplifying the use of containment. In essence, standard specifications establish ground rules, within which many different versions of a containment can be obtained. No standard specification will address all needs.

Two sample generic specifications are attached: one for glove bags and one for tents. They are designed to provide standard guidelines when ordering a containment device, however, specific details, such as size, framing material, and drawings should be developed before ordering a containiuent.

\section{D.5.2 QUALITY ASSURANCE}

Quality assurance involvement is very important to the process, while most containments do not require stringent quality assurance programs, the following should have quality assurance verification:

- Bolts or fasteners used in framing

- Verification of any required tests (i.e., air tests)

- Material verification.

Note that in the attached specifications the vendor is required to maintain these records and provide them when requested. By doing this, you can easily obtain the needed records should a containment be reapplied to a task with a more stringent impact level. 
APPENDIX D, ATTACHMENT 1-A: DESIGN CHECKLIST

DESIGN CHECKLIST

JOB TITLE

WORK PROCEDURE

LOCATION

SUMMARY OF WORK

CONTAINMENT TYPE: ( ) Tent ( ) Glove Bag ( ) Other

CONTAINMENT STYLE: ( ) Standard - Type:

( ) Custom

REQUESTING ORG:

USERS:

SOURCE:

( ) Procured

( ) On Site Manufacture (WO/PO \#__

( ) Field Construction

SPECIAL INSTRUCTIONS/TEST REQUIREMENTS:

Preparer:

REVIEWERS:

User:

User:

Radiological Control:
ATTACHMENTS:

() Tent Design Worksheet

( ) Glove Bag Design Worksheet

() Other 


\section{APPENDIX D, ATTACHMENT 1-B: DESIGN CHECKLIST - TENTS}

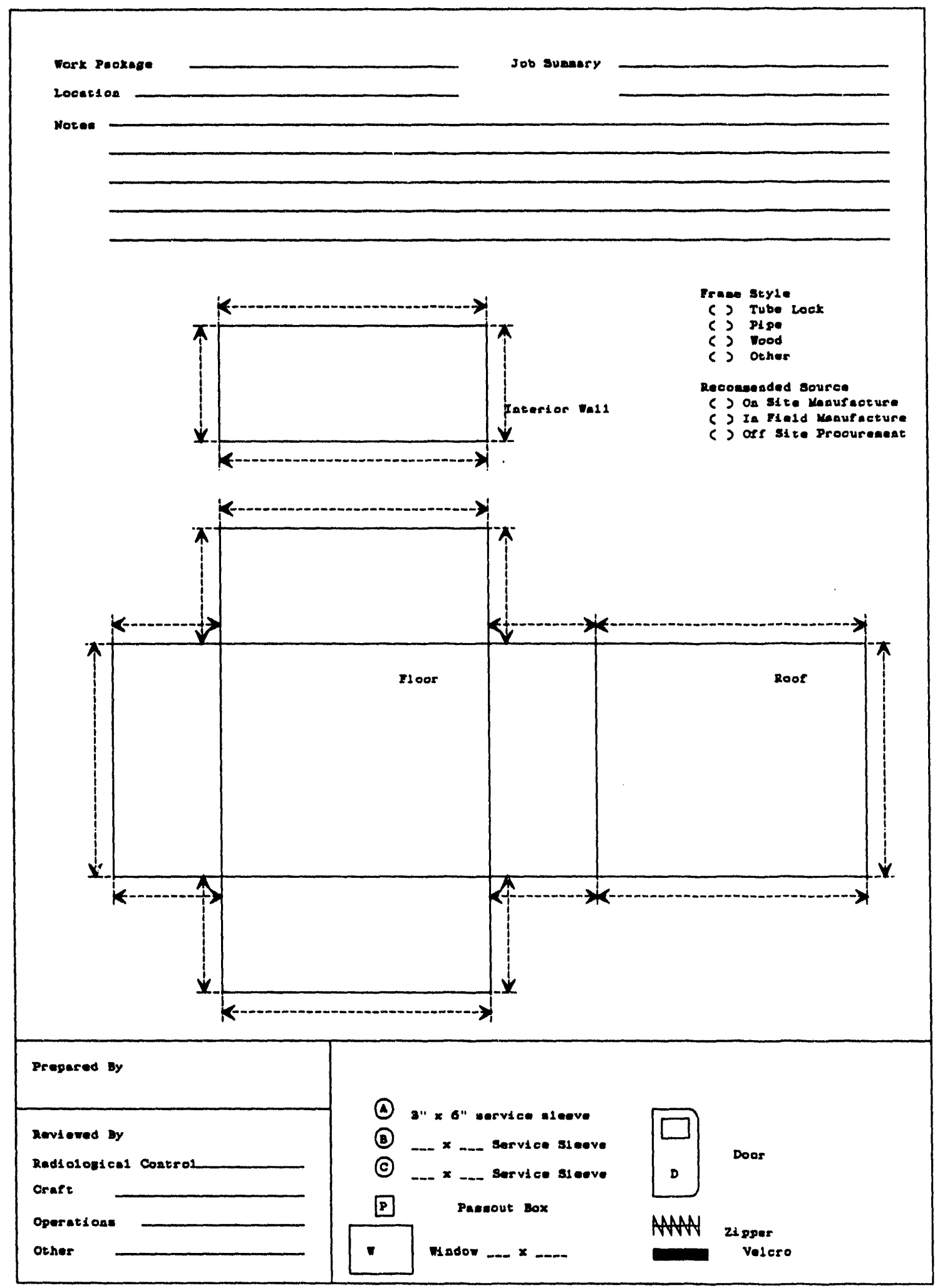

D-10 
APPENDIX D, ATTACHMENT 1-C: DESIGN CHECKLIST - GLOVE BAG

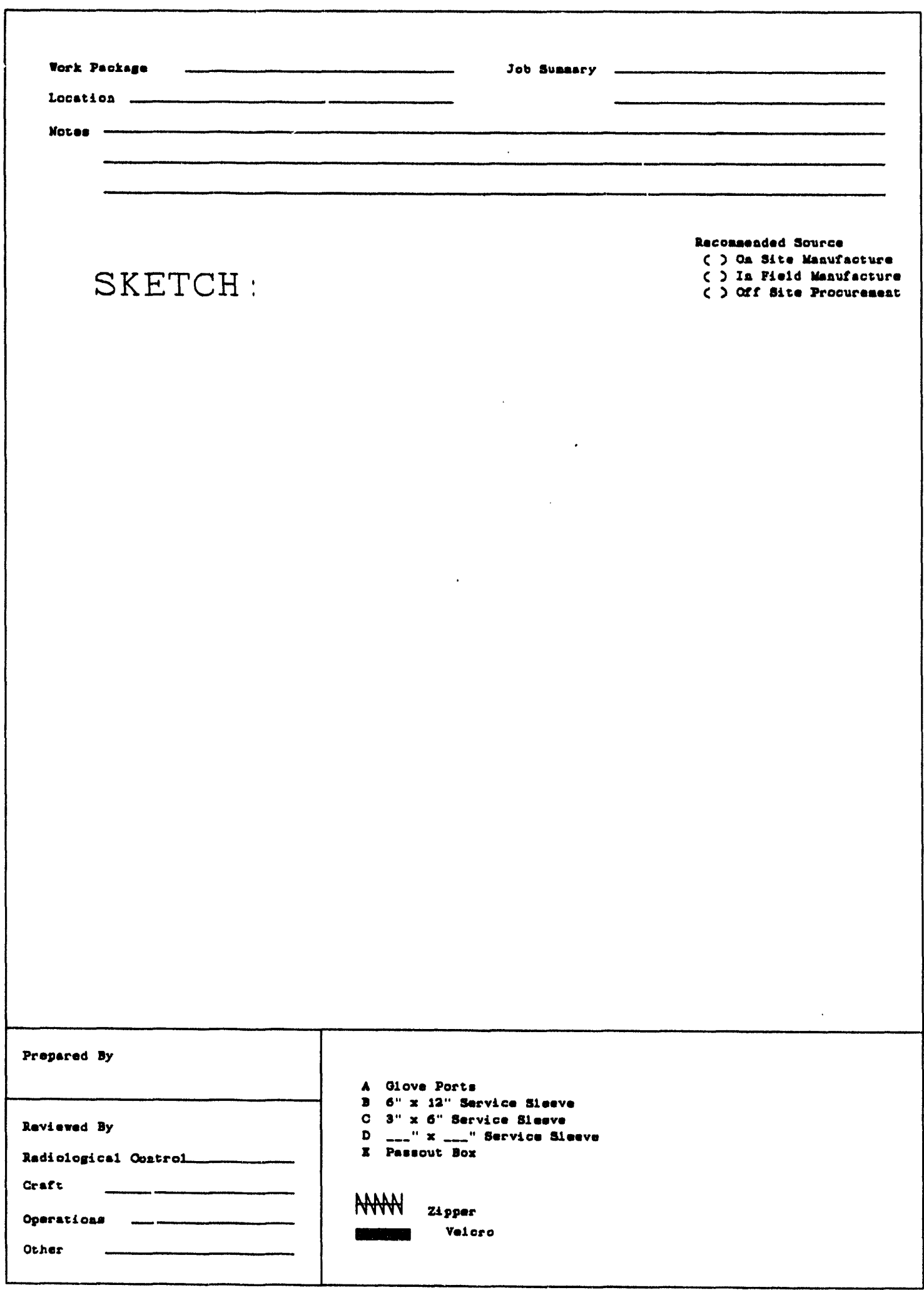




\section{APPENDIX D, ATTACHMENT 2: SAMPLE SPECIFICATION FOR SOFT-WALLED RADIOLOGICAL CONTAINMENT TENT}

\subsection{SCOPE}

This specification defines recommended requirements for soft-walled radiological walk-in containment tents used for performing radiological work.

\subsection{APPLICABLE DOCUMENTS}

\subsection{Government Documents}

MIL-C-43006G, Military Specification, Cloth and Strip, Laminated or Coated, Vinyl-Nylon or Polyester High Strength, Flexible

Federal Specification L-P-375C, Plastic Film, Flexible, Vinyl Chloride

\subsection{Nongovernment Documents}

ASTM A 47-84(1989)" , Ferritic Malleable Iron Castings

\subsection{TECHNICAL REQUIREMENTS}

\subsection{Item Definition}

The containment tent specified in this document will consist of a soft-walled enclosure supported by a rigid external framework. The tent is intended to be installed over or around the work activity to provide protection against the spread of radioactive contamination.

\subsubsection{Item Diagram}

Diagrams are attached as Figures 1, 2, and 3.

\subsection{Characteristics}

\subsubsection{Reliability}

The tent shall be of construction such that minor repairs and modifications are possible in the field. Replacement parts shall be readily available from the supplier to allow repairs to be made in the field.

\subsubsection{Environment}

The following table lists weather sonditions to which the containment tent may be exposed. Not all containments will be exposed to all environments. 
WHC-EP-0749

\begin{tabular}{|l|l|l|}
\hline \multicolumn{1}{|c|}{ Condition } & \multicolumn{1}{|c|}{ Range } & \multicolumn{1}{|c|}{ Rate of Change } \\
\hline Ambient Air Temperature & $\begin{array}{l}-20 \text { to } 115^{\circ} \mathrm{F} \text { (External) } \\
\text { Maximum of } 1400^{\circ} \mathrm{F} \text { (Internal) }\end{array}$ & $\begin{array}{l}26^{\circ} \mathrm{F} \text { decrease in } \\
20 \text { minutes, 24 } \\
\text { increase in } 60 \\
\text { minutes }\end{array}$ \\
\hline Rain & 2 in./hour maximum & N/A \\
\hline Snow, Sleet, Hail & $\begin{array}{l}8 \text { in. of snow maximum in } 24 \text { hours with } \\
12 \text { in. of snow maximum accumulation. } \\
\text { Sleet and hail account for less than 1\% of } \\
\text { frozen precipitation. Maximum hailstone } \\
\text { diameter is \% in. The site is subject to } \\
\text { blowing and driting snow. Glaze occurs } \\
\text { approximately 6 days/year. }\end{array}$ & N/A \\
\hline Solar Radiation & $300+$ days of direct sunlight & N/A \\
\hline Wind & 50 miles/hour & N/A \\
\hline
\end{tabular}

\subsubsection{Safety} work order.

If any additional safety requirements are needed, they should be specified in a purchase or

\subsection{Design and Construction}

\subsubsection{Design}

The containment tent shall be designed to include the following unless variations as noted in Section 3.3.5 are invoked:

- Anteroom - The tent shall have an anteroom measuring at least $5 \mathrm{ft}$ by $5 \mathrm{ft}$ in area. The room should also contain two 24-in. exterior diameter sleeves, a pass-out box, a 4-in. service sleeve, two windows, four 3-in. service sleeves, and one breather filter (or air damper) located in an external wall.

- Doors - The tent should have doors separating the work area and ante room. The doors should be a minimum of $30 \mathrm{in}$. wide by $66 \mathrm{in}$. high and have a clear window in the upper half of the door. The tent should include a means to support the door while open.

NOTE: For tents designed for extended or out door use, spare doors, installed in the containment, should be considered. 
- Work Ares - The work area should contain two 24-in.-diameter exterior sleeves in the work area located as near the exit as possible. Each work area shall also contain, as a minimum, a pass-out box, two 4-in. service sleeves, windows, four 3-in. service sleeves, and breather filters (or air dampers). Figure 1 shows the approximate locations of each of these components in a standard tent.

- Pass-out Boxes - The tent should have pass-out boxes located within each section. Unless otherwise specified in the purchase order, the pass-out box should be 6 in. high by 6 in. wide by 4 in. deep. The pass-out boxes shall use either Velcro or zippers for the inner and outer seal closures. Circular passout boxes may be substituted.

- Postine Pouches - Two clear pouches (two pouches together), capable of holding a sign measuring 10 in. by 13 in., shall be located on the outer surface of both doors and immediately adjacent to the doors, such that the postings are visible if the door is open.

- Adequate Support - The tie-offs used to support the tent shall be of sufficient quantity and strength to support the tent with a differential negative pressure of 0.5 in. of water inside the tent.

- Extemal Frame - The tent should be supported by an external frame capable of supporting the tent with a negative pressure of 0.5 in. of water.

- Roof Slope - Depending on location, tents should either have a sloped roof as part of the design or have a secondary structure fitted to the tent that will provide sufficient slope to allow the tent to shed water and snow accumulations.

\subsubsection{Construction}

The tent shall meet the following requirements:

- Walls. Floors and Ceilings - The walls, floors, and ceilings shall be fabricated from material meeting Military Specification (Mil-Spec) MIL-C-43006G; Type 1 material is required. The color of the material shall be yellow except where windows are installed. The floor section of the work area should be fabricated separately and affixed with a 4-in. Velcro seam as shown in Figures 1 and 2.

- Windows - Window material shall be fabricated from 20 gauge PVC meeting Federal Specification L-P-375C. The material shall be transparent, double polished, and fire retardant.

- Service/Waste Sleeves - Service and waste sleeves shall be fabricated from 12-mil-thick translucent yellow fire retardant PVC meeting Federal Specification L-P-375C or MIL-C-43006G.

- Tie-Offs - Tie-offs shall be 2.5-in.-diameter heavy-duty injection-molded PVC and be attached to the body of the containment at intervals consistent with the external frame, not to exceed 18-in. intervals. Tie-offs that support the weight of the tent shall be affixed to the tent fabric, and not to windows. Grommets may be substituted for tie-offs. 
- Dose Zippers - Door zippers should use double pull sliders or an overlapping Veloro flap. For outdoor applications, a combination of zipper and Velcro is recommended, however when used together, either the zipper or the Velcro must be able to seal the door independently as well as operate at the same time.

- Breather Filter - Breather filters allow for air inleakage as well as preventing buildup of gasses in the tent. Breather filters for air inleakage can be replaced with one way air dampers, however, if the potential exists for the tent to pressurize, HEPA-rated breather filters should be installed in sufficient quantity.

\subsubsection{Frame Structure}

The tent frame can be constructed of almost any material that can support the weight of a containment tent under negative pressure. Key considerations should be that the material be reusable. Two recommendec methods are shown below:

- Schedule 40 Pipe - The tent frame shall be fabricated from 1-in. schedule 40 galvanized pipe. Connectors shall be fabricated from malleable iron castings meeting the requirements of ASTM A 47, Grade 32510 with case-hardened set screws, sized to fit 1 -in. schedule $\mathbf{4 0}$ galvanized pipe. Pins with either threaded or hinged fittings that penetrate the piping may be used in lieu of set screws.

Where schedule 40 pipe is used, all corners should be re-enforced by with $1 / 4$-in. bolts using nylon lock washers, the holes will be $5 / 16$ in. in diameter and located such that he tent frame may be assembled without additional drilling of holes.

- Frame Scaffolding - Standard tube-type scaffolding material that can be fitted together so it forms an effective frame.

The tent frame should have vertical wall and lateral roof supports every $5 \mathrm{ft} \pm 1 \mathrm{ft}$.

\subsubsection{Fabrication}

The tent shall be constructed using the following methods:

- All seams on the walls and floors of the containment should be double sealed.

- All window seals should exhibit a minimum 1/2-in. overlap; transfer and access sleeves shall exhibit a minimum $1 / k$-in. overlap.

- Tie-offs shall be hcat sealed in place and shall be located in sufficient quantity to provide adequate support. Grommet tabs are an acceptable alternative.

- Double stitching is required on all door zippers.

- Velcro shall be placed to allow holding the doors in the open position. 
WHC-EP-0749

\subsubsection{Options and Variations}

The following variations to the design should be acceptable with no formal approval.

- Color - The color of the containment may be white.

- Rostine Pouches - Posting pouches may be relocated as needed.

- Door Sizes - Door sizes and location may vary as needed.

- Dump Sleeves - Dump sleeves may be eliminated or relocated as needed to support specific work activities.

\subsection{QUALTY ASSURANCE REQUIREMENTS}

\subsection{Responsibility for Verification}

Suppliers shall be responsible for performing all required tests before submitting any items to the buyer for acceptance. Except as otherwise specified, suppliers may use either their own or any commercial laboratory acceptable to the buyer. Records of all tests shall be kept complete and available to the buyer.

\subsection{Documentation Submittals}

The supplier shall provide copies of certifications as specified in the purchase order.

\subsection{PREPARATION FOR DELIVERY}

\subsection{Preservation and Packaging}

The tent components shall be shipped in approptiately labeled containers constructed in a manner that will ensure damage-free delivery. An assembly list and assembly instructions shall be enclosed referencing both item and packing box numbers to permit easy assembly in the field.

\subsection{Marking}

Each packing box shall be legibly and conspicuously marked with the purchase order number, specification number, name of supplier, name of component, and weight (gross and net). 


\section{WHC-EP-0749}

Figure 1. Generic Containment Tent.

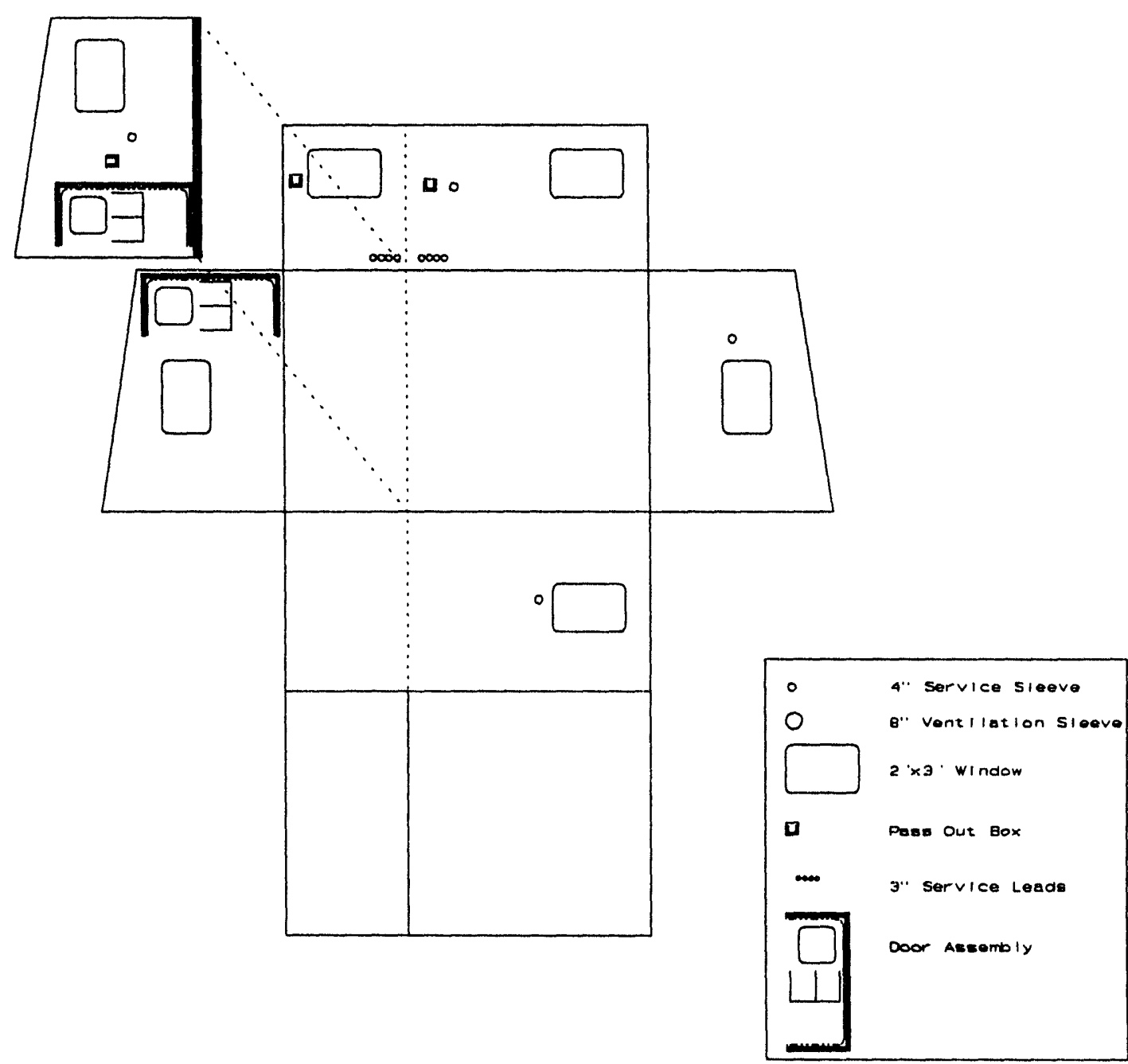




\section{WHC-EP-0749}

Figure 2. Tie-Off Location on Containment Tent.

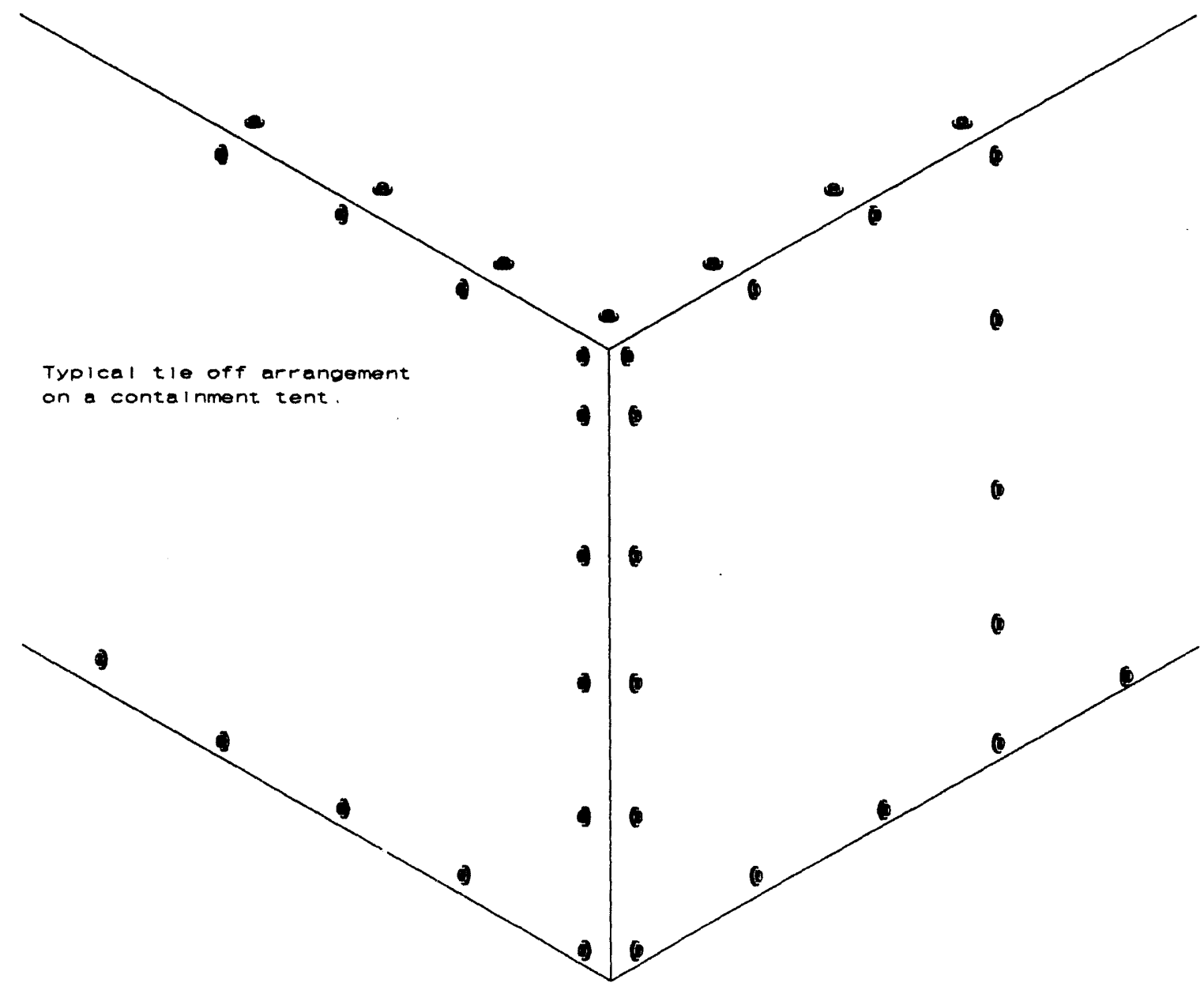


Figure 3. Breather Filter Assemblies.

Breather Filter for Ventilated Tents

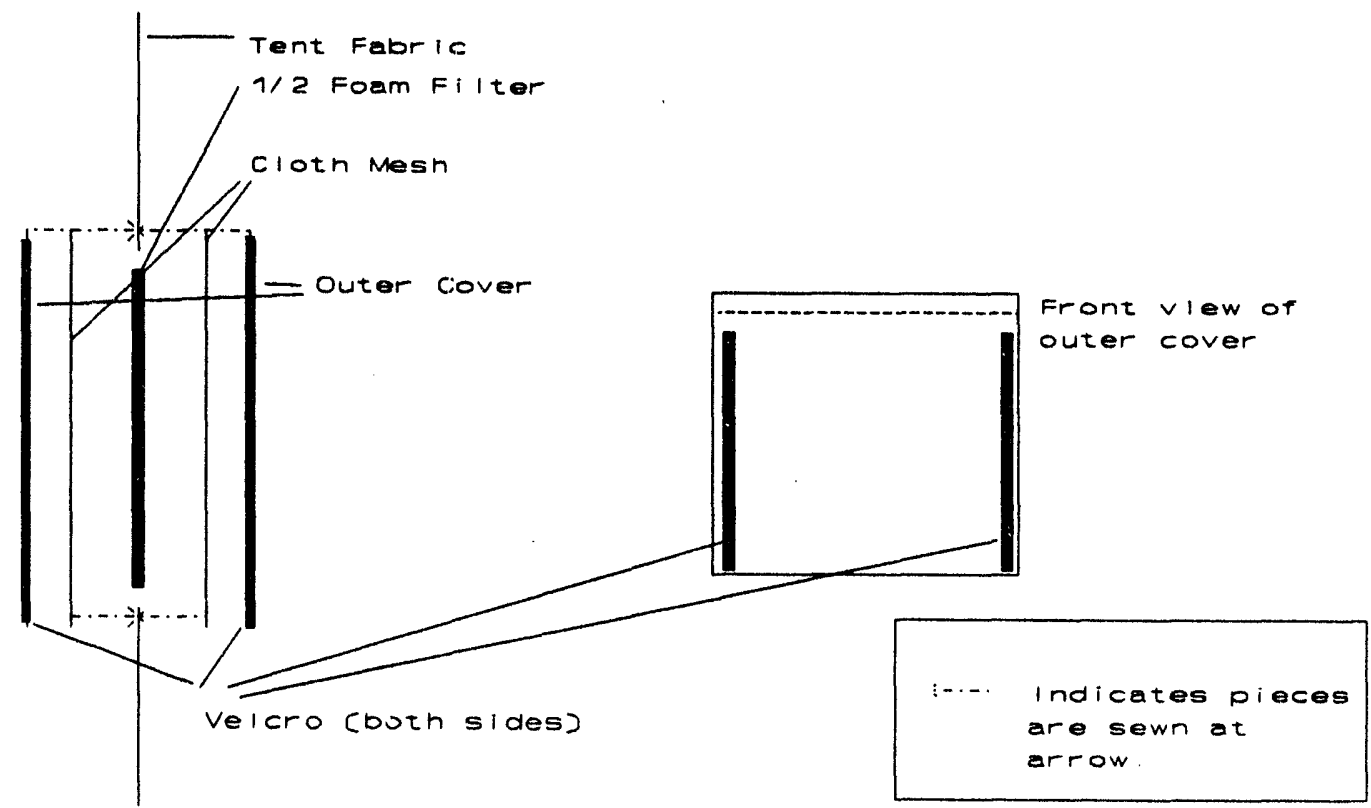

Breather Fliter for Non-Ventl lated Tents

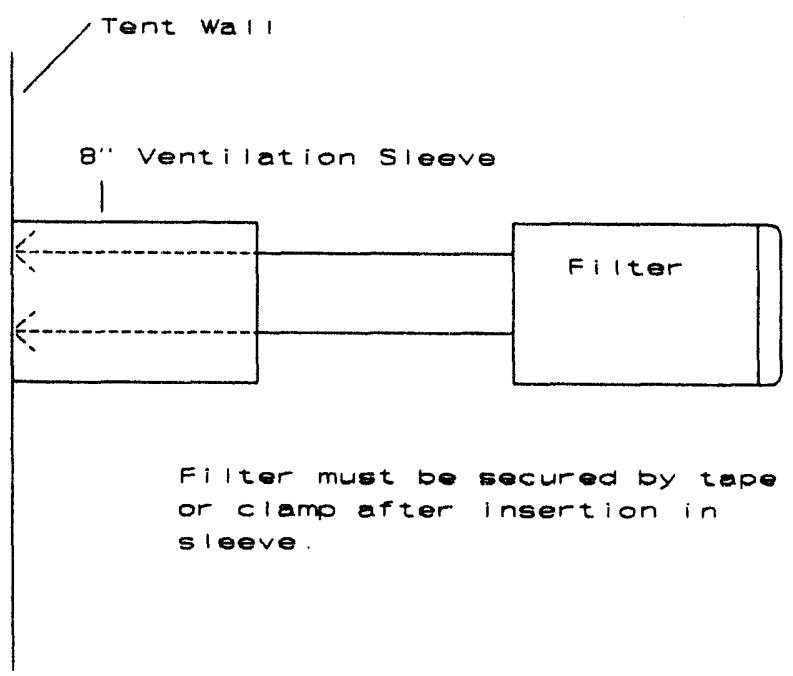

D-19 


\section{WHC-EP-0749}

Figure 4. Air Flow Regulator.

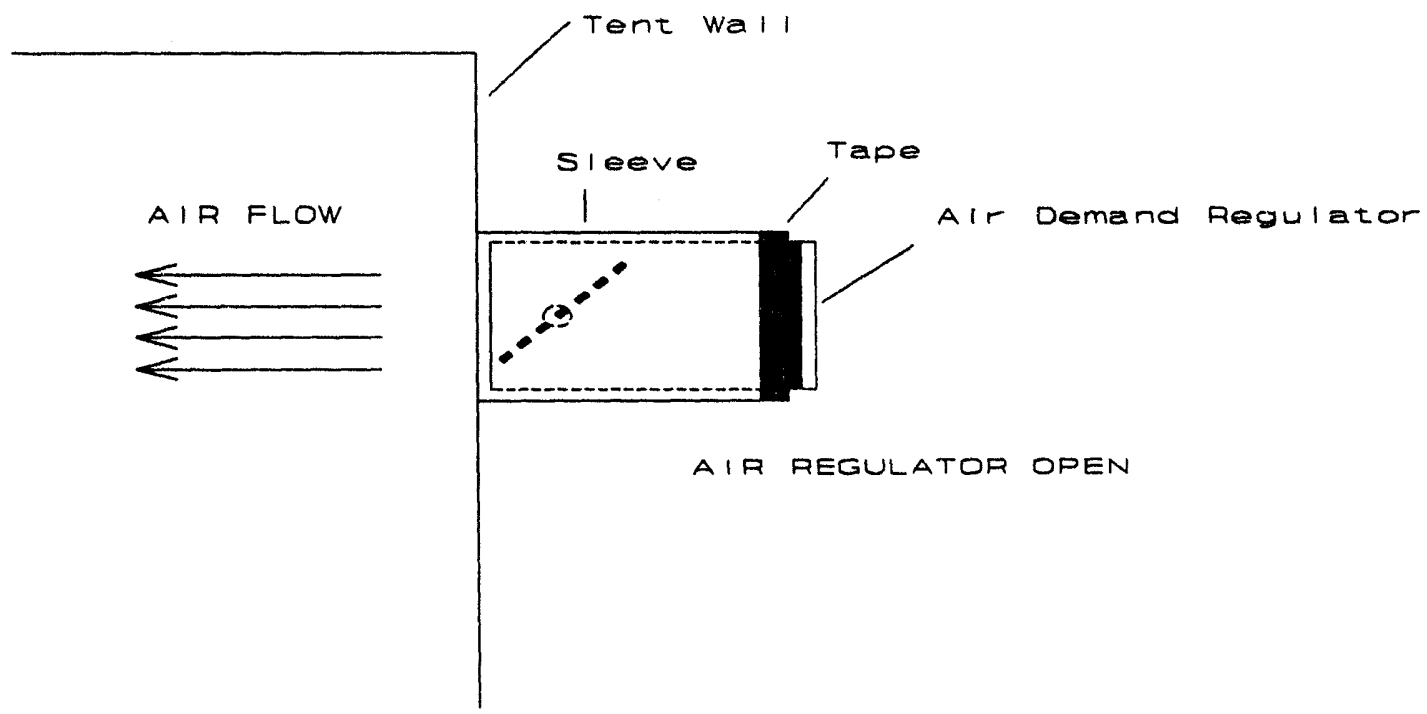

TENT PRESSURE GREATER THAN

OR EQUAL TO ATMOSPERE

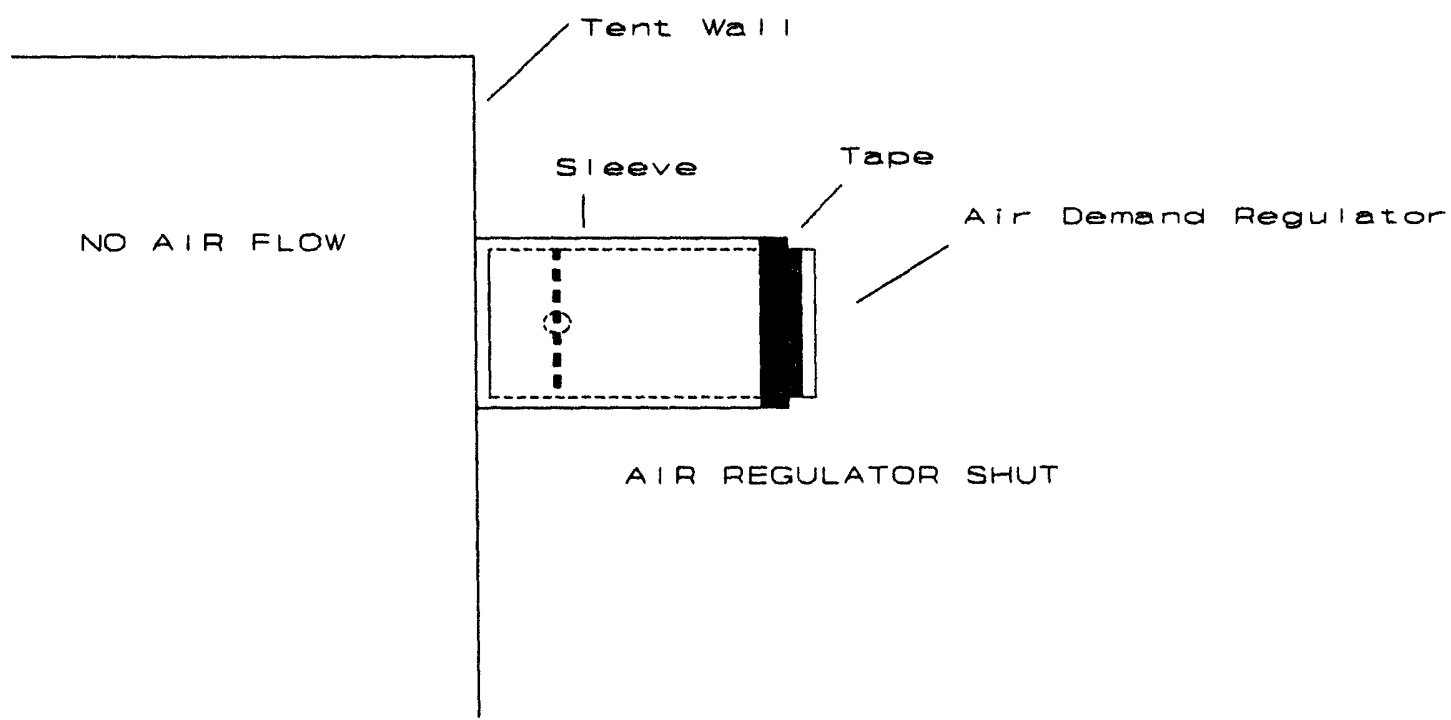


APPENDIX D, ATTACHMENT 3: SAMPLE SPECIFICATION FOR GENERIC GLOVE BAGS

\subsection{SCOPE}

This specification defines the requirements for nonstandard glove bags used for performing radiological work.

\subsection{APPLICABLE DOCUMENTS}

\subsection{Government Documents}

MIL-C-43006G, Military Specification, Cloth and Strip, Laminated or Coated, Vinyl-Nylon or Polyester High Strength, Flexible

Federal Specification L-P-375C, Plastic Film, Flexible, Vinyl Chloride

\subsection{Nongovernment Documents}

\subsubsection{ASTM Standards}

ASTM A 47-84(1989) $)^{e 1}$, Ferritic Malleable Iron Castings

\subsection{TECHNICAL REQUIREMENTS}

\subsection{Item Definition}

The containment specified in this document will consist of a soft-sided enclosure supported by a either a rigid external framework or tie-offs. The glove bag is intended to be installed over the work activity to provide protection against the spread of radioactive contamination during work activities.

\subsection{Characteristics}

\subsubsection{Reliability}

The glove bag shall minimize the transfer of either airborne or surface contamination to the environment. Replacement parts shall be readily available from the supplier to allow repairs in the field.

\subsubsection{Safety}

If additional safety requirements are needed for a glove bag purchase, the applicable safety requirements should be specified in the purchase requisition. 


\subsection{Design and Construction}

\subsubsection{Design}

The glove bag should be designed with the following features:

NOTE: For cold weather applications polyurethane may be substituted for any material requiring conformance to Federal Mil. Spec. LP375C where fire retardant material is not required.

- Armsleeves - Armsleeves must be 16-18 in. long, tapering from 9 in. in diameter at the shoulder to $4 \%$ in. in diameter at the wrist. They must be made of 8-mil PVC, yellow in color, conforming to Federal Mil. Spec. LP375C.

NOTE: Longer glove sleeves can be used if specifically requested.

- Pass-out Boxes - Pass-out boxes shall have an inner opening and an outer opening that can be secured by a Velcro or zippered seal. The box will be located on the outside of the containment and must be $4 \times 6 \times 6$ in. Pass-out boxes should be located in the upper half of the containment where possible.

- Service Sleeves - The containment should contain at least two 3-in. service sleeves for service leads.

- Bottom -The bottom of the glove bag should be designed based on the planned work. Heavier applications will require the use of nylon re-enforced material, dual floors, secondary drapes, or even a sturdy tray, external to the glove-bag.

- Sides and Top - The sides and top of the glove bag should be clear PVC, at least 8 mil thick, conforming to Federal Mil. Spec. LP375C.

- Glove Rings - Glove rings must be constructed of hard plastic and sized to be $4 \%$ inside diameter.

- Tie-offs - Glove bag support should be provided by either tie-ofts made of heavy duty injection-molded PVC, grommets, or support tabs.

- Transfer Sleeves - An 18-in.-long transfer sleeve, 6 in. in diameter, should be included in the body of the glove bag. 


\subsubsection{Construction}

The glove bag shall be constructed as follows.

- All seals in the main body have a minimum of $1 / 2$-in. overlap, seals in the transfer and access sleeves have a minimum of $1 / 4$-in. overlap.

- Tie-offs attached by heat sealing and in sufficient quantity to provide adequate support.

- Double stitching is required on all stitched seams.

- Velcro or other closure device should be plac $d$ as to seal any openings.

\subsubsection{Frame Structure}

Where required, the frame shall be fabricated from material sufficient to support the glove bag when exposed to a negative pressure of 0.5 in. of water.

\subsection{QUALTTY ASSURANCE REQUIREMENTS}

\subsection{Required Tests} standard.

Where called out on the purchase requisition the supplier will test glovebags to the required

\subsection{Responsibility for Verification}

Suppliers shall be responsible for the performing all required tests and inspections before submitting any items to the buyer for acceptance. Except as otherwise specified, suppliers may use either their own or any commercial laboratory acceptable to the buyer. Records of all tests shall be kept complete and available to the buyer.

\subsection{Documentation Submittals}

The supplier shall provide copies of certifications as specified in the purchase order. 


\subsection{PREPARATION FOR DELIVERY}

\subsection{Preservation and Packaging}

The components shall be shipped in appropriately labeled containers constructed in a manner that will ensure damage-free delivery. An assembly list and assembly instructions shall be enclosed referencing both item and packing box numbers to permit easy assembly in the field.

\subsection{Marking}

Each packing box shall be legibly and conspicuously marked with the following data:

- Purchase order number

- Specification number

- Name of supplier

- Components by name and reference key enclosed

- Gross and net weights. 
WHC-EP-0749

APPENDIX E

SAMPLE TRAINING GUIDES

E-1 
WHC-EP-0749

This page intentionally left blank.

E-2 
WHC-EP-0749

APPENDIX E.1

WESTINGHOUSE CONTAINMENT PROGRAM

RADIOLOGICAL CONTROL TECHNICIAN SUPPLEMENTAL TRAINING INSTRUCTOR GUIDE

E-3 
WHC-EP-0749

This page intentionally left blank. 
WHC-EP-0749

WESTINGHOUSE CONTAINMENT PROGRAM

\section{RADIOLOGICAL CONTROL TECHNICIAN SUPPLEMENTAL TRAINING} INSTRUCTOR GUIDE

Section Title: $\quad$ Containment Program

Revision Number: 0

NOTICE: This document is for TRAINING PURPOSES ONLY. Do not use this material in place of the current revision of controlled plant documents. 
Target Population Summary:

Health Physics Technician that has completed DOE CORE ACADEMICS.

List of Materials/Equipment Required:

A. Student Handout

B. Various Containment Manipulatives

1. Poly Bottle

2. Poly Bottle Containment

3. Cone Drape

4. Pan Drape

5. Drain Assembly

6. Filter Assembly

C. Overheads

1. Containment Tent

2. Glove Bag

3. Catch Containments

4. Frame Components

5. Ventilation

6. Glove Bag

7. Containment Selection Table

8. Inspection Tag

9. Glove Bag Checklist

10. Containment Tent Checklist 


\section{WHC-EP-0749}

\section{LIST OF SEQUENCED OBJECTIVES:}

1. OBJECTIVE

Discuss the various types of containment and familiarize the students with the applications of each.

\section{OBJECTIVE}

List the requirements and good practices associated with containment devices.

3. OBJECTIVE

Demonstrate the method used to determine the appropriate containment.

\section{ABOUT THIS LESSON}

This lesson will provide the student with the required knowledge to perform the following tasks:

1. Recognize proper containment for a given application.

2. Perform initial inspection of containments.

3. Understand the basis for the application of containments.

4. Recognize proper operation of containments. 


\section{INTRODUCTION}

This training should further serve to enable and encourage the use of containments for contamination control and to accomplish the following:

- Minimize personnel contamination

- Prevent the spread of contamination

- Minimize the required use of protective clothing and personal protective equipment.

Containment is not limited to the concept of total enclosure, but instead encompasses the application of engineered barriers applied in varying degrees to prevent the spread of radioactive contamination.

Two key principles influence the use of containments:

- Establishing the contamination barrier (the containment) as near to the source as possible

- Whenever possible, using containments around the work area instead of requiring workers to use additional protective clothing or other personal protective equipment.

\section{REQUIREMENTS AND GOOD PRACTICES}

The DOE Radiological Control manual mandates the use of engineered barriers to control the spread of airborne and surface contamination.

Good work radiological work practices dictate:

- That the opening of contaminated systems be performed with engineering barriers to prevent the spread of contamination.

- Containment be considered if the task involves:

- The likely spread of contamination

- Exposing a contaminated fluid system

- Airborne contamination.

- That the Radiological Control Organization approve containment design prior to procurement or construction

- Containments be inspected prior to initial use, routinely during operation, and monthly during standby periods. 


\section{DEFINITIONS}

Following is a summary discussion of the various containment methods:

1. Containment Tents. Large enclosures, generally constructed of flexible sheeting, which allow personnel to physically enter a contaminated environment to perform work. Containment tents can also be used to provide anterooms for access to cells, tank risers, and other highly contaminated environments.

2. Glove Bags. A glove bag is a flexible containment used to establish an enclosure around a contaminated item, allowing personnel to accomplish repairs or manipulations via gloved sleeves without contacting the contaminated environment.

3. Catch Containments (Drapes). Catch containments are partial enclosures usually used to collect falling debris or small amounts of liquid.

4. Wind Break or Bull Pen. A bull pen is a walled or partially walled enclosure that allows personnel to enter and work in a contaminated environment. Bull pens are generally roofless and are used on low risk activities to protect immediate area from contaminants, as well as protect the work area from external factors which could result in contaminated material being spread.

5. Polvethylene (poly) Bottles. Poly bottles are a 5- or 15-gal polyethylene container used for the collection of small quantities of contaminated liquids (generally includes a filtered vent assembly).

6. Air curtains. Air curtains use moving air to draw contaminants into a filtered exhaust plenum. Application of air curtains include open-faced hoods, strategically placed exhaust ducts, or any other means of capturing the contaminants at or near the source with filtered ventilation.

7. Miscellaneous, Other types of containment devices include sleeving, mechanical joint containments, plastic sheeting, and drop cloths.
MEETS OBJECTIVE 1

Display overhead of Containment Tent. (1)

Display overhead of various glove bags. (2)

Display overhead of catc $n$ containments. (3) and pass an example to class.

Pass example of poly bottle to class. Also demonstrate the drain assembly as used with catch containments.

Cite examples such as openfaced hoods, etc.

Pass an example of a mechanical joint containment around room. 


\section{CONTAINMENT FEATURES AND OPERATING CONSIDERATIONS}

Contamination control should always be the key design consideration when determining what features a containment device should incorporate; however, other considerations, including contamination levels, temperature, area

configuration, isotope(s), and the radiological characteristics of the immediate proximity, should be considered in addition to the specifics contained in the sections below.

\section{CONTAINMENT TENTS}

The following features should be used whenever possible on a containment tent:

External, reusable frame - External frames that are reusable have distinct advantages in that they are protected from contamination and do not have to be disposed of as waste.

Service sleeves - Service sleeves are used to bring services such as power, air, etc, into a tent. As a rule, they should be a minimum of 3 in. in diameter for lines, cords, etc. and sized to as needed to support ventilation duct. If the membrane is cut, service sleeves should be in use, or taped closed.

Dump sleeves - Dump sleeves are generally located near exit doors as a receptacle for waste and used protective clothing. For long-term use, dump sleeves may have collars attached that allow sleeves to be replaced or even to have long sleeves attached. If the membrane is cut, service sleeves should be in use or taped closed.

Ventilation - When ventilation is used on a tent, the flow rate should allow for 4-20 air changes per hour. The ventilation should allow for running a flexible ventilation duct to the source of the contamination in lieu of a simple wall duct. Also, there must be a means of taking in make up air into the tent, acceptable methods of this include, but are not limited to, inlet breather filters and one-way louvers.
MEETS OBJECTIVE 2

Display overhead of frame components (may vary by site) (4)

Display overhead with graphic display of good vs. bad arrangements for ventilation.

Pass around examples of breather filters. 


\section{GLOVE BAG INSTALLATIONS}

External Support - Glove bags should use an external support to prevent the glove bag from collapsing when negative ventilation systems are operating.

Service Sleeves - Service sleeves are used to bring needed services into a glove bag. As with tents, once the membrane is cut, a service sleeve should be in service or taped shut.

Ventilation - For tasks where high contamination is expected, HEPA filtered vacuum cleaners are often used on glove bags. Appropriately sized breather filters should be in place to support the ventilation. If no ventilation is present, a 2-cfm cartridge HEPA filter will suffice. The exhaust from air tools should always be routed outside of glove bags.

Temperature - Glove bags that are to be attached to piping or components where temperatures may exceed $150^{\circ} \mathrm{F}$ should be protected by heat insulating material.

Liquid - Where liquid is expected or likely to collect in the glove bag, the design should be water tight, have a external catch containment, and, if a drain is required, have a drain installed in the low point of the glove bag.

\section{POLY BOTTLE INSTALLATIONS}

Location - Where possible, poly bottles should not be located in walkways or other locations where the bottle or the attached hose could easily become disconnected or spilled.

Spillage - Poly bottles should be supported or tied off to a sturdy point to prevent tip over.

Freezing - Where poly bottles are exposed to freezing conditions, freeze protection should be included in the installation.

Liquid Temp - Liquids greater that $150^{\circ} \mathrm{F}$ should not be collected in PVC poly bottles, but in bottles specially designed to collect such liquids unless an adequate reservoir of liquid is included in the bottle as a heat sink.
Discuss importance of not having inlet filters closed during ventilation start up.

Discuss importance of only one door open at a time.

Display overhead of a standard glove bag. (6) Refer to it to demonstrate each feature.
Using poly bottle, demonstrate connections, key to importance of avoiding low points in tubing, and of using tubing of sufficient wall thickness to avoid pinching. 


\section{SELECTION PROCESS}

Determining the appropriate level of a containment requires a basic understanding of the task to be performed, the level of contamination likely, and the nature of the contamination. Specific criteria assessed are: removable contamination levels, contamination stability, and work activity. Each is discussed in the following text:

\section{Removable Contamination Levels}

Removable contamination is defined as radioactive material that can be removed from surfaces by nondestructive means such as casual contact, wiping, brushing, or washirg. The table breaks the criteria down into three distinct categories, those being less than 10 times Table 2-2 $(<10,000 \mathrm{dpm} B \tau$, $200 \mathrm{dpm} \alpha), 10$ to 100 times Table 2-2 (10,000 to $100,000 \mathrm{dpm} B-\tau$ or 200 to $2000 \mathrm{dpm} \alpha)$, or greater than 100 times Table 2-2 (>100,000 dpm B-T, $2000 \mathrm{dpm} \alpha)$. If the likely contamination levels cannot be obtained from survey or historical data, the most limiting category should be used.

\section{Contamination Stability}

As noted above, removable contamination is defined as radioactive material that can be removed from surfaces by casual contact. Stability is a qualitative assessment of how easily this transfer occurs and how easily the contamination may be transported from surface to surface or surface to air. For determining containment stability is broken into three categories, high, medium, and low. For example, contamination that, if disturbed, readily resuspends into the air would be categorized as low stability, while conta nination suspended in liquid, or on a moist or oily surface would generally be considered high stability, other contaminated surfaces would generally fall between these criteria based on surface texture, weathering and a variety of other factors to be considered.

\section{Work Activity}

Work activities are considered to be those actions which will be performed in the contaminated portion of the work area. The containment selection process breaks work activities into five categories:

1. Simple material movement such as walking, lifting, carrying.

\section{MEETS OBJECTIVE 3}

Display overhead of Containment Selection Table (7). Demonstrate how it should work for a variety of jobs.

Draw from student experience if possible. 
2. Vigorous material movement such as repackaging waste, HEPA filter manipulation, packing replacement, etc.

3. Using power tools in the area or manually cutting, abrading, or shaping the material.

4. Using low-velocity power tools (portable band saws, electric drills operated at low speeds, etc.) on the contaminated components.

5. Using high-velocity power tools (grinders, high-speed drills, etc.) on the contaminated components.

After assigning a value for each category, the numbers are added and the value compared to the end column. At this point the knowledge base of involved parties should be considered. The appropriate containment for a given task should be selected based on the fundamental concept of contamination control. In this document containment has been broken down into four categories

Very Low Risk For tasks involving such a small risk of contamination spread that no specific containment type beyond the administrative controls of good work practices would apply. This is not to say none would be used, but the experience and training of the work force would be the basis for selection. In this category, containment might be a damp rag, sleeving, an air curtain, or even a plastic bag substituted for a catch containment.

Low Risk

Tasks where the risk of contamination spread is low, but the actual device is specified. Examples of such devices use in this category are catch containments, drip pans, bull pens, sleeving, air curtains, etc.

Moderate Risk Tasks where the risk of a contamination spread is moderate and containment becomes total enclosure such as is obtained by heavy sleeving, glove bags, or containment tents.

High Risk

Tasks where the risk of a contamination spread is high and containment should be accomplished by ventilated tents, glove 
Note that the categories above are very subjective in nature and other factors should be considered as modifiers. For example if the work area is immediately adjacent to a lunch room or heavily travelled corridor, the containment requirements might be elevated based on the consequences of a contamination spread. Conversely, in a remote location where low levels of contamination already exist in the work area, and the consequences of a spread are low, it is unlikely the recommended containment levels would be increased.

Understand that this ngure is subjective. It is a guideline from which to begin the planning and evaluation process and is not intended to be the sole means of determining what level of containment should be used.

Multiple containment devices may be used to obtain the appropriate level of containment. For instance a poly bottle may be connected to a glove bag, or be installed inside of a tent. A catch containment is commonly used under glove bags or inside of tents in an effort to localize contamination.

\section{INSTALLATION AND INSPECTION}

Containments will likely be installed by operations personnel. Upon completing installation they will inspect the containment and install a Containment Identification Tag with the work package number and installer identified.

A formal documented inspection of radiological containments by Health Physics is necessary to ensure the end product of the containment design and installation process meets established standards.

Inspections for certified containments should be performed before use, daily while in use, and at least monthly when not in use to determine need for repairs, replacement, or decontamination and removal.

Inspections for noncertified containments are not formally documented but should be performed routinely as part of housekeeping inspections, etc.
Stress this note, it is a fundamental concept.

Display overhead of an inspection tag. (8) 


\section{OPERATION}

All operation of containment devices should revolve around the central precept that containments are used to prevent the spread of contamination. Many cperational considerations were presented during the design phase of this class. This section contains additional guidelines that should be considered during containment operations.

\section{General}

The same good practices needed for effective contamination control apply to containment activities. Contamination spreads and the levels tolerated in the work area must be minimized. The use of a containment does not replace sound work habits.
Display glove bag (9) and containment checklist (10). 
WHC-EP-0749

This page intentionally left blank.

E-16 
WHC-EP-0749

APPENDIX E.2

WESTINGHOUSE CONTAINMENT PROGRAM

RADIATION WORKER II SUPPLEMENTAL TRAINING PROGRAM INSTRUCTOR GUIDE 
WHC-EP-0749

This page intentionally left blank.

E-18 
WESTINGHOUSE CONTAINMENT PROGRAM

\section{RADIATION WORKER II SUPPLEMENTAL TRAINING PROGRAM} INSTRUCTOR GUIDE

Section Title: Containment Program

Revision Number: 0

NOTICE: This document is for TRAINING PURPOSES ONLY. Do not use this material in place of the current revision of controlled plant documents. 
Target Population Summary:

Radiological Worker II Trainees

List of Materials/Equipment Required:

A. Student Handouts

1. Lesson Plan

2. Appendix B of GOBU Containment Handbook

B. Various Containment Manipulatives

1. Poly Bottle

2. Poly Bottle Containment

3. Cone Drape

4. Pan Drape

5. Drain Assembly

6. Filter Assembly

7. Assembled glove bag with spare gloves and sleeves.

C. Overheads

1. Containment Tent

2. Glove Bag

3. Catch Containments

4. Frame Components

5. Ventilation

6. Glove Bag

7. Containment Selection Table

8. Inspection Tag

9. Glove Bag Checklist

10. Containment Tent Checklist 


\section{WHC-EP-0749}

\section{LIST OF SEQUENCED OBJECTIVES:}

1. OBJECTIVE

Discuss the various types of containment and familiarize the students with the applications of each.

\section{OBJECTIVE}

List the requirements and good practices associated with containment devices.

\section{OBJECTIVE}

Demonstrate basic operating techniques for containments.

\section{ABOUT THIS LESSON}

This lesson will provide the student with the required knowledge to perform the following tasks:

1. Understand the basis for the application of containments.

2. Recognize proper operation of containments.

3. Perform routine operations with a glove bags. 


\section{INTRODUCTION}

This training should further serve to enable and encourage the use of containments for contamination control and to accomplish the following:

- Minimize personnel contamination

- Prevent the spread of contamination

- Minimize the required use of protective clothing and personal protective equipment.

Containment is not limited to the concept of total enclosure, but instead encompasse : the application of engineered barriers applied in varying degrees to prevent the spread of radioactive contamination.

Two key principles influence the use of containments:

- Establishing the contamination barrier (the containment) as near to the source as possible

- Whenever possible, using containments around the work area instead of requiring workers to use additional protective clothing (PC) or other personal protective equipment (PPE).

\section{REQUIREMENTS AND GOOD PRACTICES}

The DOE Radiological Control manual mandates the use of engineered barriers to control the spread of airborne and surface contamination.

Good work radiological work practices dictate:

- That the opening of contaminated systems be performed with engineering barriers to prevent the spread of contamination.

- Containment be considered if the task involves:

- The likely spread of contamination

- Exposing a contaminated fluid system

- Airborne contamination.

- That the Radiological Control Organization approve containment design prior to procurement or construction

- Containments be inspected prior to initial use, routinely during operation, and monthly during standby periods. 


\section{DEFINITIONS}

Following is a summary discussion of the various containment methods:

1. Containment Tents. Large enclosures, generally constructed of flexible sheeting, which allow personnel to physically enter a contaminated environment to perform work. Containment tents can also be used to provide ante rooms for access to cells, tank risers, and other highly contaminated environments.

2. Glove Bags. A glove bag is a flexible containment used to establish an enclosure around a contaminated item, allowing personnel to accomplish repairs or manipulations via glove sleeves without contacting the contaminated environment.

3. Catch Containments (Drapes). Catch containments are partial enclosures usually used to collect falling debris or small amounts of liquid.

4. Wind Break or Bull Pen. A bull pen is a walled, or partially walled, enclosure that allows personnel to enter and work in a contaminated environment. They are generally roofless and are used on low-risk activities to protect immediate area from contaminants, as well as protect the work area from external factors which could result in contaminated material being spread.

5. Polyethylene (ooly) Bottles. Poly bottles are a 5- or 15-gal polyethylene container used for the collection of small quantities of contaminated liquids (generally includes a filtered vent assembly).

6. Air curtains. Air curtains use moving air to draw contaminants into a filtered exhaust plenum. Application of air curtains include open faced hoods, strategically placed exhaust ducts, or any other means of capturing the contaminants at or near the source with filtered ventilation.

7. Miscellaneous, Other types of containment devices include sleeving, mechanical joint containments, plastic sheeting, and drop cloths.
MEETS OBJECTIVE 1

Display overhead of Containment Tent. (1)

Display overhead of various glove bags. (2)

Display overhead of catch containments. (3)

Pass an example of a catch containment to class.

Instruct students that catch containments should be treated the same as SCAs

Pass example of poly bottle to class. Also demonstrate the drain asse ly as used with catch cont.inments.

Cite examples such as open faced hoods, etc.

Pass an example of a mechanical joint containment around room. 


\section{CONTAINMENT FEATURES AND OPERATING CONSIDERATIONS}

Contamination control should always be the key design consideration when determining what features a containment device should incorporate; however other considerations, including contamination levels, temperature, area configuration, isotope(s), and the radiological characteristics of the immediate proximity, should be considered in addition to the specifics contained in the sections below.

\section{CONTAINMENT TENTS}

The following features should be used when ever possible on a containment tent:

External, reusable frame - External frames that are reusable have distinct advantages in that they are protected from contamination and do not have to be disposed of as waste.

Service sleeves - Service sleeves are used to bring services such as power, air, etc, into a tent. As a rule, they should be a minimum of $3 \mathrm{IN}$. in diameter for lines, cords, etc. and sized to as needed to support ventilation duct. If the membrane is cut, service sleeves should be in use, or taped closed.

Dump sleeves - Dump sleeves are generally located near exit doors as a receptacle for waste and used protective clothing. For long term use, dump sleeves may have collars attached that allow sleeves to be replaced or even to have long sleeves attached. If the membrane is cut, service sleeves should be in use or taped closed.

Ventilation - When ventilation is used on a tent the flow rate should allow for 4-20 air changes per hour. The ventilation should allow for running a flexible ventilation duct to the source of the contamination in lieu of a simple wall duct. Also, there must be a means of taking in make up air into the tent, acceptable methods of this include, but are not limited to, inlet breather filters and one way louvers.
MEETS OBJECTTVE 2

Display overhead of frame components. (MAY VARY BY SITE) (4)

Display overhead with graphic display of good vs. bad arrangements for ventilation.

Pass around examples of breather filters.

Discuss importance of not having inlet filters closed during ventilation start up.

Discuss importance of only one door open at a time. 


\section{GLOVE BAG INSTALLATIONS}

External Support - Glove bags should use an external support to prevent the glove bag from collapsing when negative ventilation/chip collecting systems are operating.

Service Sleeves - Service sleeves are used to bring needed services into a glove bag. As with tents, once the tnembrane is cut, a service sleeve should be in service or taped shut.

Ventilation - For tasks where high contamination is expected, HEPA filtered vacuum cleaners are often used on glove bags. Appropriately sized breather filters should be in place to support the ventilation. If no ventilation is present, a 2-cfm cartridge HEPA filter will suffice. The exhaust from air tocis should always be routed outside of glove bags.

Temperature - Glove bags that are to be attached to piping or components where temperatures may exceed $150{ }^{\circ} \mathrm{F}$ should be protected by heat insulating material.

Liquid - Where liquid is expected or likely to collect in the glove bag, the design should be water tight, have a external catch containment, and, if a drain is required, have a drain installed in the low point of the glove bag.

\section{POLY BOTTLE INSTALLATIONS}

Location - Where possible, poly bottles should not be located in walkways or other locations where the bottle or the attached hose could easily become disconnected or spilled.

Spillage - Poly bottles should be supported or tied off to a sturdy point to prevent tip over.

Freezing - Where poly bottles are exposed to freezing conditions, freeze protection should be included in the installation.

Liquid Temp - Liquids greater that $150^{\circ} \mathrm{F}$ should not be collected in PVC poly bottles, but in bottles specially designed to collect such liquids unless an adequate reservoir of liquid is included in the bottle as a heat sink.
Display overhead of a standard glove bag. (6) Refer to it to demonstrate each feature.

Using poly bottle, demonstrate connections, key to importance of avoiding low points in tubing, and of using tubing of sufficient wall thickness to avoid pinching.

NOTE: This can be delayed to the OJT phase of the instruction. 


\section{SELECTION PROCESS}

Deciermining the appropriate level of a containment requires a basic understanding of the task to be performed, the level of contamination likely, and the nature of the contamination. Specific criteria assessed are: removable contamination levels, contamination stabllity, and work activity. Each is discussed in the following text:

\section{Removable Contamination Levels}

Removable contamination is defined as radioactive material that can be removed from surfaces by non destructive means such as casual contact, wiping, brushing, or washing.

\section{Contamination stability}

As noted above, removable contamination is defined as radioactive material that can be removed from surfaces by casual contact. Stability is a qualitative assessment of how casily this transfer occurs and how easily the contamination may be transported from surface to surface or surface to air.
Display overhead of Containment Selection Table (7). Demonstrate how it should work for a variety of jobs. Draw from student experience if possible. 


\section{Work Activity}

Work activities are considered to be those actions which will be performed in the contaminated portion of the work area. After considering the contamination levels, contamination stability and the work activity being performed, the level of containment needed is selected. All things considered, the appropriate containment for a given task should be selected based on the fundamental concept of contamination control. In this document containment has been broken down into four categories:

Very Low Risk For tasks involving such a very small risk of contamination, the experience and training of the work force would be the basis for selection. In this category, containment might be a damp rag, sleeving, an air curtain, or cien a plastic bag substituted for a catch containment.

Low Risk For tasks where the risk of contamination spread is low the contamination control device is specified in work control documents, but is usually minimal. Examples of such devices use in this category are catch containments, drip pans, bull pens, sleeving, air curtains, etc.

Moderate Risk For tasks where the risk of a contamination spread is moderate, containment becomes total enclosure such as is obtained by heavy sleeving, glove bags, or containment tents.

High Risk For tasks where the risk of a contamination spread is high, containment should be accomplished by ventilated tents, glove bags, used independently or in conjunction with each other.

Multiple containment devices may be used to obtain the appropriate level of containment. For instance a poly bottle may be connected to a glove bag, or be installed inside of a tent. A catch containment is commonly used under glove bags or inside of tents in an effort to localize contamination. 


\section{INSTALLATION AND INSPECTION}

Containments will likely be installed by operations personnel. Upon completing installation they will inspect the containment and install a Containment Identification Tag with the work package number and installer identified.

A formal documented inspection of radiological containments by Health Physics is necessary to ensure the end product of the containment design and installation process meets established standards.

Inspections for certified containments should be performed prior to use, daily while in use, and at least monthly when not in use to determine need for repairs, replacement, or decontamination and removal.

Inspections for noncertified containments are not formally documented but should be performed routinely as part of housekeeping inspections, etc.

\section{OPERATION}

All operation of containment devices should revolve around the central precept that containments are used to prevent the spread of contamination. Many operational considerations were presented during the design phase of this class. This section contains additional guidelines that should be considered during containment operations.

\section{General}

The same good practices needed for effective contamination control apply to containment activities. Contamination spreads and the levels tolerated in the work area must be minimized. The use of a containment does not replace sound work habits.
Display overhead of an inspection tag (8).

Display glove bag (9) and containment checklist (10). 


\section{HANDS-ON TRAINING}

Tt is section of the training is focused on showing the stucients how to perform specific functions associated with glove bags. Using the nethodology found in Appendix B, lead the class throughout he following evolutions:

1. Installing gloves on a glove bag.

2 Replacing a damaged glove.

3. Installing a drain assembly on a glove bag and connecting it to a poly bottle.

4. Passing material out of a glove bag via a transfer sleeve.

5. Replacing a transfer sleeve.
For large classes it is recommend to have team activities where the class observes a team perform an activity such that all persons are on at least one team. The steps for these activities are delineated in Appendix B, Section B.3. 
WHC-EP-0749

This page intentionally left blank. 
WHC-EP-0749

APPENDIX E.3

WESTINGHOUSE CONTAINMENT PROGRAM

PLANNER TRAINING PROGRAM

INSTRUCTOR GUIDE 


\section{WHC-EP-0749}

This page intentionally left blank. 
WHC-EP-0749

\section{WESTINGHOUSE CONTAINMENT PROGRAM}

PLANNER TRAINING PROGRAM

INSTRUCTOR GUIDE

Section Title: Containment Program

Revision Number: 0

NOTICE: This document is for TRAINING PURPOSES ONLY. Do not use this material in place of the current revision of controlled plant documents. 


\section{WHC-EP-0749}

Target Population Summary:

Job planners and engineers for tasks involving containment activities.

List of Materials/Equipment Required:

A. Student Handout

1. Lesson Plan

2. Appendix E of GOBU Containment Handbook

B. Various Containment Manipulatives

1. Poly Bottle

2. Poly Bottle Containment

3. Cone Drape

4. Pan Drape

5. Drain Assembly

6. Filter Assembly

C. Overheads

1. Containment Tent

2. Glove Bag

3. Catch Containments

4. Frame Components

5. Ventilation

6. Glove Bag

7. Containment Selection Table

8. Inspection Tag

9. Glove Bag Checklist

10. Containment Tent Checklist

11. Design Checklist-Cover

12. Design Checklist-Tents

13. Design Checklist-Glove Bag 


\section{WHC-EP-0749}

\section{LIST OF SEQUENCED OBJECTIVES:}

1. OBJECTIVE

Discuss the various types of containment and familiarize the students with the applications of each.

\section{OBJECTIVE}

Demonstrate the method used to determine the appropriate containment.

\section{OBJECTIVE}

Demonstrate the elements of containment design.

\section{ABOUT THIS LESSON}

This lesson will provide the student with the required knowledge to perform the following tasks:

1. Select the proper containment for a given application.

2. Provide design criteria for containment.

3. Understand the basic requirements for use of containments. 


\section{INTRODUCTION}

This training should further serve to enable and encourage the use of containments for contamination control and to accomplish the following:

- Minimize personnel contamination

- Prevent the spread of contamination

- Minimize the required use of protective clothing and personal protective equipment.

Containment is not limited to the concept of total enclosure, but instead encompasses the application of engineered barriers applied in varying degrees to prevent the spread of radioactive contamination.

Two key principles influence the use of containments:

- Establishing the contamination barrier (the containment) as near to the source as possible

- Whenever possible, using containments around the work area instead of requiring workers to use additional protective clothing or other personal protective equipment.

\section{REQUIREMENTS AND GOOD PRACTICES}

The DOE Radiological Control manual mandates the use of engineered barriers to control the spread of airborne and surface contamination.

Good work radiological work practices dictate:

- That the openi- - of contaminated systems be performed with engineering barriers to prevent the spre : of contamination.

- Containment be considered if the task involves:

- The likely spread of contamination

- Exposing a contaminated fluid system

- Airborne contamination.

- That the Radiological Control Organization approve containment design prior to procurement or construction

- Containments be inspected before initial use, routinely during operation, and monthly during standby periods. 


\section{DEFINITIONS}

Following is a summary discussion of the various containment methods:

1. Containment Tents. Large enclosures, generally constructed of flexible sheeting, which allow personnel to physically enter a contaminated environment to perform work. Containment tents can also be used to provide ante rooms for access to cells, tank risers, and other highly contaminated environments.

2. Glove Bags. A glove bag is a flexible containment used to establish an enclosure around a contaminated item, allowing personnel to accomplish repairs or manipulations via glove sleeves without contacting the contaminated environment.

3. Catch Containments (Drapes). Catch containments are partial enclosures usually used to collect falling debris or small amounts of liquid.

4. Wind Break or Bull Pen. A bull pen is a walled or partially walled enclosure that allows personnel to enter and work in a contaminated environment. They are generally roofless and are used on low-risk activities to protect immediate area from contaminants, as well as protect the work area from external factors which could result in contaminated material being spread.

5. Polyethylene (poly) Bottles. Poly bottles are 5- or 15-gal polyethylene containers used for the collection of small quantities of contaminated liquids (poly bottles generally include a filtered vent assembly).

6. Air curtains. Air curtains use moving air to draw contaminants into a filtered exhaust plenum. Application of air curtains include open faced hoods, strategically placed exhaust ducts, or any other means of capturing the contaminants at or near the source with filtered ventilation.

7. Miscellaneous, Other types of containment devices include sleeving, mechanical joint containments, plastic sheeting, and drop cloths.
MEETS OBJECTIVE 1

Display overhead of Containment Tent. (1)

Display overhead of various Miscelaneous Glove Bag Styles. (2)

Display overhead of Catch Containments. (3)

Pass an example of a catch containment to class.

Pass example of 5-gal poly bottle to class.

Demonstrate the drain assembly as used with catch containments.

Cite examples such as open faced hoods, etc. Note the proper location of exhaust.

Pass an example of a mechanical joint containment around room. Note that the drain assemblies are appropriate for catch containments, too. 


\section{SELECTION PROCESS}

Determining the appropriate level of a containment requires a basic understanding of the task to be performed, the level of contamination likely, and the nature of the contamination. Specific criteria assessed are: removable contamination levels, contamination stability, and work activity. Each is discussed in the following text:

\section{Removable Contamination Levels}

Removable contamination is defined as radioactive material that can be removed from surfaces by nondestructive means such as casual contact, wiping, brushing, or washing. The selection process breaks the criteria down into three distinct categories, those being less than 10 times Table 2-2 $(<10,000 \mathrm{dpm} B \tau, 200 \mathrm{dpm} \alpha), 10$ to 100 times Table 2-2 $(10,000$ to $100,000 \mathrm{dpm} \mathrm{B- \tau}$ or 200 to $2000 \mathrm{dpm} \alpha)$, or greater than 100 times Table 2-2 (>100,000 dpm B-T, $2000 \mathrm{dpm} \alpha$ ). If the likely contamination levels cannot be obtained from survey or historical data, the most limiting category should be used.

NOTE: Table 2-2 is from the DOE Radiological Control Manual

\section{Contamination Stability}

As noted above, removable contamination is defined as radioactive material that can be removed from surfaces by casual contact. Stability is a qualitative assessment of how easily this transfer occurs and how easily the contamination may be transported from surface to surface or surface to air. For determining containment stability is broken into three categories, high, medium and low. For example, contamination that, if disturbed, readily resuspends into the air would be categorized as low stability, while contamination suspended in liquid, or on a moist or oily surface would generally be considered high stability, other contaminated surfaces would generally fall between these criteria based on surface texture, weathering and a variety of other factors to be considered.

\section{MEETS OBJECTIVE 2}

Display overhead of Containment Selection Table (7). Demonstrate how it should work for a variety of jobs. Draw from student experience if possible. 


\section{Work Activity}

Work activities are considered to be those actions which will be performed in the contaminated portion of the work ares. The containment selection process breaks work activities into five categories:

1. Simple material movement such as walking, lifting, carrying.

2. Vigorous material movement such as repackaging waste, HEPA filter manipulation, packing replacement, etc.

3. Using power tools in the area or manually cutting, abrading, or shaping the material.

4. Using low-velocity power (portable band saws, electric drills operated at low speeds, etc.) tools on the contaminated components.

5. Using high-velocity power tools (grinders, high speed drills, etc.) on the contaminated components.

After assigning a value for each category, the numbers are added and the value compared to the end column. At this point the knowledge base of involved parties should be considered. The appropriate containment for a given task should be selected based on the fundamental concept of contamination control. In this document containment has been broken down into four categories: 
Very Low Risk For tasks involving such a small risk of contamination spread that no specific containment type beyond the sdministrative controls of good work practices would apply. This is not to say none would be used, but the experience and training of the work force would be the basis for selection. In this category, containment might be a damp rag, sleeving, an air curtain, or even a plastic bag substituted for a catch containment.

Low Risk Tasks where the risk of contamination spread is low, but the actual device is specified. Examples of such devices use in this category are catch containments, drip pans, bull pens, sleeving, ait curtains, etc.

Moderate Risk Tasks where the risk of a contamination spread is moderate and containment becomes total enclosure such as is obtained by heavy sleeving, glove bags, or containment tents.

High Risk Tasks where the risk of a contamination spread is high and containment should be accomplished by ventilated tents, glove bags, used independently or in conjunction with each other.

The categories above are very subjective in nature and other factors should be considered as modifiers. For example if the work area is immediately adjacent to a lunch room or heavily travelled corridor, the containment requirements might be elevated based on the consequences of a contamination spread. Conversely, in a remote location where low levels of contamination already exist in the work area, and the consequences of a spread are low, it is unlikely the recommended containment levels would be increased.

Understand that this ngure is subjective. It is a guideline from which to begin the planning and evaluation process and is not intended to be the sole means of determining what level of containment should be used.

Multiple containment devices may be used to obtain the appropriate level of containment. For instance a poly bottle may be connected to a glove bag, or be installed inside of a tent. A catch containment is commonly used under glove bags or inside of tents in an effort to localize contamination.

Stress this note; it is a fundamental concept. 
TEAM EXERCISE-Part 1

\section{DESIGN}

Contamination control should always be the key design consideration when determining what features a containment device should incorporate; however other considerations, including contamination levels, temperature, area configuration, isotope(s), and the radiological characteristics of the immediate proximity, should be considered in addition to the specifics contained in the sections below.

\section{Design Process}

An effective containment starts with good materials, clear design, concise specifications, and quality craftsmanship.

Assuming a good understanding of the facility and job to be performed, designing a glove bag or tent is generally a simple process that can be easily documented. The design checklist is a tool that will meet most needs.

The Containment design checklist is a two page document, page 1 collects needed information, page two includes a sketch that can be used to build the device. Two versions of page 2 are included, one for glove bags, one for tents.

\section{Design Considerations- General}

Contamination control and personnel safety are the key considerations when designing containments. Contamination levels, temperature, area configuration, isotope(s), and the radiological characteristics of the immediate vicinity should also be considered.

Designs of certifiable containments should be approved by the Radiological Controls Organization and the Line Organization.
Team Exarcise-Part 1 Divide the class into two or more groups and have them determine the containment class for a given job. The class may use a job they are familliar with or use the task shown in Attachment 1. NOTE: Keep the sheets for part 2 of the exercise.

MEETS OBJECTIVE 3 


\section{Deaign Considerations-Spedific}

The following festurcs should be considered when designing a containment tent:

Construction requirements for rediological structures can be segregated into two basic categories, these are as follows:

External Frame - Where possible, containments should use in external frame. If, for structural or other reasons, an external frame is not practical, every effort should be made tw prevent framing materials from becoming contaminated.

Material - Material should be a compactable reinforced vinyl that is of sufficient strength to meat the specific environmental conditions.

Service Sleeves - Service sleeves are used to bring services such power, air, ac, into a tent. As a rule, they should be a minimum of 3 in. in diameter.

Dump Sleeves - Dump sleeves are generally located near exit doors as a receptacle for waste and used protective clothing. Dump sleeves may have collars attached that allow sleeves to be replaced or have long sleeves attached. The advantage of long sleeves is they allow waste to be collected in the sleeve and removed much as waste is removed from a glove bag sleeve.

Color - Tents should be yellow in color, with clear windows. However, temperature considerations will, at times, necessitate other options such as white or a reflective material.

Windows - Windows should be clear, and of sufficient number to allow use of external lighting. For outdoor applications, covers should considered on windows that allow sun side windows to be closed.

Ventilation - When ventilation is used on a tent the flow rate should allow for $\mathbf{4 - 2 0}$ air changes per hour. The ventilation should allow for running a flexible ventilation duct to the source of the contamination in lieu of a simple wall duct. Also, there must be a means of taking in make up air into the tent, acceptable methods of this include, but are not limited to, inlet breather filters und one way louvers.
Display overhead of containment design checklist 11,12 , and 13.

Display overhead of frame components. (MAY VARY BY SITE) (4)
Display overhead with graphic display of good vs bad arrangements for ventilation.

Pass around examples of breather filters.

Discuss importance of not having inlet filters closed during ventilation start up. 
Doors - Doors should be designed to be opened and closed easily. If high-radiation area controls are required, consideration should be given to using doors that can be locked. Doors should have a clear viewing panel in the upper half and have posting pouches capable of holding standard size signs on the lower half.

Design for glove bags should consider the following:

External Support - Glove bags should use an external support to prevent the glove bag from collapsing. Support for glove bags is often incorporated into stock bag designs, but additional frame may be noeded depending on application and ventilation requirements. Flexible tie-0ins are preferable for supporting glove bags.

Service Sleeves - Service sleeves are used to bring needed services into a glove bag. Consideration should be given to the need for:

- Transfer sleeves (usually at least one)

- Liquid drain

- Electrical service

- Pneumatic tools

- Ventilation inlet/exhaust

- Glove sleeves

- Contamination survey pass-out box.

Color - Glove bags should be clear and/or yellow. Accessories need not be specially colored if they are appropriately labeled.

Ventilation - All glove bags should contain $2 \mathrm{cfm}$ or larger HEPA filter located in the upper half of the glove bag. Glove bags having negative ventilation should contain HEPA filters of sufficient flow capacity to prevent the glove bag from collapsing. If air tools are used, the exhaust should be directed out of the glove bag, unless adequate exhaust ventilation is provided.

Temperature - Glove bags that will be in contact with piping or components where temperatures may exceed $150^{\circ} \mathrm{F}$ should be protected by heat insulating material.

Liquid Collection - Where liquid is expected or likely to collect in the glove bag, the glove bag must be verified liquid tight, have a external catch containment, and, if required, have a drain installed near the low point of the glove bag.
Discuss importance of only one door open at a time.

Display overhead of a standard glove bag. (6) Refer to it to demonstrate each feature. 
Deaign considerations for poly bottle installations should include the following:

Anticipated Volume - Estimated volumes of liquid expected should be planned for as part of poly bottle installations; staging of spare poly bottles should be considered.

Location - Where possible, poly bottles should not be located in walkways or other locations where the bottle, hose, or attachments could easily become damaged, disconnected, or spilled.

Sizing - Poly bottles generally come in two sizes, 5 and $15 \mathrm{gal}$. Where movement of a partial to full bottle is difficult (l.e. stairwells, ladders, etc.), the bottle size should be minimized.

Inspections - Since poly bottles are not routinely certified, consideration must be given to an inspection frequency during the design phase of the process. Considerations should include, area traffic, contamination levels, radiation levels, and the expected flow rate into the bottle.

Spillage - Poly bottles should be supported or tied off to a sturdy point to prevent tip over.

Ventilation - Poly bottles should be vented in a controlled manner to allow displacement of air due to introduced liquid. Consider nature of hazard when designing ventilation for poly bottles (i.e., do not vent liquids which may contain tritium through HEPA filters).

Criticality - The use of poly bottles should be evaluated by qualified personnel when used with fissile isotopes.

Freezing - Where poly bottles are exposed to freezing conditions, freeze protection should be included in the design.

Liquid Temp - Liquids greater that $150^{\circ} \mathrm{F}$ should be collected in bottles designed for high temperature liquids. Poly bottles should not be used unless sufficient liquid is included in the bottle as a heat sink.

Change Out - The organization responsible of changing and/or emptying full poly bottles should bè identified.
Using poly bottle, demonstrate connections, key to importance of avoiding low points in tubing, and of using tubing of sufficient wall thickness to avoid pinching. 


\section{OBTAINING A CONTAINMENT}

After a containment has been designed, it must still be procured or manufactured, this is generally done to a standard specification. Specifications should address the following:

\section{Reference Standards \\ Material \\ Fabrication \\ Framing \\ Components}

Quality Assurance Requirements

\section{DOCUMENTATION AND ADMINISTRATION}

Containments will likely be installed by operations personnel. Upon completing installation they will inspect the containment and install a Containment Identification Tag with the work package number and installer identified.

A formal documented inspection of radiological containments by Health Physics is necessary to ensure the end product of the containment design and installation process meets established standards.

Inspections for certified containments should be performed prior to use, daily while in use, and at least monthly when not in use to determine need for repairs, replacement, or decontamination and removal.

Inspections for noncertified containments are not formally documented but should be performed routinely as part of housekeeping inspections, etc.
Display overhead of an inspection tag. (8)

Display glove bag (9) and containment checklist (10). 


\section{OPERATION}

All operation of containment devices should revolve around the central precept that containments are used to prevent the spread of contamination. Many operational considerations were presented during the design phase of this class. This section contains additional guidelines that should be considered during containment operations.

\section{General}

The same good practices needed for effective contamination control apply to containment activities. Contamination spreads and the levels tolerated in the work area must be minimized. The use of a containment does not replace sound work habits.

TEAM EXERCISE - PART 2
Team Exercise Part 2-Divide the classroom into two (or more groups) provide them with a task (Define your own or use attachment 1). Using the Containment design checklist, have each group design complete the form for the task. Have one groip design the task for a glove bag,, and one a tent.

\section{ATTACHMENT 1}

Job - Replace the stem in a valve in a known contaminated system. The last time the system was opened was a pressure gauge near the valve, 7,000 dpm beta gamma, no detectable alpha. The valve is the discharge of a decontamination room collection tank and is located under a floor panel in a clean change room. The packing in the valve was changed three months ago, the contamination levels on the stem were $6,000 \mathrm{dpm}$.

The tank contains water and soap residue.

The job will consist of removing the top of the valve, hand grinding the seat, and replacing the valve stem.
Key points:

1. Know contamination levels 6-7,000 dpm removable.

2. Work activity - Manual abrading of material.

3. Soapy water residue - Very stable to moderately stable.

4. Mitigating factors:
A. Consequences of a spread very high.
B. Lucalized work area-easy to ventilate.


WHC-EP-0749

APPENDIX F

GLOSSARY 
WHC-EP-0749

This page intentionally left blank. 


\section{GLOSSARY}

\section{ABBREVIATIONS, ACRONYMS, AND INITIALISMS}

$\begin{array}{ll}\text { ALARA } & \text { as low as reasonably achievable } \\ \text { HEPA } & \text { high-efficiency particulate air (filter) } \\ \text { PVC } & \text { polyvinyl chloride } \\ \text { RWP } & \text { radiation work permit }\end{array}$

\section{DEFINITIONS OF TERMS}

Air Curtain Containment. Air curtains use moving air to draw contaminants into a filtered exhaust plenum. Application of air curtains include open faced hoods, strategically placed exhaust ducts, or any other means of capturing the contaminants at or near the source with filtered ventilation.

Bull Pen. A bull pen is a walled or partially walled enclosure that allows personnel to enter and work in a contaminated environment. Bull pens are generally roofless and used on low-risk activities to protect immediate area from contaminants, as well as protect the work area from external factors which could result in contaminated material being spread.

Catch Containment. Catch containments are partial enclosures usually used to collect falling debris or to collect and direct liquid contaminants from a source to a collecting device such as a poly bottle or drain line.

Containment Tent. Containment tents are large enclosures which allow personnel to physically enter a contaminated environment to perform work. Containment tents can also be used to provide ante rooms for access to cells, tank risers, and other highly contaminated environments.

Curtain Wall. A temporary installation used to partially isolate a work area thereby perimitting personnel to work in adjacent areas with no significant impact from the work area operation. A bullpen consists of multiple adjacent curtain walls.

Drop Cloth. Absorbent material with a waterproof backing.

Electronic (RF) Sealing. Sealing process used to bond materials in the manufacture of glove bags, tents, etc.

Glove Bag. A flexible containment which is used to establish a complete enclosure around a small work area or component. Personnel work inside the containment through glove sleeves while remaining outside the contaminated environiment.

Glovebox. A rigid sealed enclosure in which workers can handle radioactive materials safely from the outside using gloves attached to and passing through openings in the box.

Laydown Area. An area where contaminated or potentially contaminated tools or components used while working on contaminated systems are staged or placed during work operations. 
Mechanical Joint Containment. A containment used to wrap mechanical joints to contain any minor leakage, provide spray protection, and prevent spills.

Membrane. Containment wall fabric left intact after the attachment of a sleeve, door, zipper or other component.

Rigid Panel Containment. A large enclosure constructed largely of interchangeable standard size panels made of Lucite, sheet stainless steel or other rigid and easily decontaminatable material.

Special Containment. Containments that are designed for specific tasks and that are engineered and manufactured on an as-required basis.

Standard Containment. Containment designs that are intended for general use and are available off-the-shelf.

Poly Bottle. A 5- or 15-gal polyethylene container used to collect small quantities of contaminated liquids (generally includes a filtered vent assembly). 
WHC-EP-0749

\section{DISTRIBUTION}

\section{Number of Copies}

\section{OFFSITE}

1

U.S. Department of Energy. Albuquerque Operations Office

Health Protection Division

P.O. Box 5400

Albuquerque, New Mexico 87175

J. Low

1

U.S. Department of Energy Office of Energy Research

ER.8.1, GTN

Washington, D.C. 20585

R. Jarrett

1

U.S. Department of Energy

1301 Clay Street, 4th Floor

Oakland, California 94612

T. Hsich

1

U.S. Department of Energy

Century 21 Building, Room 100

Washington, D.C. 20585

E. Blackwood

EH-16

2

U.S. Department of Energy. Oak Ridge Operators Office

P.O. Box 2001

Oak Ridge, Tennessee 37831

M. Henderson

J. Polehn .

EW-912

U.S. Department of Energy Headquarters 1000 Independence Avenue Washington, D.C. 20585

H. Amirmokri NE-44 


\section{DISTRIBUTION (cont.)}

Number of Copies

\section{OFFSITE}

1

\section{U.S. Department of Energy.}

Headquarters

19901 Germantown Road

Germantown, Maryland 20585

M. Gavrilas

EM-25

1

Brookhaven National Laboratory

Building 535A

Upton, New York 11973

H. Kahnhauser

1

Lawrence Livermore National Laboratory 20201 Century Blvd., 2nd Floor

Germantown, Maryland 20874

T. Crites

1

Lawrence Berkley Laboratory

One Cyclotron Road

Berkley, California

R. Kloepping

MS 71-259

Los Alamos National Laboratory

P.O. Box 1663

Los Alamos, New Mexico 87545

W. Eisele

R. Huchton

R. F. Smale

New Brunswick Laboratory

9800 South Cass Avenue

Argonne, Illinois 60439

R. Mason
MS K483

MS KA87

MS K483

BLD-350 
WHC-EP-0749

\section{DISTRIBUTION (cont.)}

Number of Copies

OFESITE

1

Reynolds Electrical and

Engineerine $\mathrm{C}_{0 .}$ Inc.

P.O. Box 98521

Las Vegas, Nevada 89191

H. Kerschner

1

Sandia National Laboratories

P.O. Box 969

Livermore, California 94561

D. Wright

MS 9221

\section{ONSITE}

2

U.S. Department of Energy,

Richland Operations Office

D. L. Clark

A5-55

RL Public Reading Room

A1-65

1

Kaiser Enoineers Hanford

G. H. Sudikatus

GH-01

1

Pacific Northwest Laboratory

PNL Technical Files

K1-11

22

Westinghouse Hanford Company

T. L. Aldridge

L8-20

D. E. Ames

L6-51

D. D. Beers

L8-20

R. L. Brown

R3-12

C. L. Caldwell

G6-73

G. L. Eaton

G6-71

R. E. Heineman

R3-12

M. E. Hevland

R3-12

Distr-3 
WHC-EP-0749

DISTRIBUTION (cont.)

Number of Copies

ONSITE

Westinghouse Hanford Company (cont.)

S. R. Johnson S0-05

B. H. Lueck $\quad$ L8-20

W. C. Mallory L8-16

$\begin{array}{ll}\text { C. T. Miller } & \text { R3-50 }\end{array}$

C. P. Seilhymer G6-71

J. L. Shelor R1-51

R. N. Smith R3-12

W. L. Smoot B2-18

A. L. Trego B3-02

R. J. Van Tuinen SO-02

Information Release
Administration
L8-07

Document Processing and

Distribution (2) L8-15

Central Files L8-04 

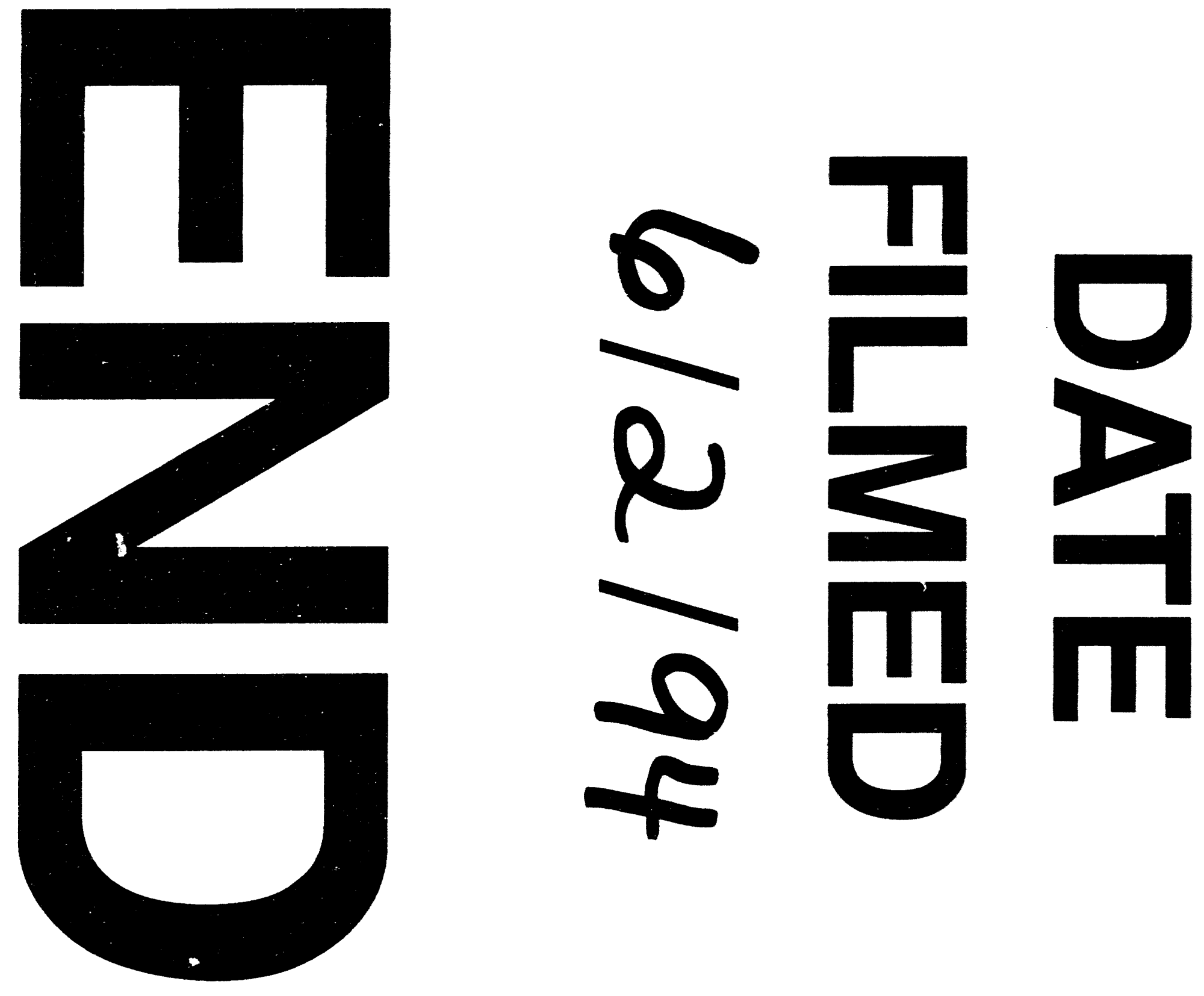
